\title{
Epidemiology and control of potato virus $Y$ in Kenya
}

\author{
John Onditi
}

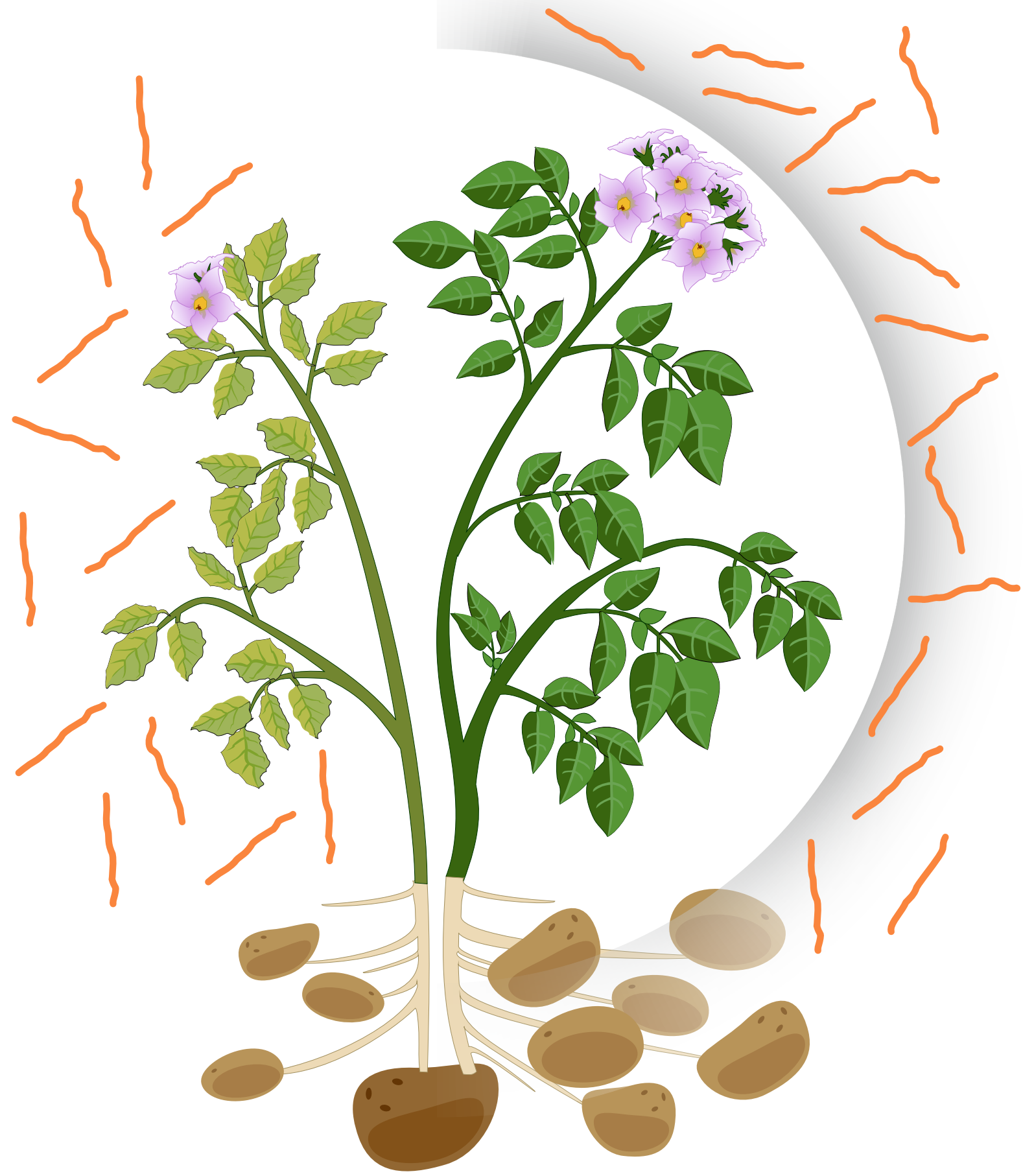




\section{Propositions}

1. Knowledge of virus prevalence alone is not sufficient in making decisions about virus control.

(this thesis)

2. Farmers are always ahead of scientist in looking for solutions to the problems in their farms.

(this thesis)

3. GMO virus-based plant-produced pharmaceuticals (Virology Journal 16:167) fit well within remote rural communities without access to medical care.

4. Lessons learnt from unsuccessful experiments is one of the reasons for ground breaking scientific discoveries.

5. Naming successful scientists in school textbooks inspires future scientists.

6. One's own culture and traditions are best appreciated in the midst of other cultures.

Propositions belonging to the thesis entitled

Epidemiology and control of potato virus $Y$ in Kenya

John Onditi

Wageningen, 23 April 2020 
Epidemiology and control of potato virus $Y$ in Kenya 


\section{Thesis committee}

\section{Promotors}

Prof. Dr RAA van der Vlugt

Special Professor Ecological Plant Virology

Wageningen University \& Research

Prof. Dr MM van Oers

Professor of Virology

Wageningen University \& Research

\section{Co-promotor}

Dr MW Nyongesa

Centre Director

Kenya Agricultural and Livestock Research Organization (KALRO), Tigoni, Kenya

\section{Other members}

Prof. Dr PC Struik, Wageningen University \& Research

Dr CJM Almekinders, Wageningen University \& Research

Dr M Kooman-Gersmann - Nederlandse Algemene Keuringsdienst voor zaaizaad

en pootgoed van landbouwgewassen (NAK), Wageningen

Dr C Lacomme -Science Advice for Scottish Agriculture (SASA), Edinburgh, UK

This research was conducted under the auspices of the Graduate School for Production Ecology and Resource Conservation. 


\section{Epidemiology and control of potato virus $Y$ in Kenya}

John Onditi

Thesis

submitted in fulfilment of the requirements for the degree of doctor at Wageningen University

by the authority of the Rector Magnificus,

Prof. Dr A.P.J. Mol,

in the presence of the

Thesis Committee appointed by the Academic Board to be defended in public

on Thursday 23 April 2020

at 11 a.m. in the Aula. 
John Onditi,

Epidemiology and control of potato virus $Y$ in Kenya, 140 pages.

PhD thesis, Wageningen University, Wageningen, The Netherlands (2020) With references, with summary in English

ISBN: 978-94-6395-322-1

DOI: https://doi.org/10.18174/515366 


\section{Table of contents}

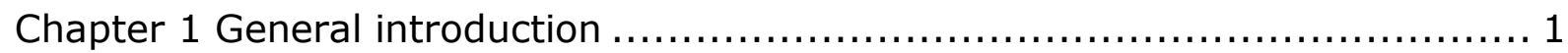

Chapter 2 Farmer knowledge in potato virus epidemiology and control in Kenya

Chapter 3 Prevalence, distribution and relative importance of the six major

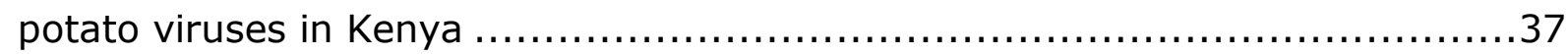

Chapter 4 Prevalence of potato virus $Y$ strains in Kenyan potato cultivars .......57

Chapter 5 Screening for PVYN-Wi resistance in Kenyan potato cultivars............77

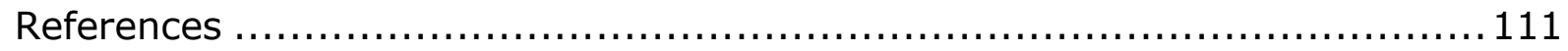

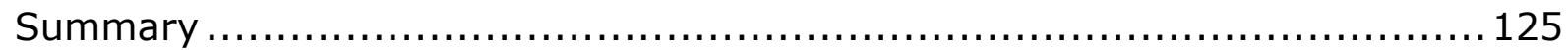

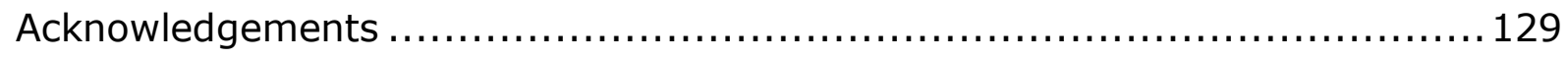

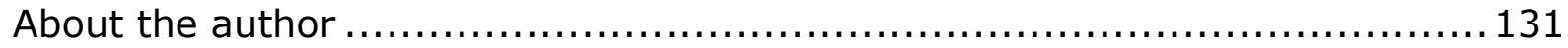

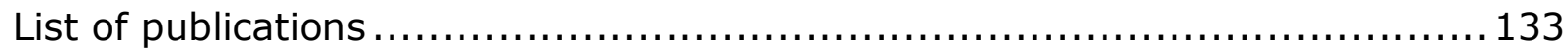





\section{Chapter 1}

\section{General introduction}

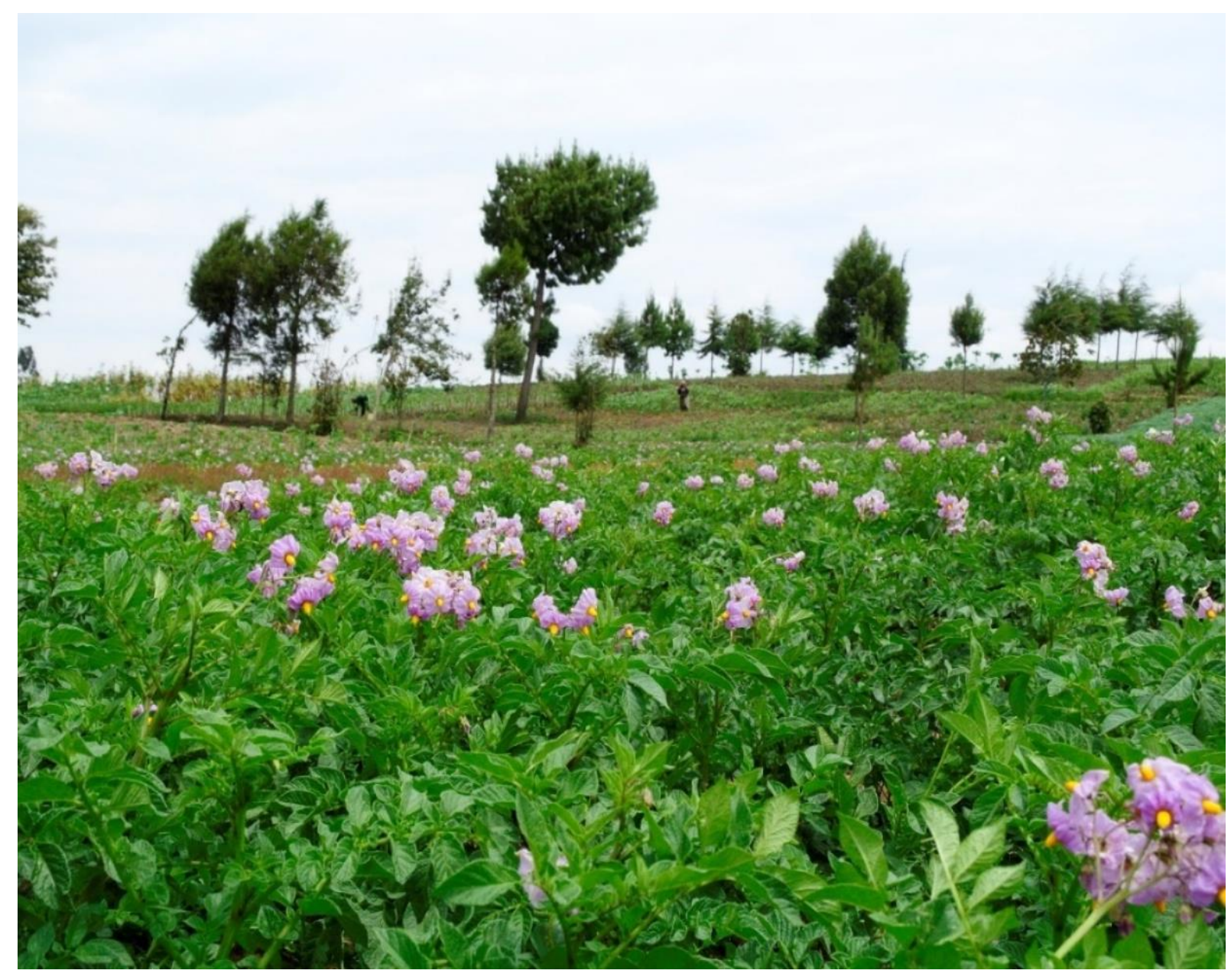




\subsection{The potato crop in Kenya}

In Kenya, agriculture is an important economic activity contributing $25 \%$ to the gross domestic products (GDP) and 75\% of export earnings (MoALF 2016). The Kenyan government has therefore focused on revitalizing the agricultural sector in order to address rural poverty and improve the living standards (MoALF 2016). Potato (Solanum tuberosum L.) is highlighted as a key crop in the government's agenda (on agriculture) because of its potential to improve the food and nutritional security situation in the country (MoALF 2016). The crop is ranked as the second most important food crop after the major staple crop maize. Unlike maize, which is harvested after 5-6 months, many potato varieties mature after 3-4 months and provide food and income earlier in the season (Kaguongo et al. 2008). Potato has a balanced nutrition of proteins, carbohydrates and vitamins and a higher productivity in terms of the energy produced per unit area of land compared to maize (Scott et al. 2013). In the Kenyan highlands, the crop is grown mainly around the Rift Valley and Mt. Kenya at an altitude ranging from 1500 to 3000 metres above sea level and in other regions with cool climatic conditions favouring its production (Lung'aho et al. 2007). Potato growing counties (regions) in Kenya, shown in Fig 1, are classified based on their potential for potato production in the government's plan to expand potato production (MoALF 2016). In these regions, potato is grown mainly by smallholder farmers with average farms sizes of less than 1 hectare $(\mathrm{Ha})$. These farmers produce potatoes primarily for their own consumption, the surplus is sold to generate household income (Kaguongo et al. 2008). Potatoes are grown twice a year during the long rains periods which extends from April to July and in the short rains which starts in September and last till November (NPCK 2017).

Potato was introduced to the country by European settlers in the 1890's and has been cultivated since then (Crissman 1993). Over time, there has been a steady increase in the area under potato cultivation and in the volume of potatoes produced. Presently, it is estimated that 1.5 million tons of potatoes worth between KSh. 40-50 billion (approximately 350-450 million Euro's) are produced on about 161,000 hectares of land per year (MoALF 2016). The potato industry employs about 3.3 million actors either as producers, processors, market agents, retailers, transporters, vendors and exporters (MoALF 2016). 


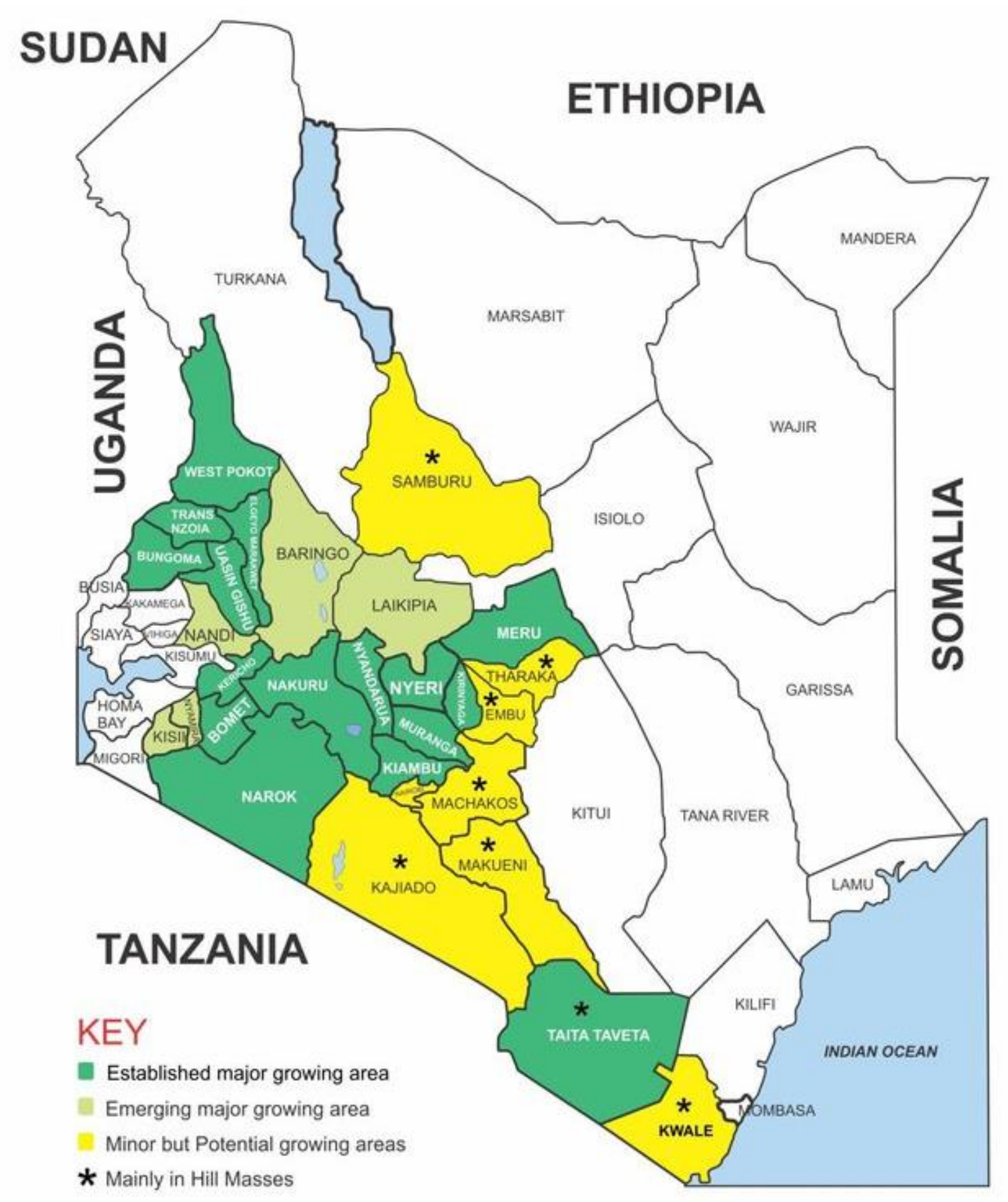

Fig 1: Map of Kenya showing potato producing counties as ranked by the government based on their potential for potato production in the government's plan to expand potato production (MoALF 2016) 
The demand for potato and potato products is increasing due to urbanization, population growth and changes in consumer tastes and preferences (Janssen et al. 2013). The major players in the potato sector include the Kenya Agricultural and Livestock Research Organization (KALRO), which conducts potato research in collaboration with local and international research and development partners. KALRO is also mandated by the government to produce basic seed potato which is then handed over to the Agricultural Development Corporation (ADC), the government institution charged with the responsibility of multiplication and distribution certified potato seed. The Kenya Plant Health Inspectorate Service (KEPHIS) regulates potato seed production through inspection and certification, registration of new plant varieties as well as ensuring quarantine pests and diseases are not introduced to the country. The National Potato Council of Kenya (NPCK) is a public private partnership platform in charge of advocacy and coordinating activities within the potato sector. Technologies and products developed by scientists and development partners are then transferred to the farmers by the extension officers from the Ministry of Agriculture Livestock and Fisheries (MoALF), in collaboration with the county governments, nongovernmental organizations (NGOs) and community-based organizations (CBOs) and the private sector (KEPHIS 2016).

\subsection{Potato virus problem in Kenya}

Inadequate supply of certified seed potato is the foremost challenge limiting potato production in Kenya (Gildemacher et al. 2009; KEPHIS 2016; NPCK 2017). Certified potato seed is a class of potato seed tubers which is normally produced by specialized or formal seed growers and regulated by inspection authorities to ascertain that pest and disease incidence in the seed lot is below the established limits (Thomas-Sharma et al. 2016). Typically, certified potato seed tubers are produced over a duration of approximately four years involving rapid multiplication of in vitro potato plantlets and greenhouse mini-tuber production followed by six seasons of field multiplications (Struik and Wiersema 1999). During this time, stringent sanitary measures are followed to ensure viruses and other seed borne diseases do not get into the seed lot and also to prevent them from getting passed from one seed generation to another (Struik and Wiersema 1999). Considering the long duration of investment without return, potato seed production in Kenya has 
not attracted many private investors. On top of that comes the risk of rejection of seed lots by KEPHIS due to infection by regulated diseases which deters potential investors. Seed lots are normally produced in cool high-altitude regions, where insects that vector the transmission of potato viruses are present in low numbers. However, there is shortage of such suitable lands for seed production in these high-altitude areas (KEPHIS 2016). A combination of these factors has caused a persistent shortage of certified seed in Kenya.

Presently, the formal sources of certified seed tubers can only satisfy $5 \%$ of the national demand in Kenya (NPCK 2017). This situation has left many farmers with no options but to re-plant their own saved seed tubers or acquiring from other sources whose health status is unknown (Gildemacher et al. 2009; Janssen et al. 2013). The resulting seed supply system supports easy spread of diseases including potato viruses which are passed from one cropping generation to another leading to disease build-up in the farmer's fields (Chandla et al. 2001). With regard to potato viruses, six are considered most important (Salazar 1996), namely; potato virus $Y(P V Y)$, potato leaf roll virus (PLRV), potato virus $X(P V X)$, potato virus $A$ (PVA), potato virus $S$ (PVS) and potato virus $M$ (PVM). These have been found with high prevalence in all the major potato growing regions and are considered a serious problem in Kenyan potato production (Nderitu and Mueke 1986; Machangi et al. 2003; Muthomi et al. 2009). Recent estimates show that average potato tuber yields in the farmer's fields are very low (8.7 T/Ha) (FAOSTAT 2017), however under improved conditions in field trials with local cultivars, over 40 T/Ha have been reported (Lung'aho et al. 2006; Onditi et al. 2012).

To lower virus prevalence in farmer's fields, different virus control strategies have been tested by scientists working in Kenya and the East Africa region and were found to have the potential to improve potato tuber yields. Some of these strategies include measures or combinations of measures like spraying insecticides against the virus vectors (Lung'aho et al. 2007), use of cultural methods like border crops, mulching and organic plant extracts to control vectors (Muindi et al. 2009; Olubayo et al. 2010), the use of 'positive seed selection' to obtain tubers from healthy looking plants (without virus symptoms) as planting material for subsequent seasons (Gildemacher et al. 2011; Schulte-Geldermann et al. 2012; Onduru et al. 2018; Priegnitz et al. 2019) and selecting cultivars with tolerance to the viruses under field conditions (Onditi et al. 2013; Onduru et al. 2019). 
However, the continuing situation of high virus prevalence and low potato yields in Kenyan potato farms could be an indication that the present levels of knowledge and capacity of farmers to manage potato viruses is not sufficient. In order to mitigate against this lack of farmer knowledge becoming a hindrance to potato virus control, improving farmer's knowledge and implementation of intervention strategies based on scientific data is a pre-requisite.

In the Kenyan farming situation where there is a high prevalence of potato viruses, lack of certified seed potatoes and limited farmer knowledge to manage the viruses, the use of virus resistant varieties would have great potential to manage the potato virus problem. However, so far very little attention has been given to the selection and release of such virus resistant and improved cultivars. This is because from the 1980's onwards, the breeding objective of the national potato program at KALRO and research collaborators has been to avail varieties with resistance to late blight (Phytophthora infestans), higher yields and good cooking and processing qualities (Lung'aho et al. 2006; Onditi et al. 2012). This resulted in better understanding in the use of host resistance to manage late blight than there is on deployment of host resistance against any of the six important potato viruses mentioned above. The current status of virus prevalence in cultivars grown in different regions in the country is not well known however necessary for developing effective breeding programs to support development of virus resistant varieties and in giving appropriate recommendations for virus control to the farmers.

\subsection{Potato virus Y (PVY): a worldwide potato production problem}

PVY is a single-stranded positive sense RNA virus with a genome of about 9700 nucleotides surrounded by a flexible filamentous structure of coat protein subunits (Adams et al. 2012). The PVY genome contains one open reading frame (ORF) that encodes for a single polyprotein, which is subsequently cleaved by viral encoded proteases into 10 functional proteins (Dougherty and Carrington 1988). One of these functional proteins is the VPg protein, covalently connected to the $5^{\prime}$ terminus of the RNA genome. The RNA genome has a poly-A tail at its 3'end (Riechmann et al. 1992). 


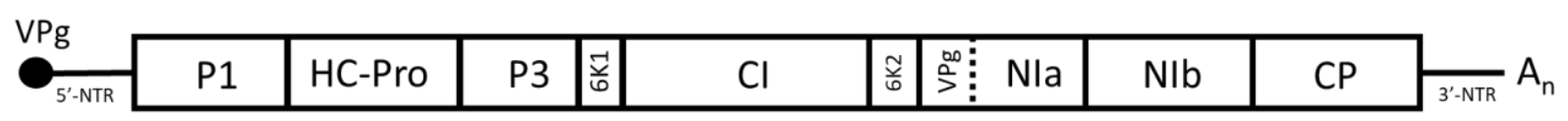

Fig 2. Schematic drawing of the potato virus $Y(+)$-sense, single-stranded RNA genome depicting the 5'-non-translated region (NTR) with the VPg covalently linked, one large open reading frame (ORF) from which the individual viral proteins are released through viral encoded proteases and the 3'-NTR with the 3'-terminal poly-A tail $\left(A_{n}\right)$. P1 = P1 protein, $H C$-Pro $=$ Helper Component/Protease, $P 3=P 3$ protein, $6 K 1=$ first $6 K$ protein, $C I=$ cytoplasmatic inclusion protein, $6 K 2=$ second $6 K$ protein; $V P g=$ viral protein genomelinked, $N I a=$ nuclear inclusion protein $A, N I b=$ nuclear inclusion protein $b$ and $C P=$ coat protein

The PVY genome structure and the various coding regions that aids its replication, transmission and survival within the host cell (Adams et al. 2012) are shown in Fig 2. PVY occurs worldwide, with potatoes as the economically most important host, though the virus also infects other important Solanaeceous crops like tobacco, tomato and pepper (Loebenstein et al. 2001; Kerlan and Moury 2008; Gray et al. 2010). PVY causes yield reduction in potato ranging from 10-80\% (De Bokx and Huttinga 1981) which often vary depending on the cultivar and the geographical region were the potatoes are grown (Hanne and Hamm 1999; Nolte et al. 2004). PVY is known to occur as different strains which can be distinguished biologically on host plants, serological reaction and in their genome nucleotide sequence. The strains of the virus were first described and classified in the 1930s, mainly based on the symptoms they elicited on hosts plants like tobacco and potato (Smith 1931). PVY initially occurred as three main strains: $P V Y^{O}, P V Y^{N}$ and $P V Y^{C}$ (de Bokx and van der Want 1987; Jones 1990). PVYO is generally referred to as the 'O' ordinary strain inducing systemic mosaic on both tobacco and potato plants. PVYN is known as the necrotic ' $\mathrm{N}$ ' strain and induces necrotic symptoms in tobacco (Nicotiana tabacum 'White Burley' (de Bokx and Huttinga 1981). PVYC, the common strain, causes 'stipple streak' in some potato cultivars, but it is found mainly in tomato and pepper (Moury 2010) and is less commonly reported in potato. PVY strains were also differentiated based on the symptoms they produced on tobacco plants and their reaction to potato cultivars carrying certain genes. For instance, $\mathrm{PVY}^{\circ}$ was identified by a hypersensitive response (HR) on potato cultivars Desiree and Pentland Crown that carry the Ny:nc:nz or Nytbr genes (Cockerham 
1943; Cockerham 1970) and similarly PVYC elicited a HR in cultivars like King Edward containing the ny:Nc:nz genes (Davidson 1978). PVYN was distinguished from $P V Y^{\circ}$ and $P V Y^{C}$ by not eliciting $H R$ on the potato cultivars but inducing veinal necrosis on tobacco plants (Nicotiana tabacum 'White Burley') (Singh et al. 2008). In the 1980s, the PVYZ strain was first described, which is characterized by not producing an HR on cultivars of either $N c$ or $N y$ genetic background but eliciting an HR on the cultivars Pentland Ivory and Maris Bard with Nc: Ny: Nz genes (Jones 1990). Later another strain, $\mathrm{PVY}^{\mathrm{E}}$ was reported, characterized by overcoming the Nc: Ny: Nz genes in Maris Bard, unlike other strains (Kerlan et al. 1999).

Also since the 1980's new strain variants of PVY have been described that are based on different genetic recombination's between the original PVY ${ }^{\circ}$ and $\mathrm{PVY}^{\mathrm{N}}$ strains (Nie and Singh 2002; Lorenzen et al. 2006; Schubert et al. 2007). These recombinations occur at specific recombination junctions of which at least eight have been identified. Different recombinants gave been found worldwide of which generally PVYN-Wi and PVY ${ }^{\mathrm{NTN}}$ are considered to be the most prominent.

Double antibody sandwich enzyme-linked immune-sorbent assay (DAS-ELISA) is one of the most sensitive serological techniques commonly used for routine PVY detection (and other potato viruses) (Davidson 1978; Solomon-Blackburn and Barker 2001). Virus detection using this technique is based on the ability of virus specific antibodies (monoclonal and polyclonal antibodies) to react in vitro with their antigens (i.e. virus particles). Monoclonal antibodies are used to classify all the different PVY strains either as the ' $O$ ' or ' $N$ ' serotypes, while polyclonal antibodies are used to detect all strains without differentiating between the serotypes (Rose and Hubbard 1986; Ellis et al. 1996; Crosslin et al. 2005).

Due to the limitation of serological methods in distinguishing between the different PVY strains, Reverse Transcription Polymerase Chain Reaction (RT-PCR) assays have been developed, using specific primers targeting specific regions in the PVY genome. Some of these assays can simultaneously differentiate between the strains in one assay (Nie and Singh 2002; Schubert et al. 2007; Lorenzen et al. 2006). Sequence analysis has the ability to further differentiate the strains up to the nucleotide level and is commonly used in discovery of new PVY strains and for studying PVY sequence diversity and evolution (Green et al. 2017). 


\section{ELISA RT-PCR}

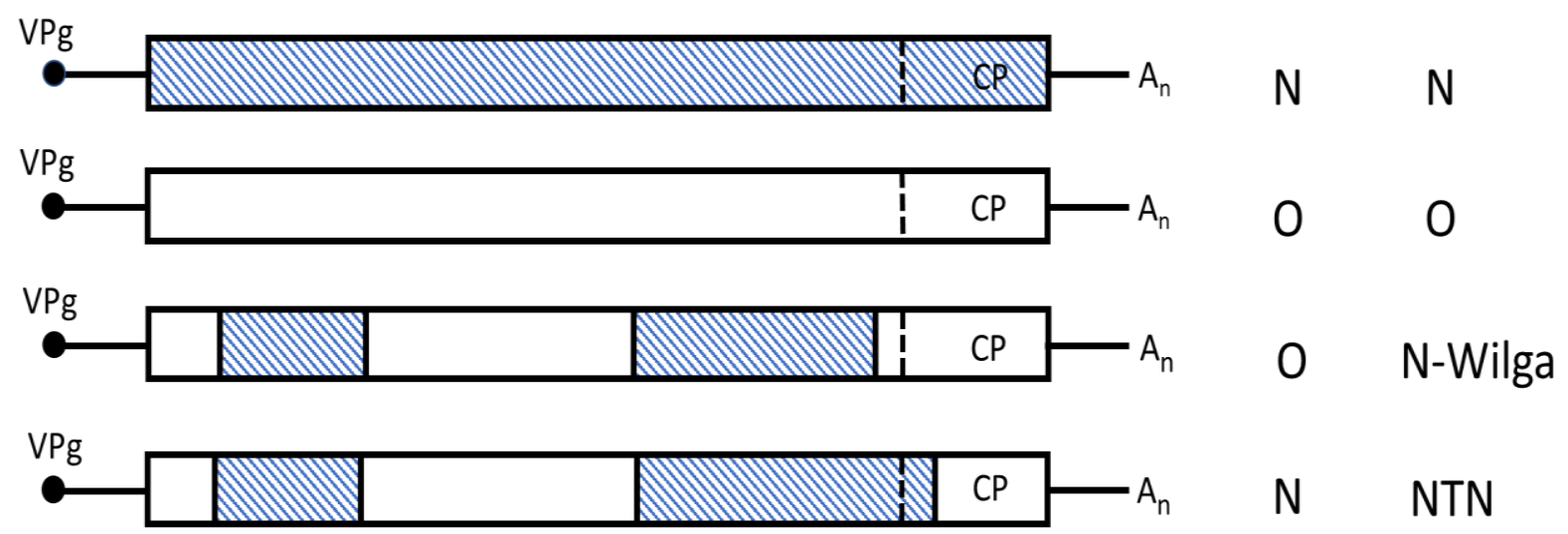

Fig 3: Schematic representations of the genomes of potato virus $Y$ (PVY) strains $N, O$ and genetic recombinant strains $P V Y^{N-W i}$ and $P V Y^{N T N}$. Shaded and unshaded regions represent $P V Y^{N}$ and $P V Y^{O}$ specific regions respectively. CP represent the viral coat protein encoding region. Indicated is the capability of either ELISA or RT-PCR to distinguish between the four PVY strains

The genome structures of four major PVY strains and their serological and molecular differences at different positions in the genome are summarized in Fig 3. The PVY ${ }^{\mathrm{N}-\mathrm{Wi}}$ and $\mathrm{PVY} \mathrm{NTN}^{\mathrm{NTN}}$ are both characterized by recombination of nucleotide sequences of both $\mathrm{PVY}^{\mathrm{O}}$ and $\mathrm{PVY}^{\mathrm{N}}$ in their genomes. The two PVY strains however differ in the $\mathrm{N}$-terminal region of the viral $\mathrm{CP}$ where $\mathrm{PVY}^{\mathrm{N}-\mathrm{Wi}}$ carries the $\mathrm{PVY}^{\circ}$ genome and $P V Y^{N T N}$ carries the $P V Y^{N}$ genome. Nucleotide sequences at the recombination junction in this $3^{\prime}$-terminal region of the PVY RNA are used to differentiate between the two strains. The CP of PVY ${ }^{\mathrm{N}-\mathrm{Wi}_{\mathrm{i}}}$ in this region is detected in ELISA as PVY ${ }^{\circ}$ while that of PVY ${ }^{N T N}$ is detected as PVYN (Nie and Singh 2002; Schubert et al. 2007; Lorenzen et al. 2006).

\subsection{Occurrence of potato viruses in Kenya}

The PVY problem in potato production systems in Kenya is not new. It was first reported in 1943 as a major mosaic disease affecting potato production in all the regions where potato is grown (Bock and Robertson, 1976). The first organized field survey on potato viruses in general was conducted during the potato-growing seasons of 1996 and 1998 in four regions (Nyamira, Kisii, Meru and Kiambu) on a total of 80 leaf samples. Only PLRV was detected and a prevalence of $7.7 \%$ based on ELISA tests and $8.9 \%$ based on virus symptoms was reported (Were et al. 2003). Almost a decade later (in 2006), another field survey was conducted in the 
Nakuru, Kirinyaga, Nyeri, Laikipia, Meru, Nyeri and Nyandarua counties. Tubers sprouts of one thousand (1000) samples of potatoes were tested for four viruses (PVY, PLRV, PVX and PVA) in ELISA. These samples were collected from potatoes sold informally as seed tubers in local markets. PVY was the most prevalent virus with $77.6 \%$, followed by PLRV (74.0\%), PVX (57\%) and PVA (42\%) (Gildemacher et al. 2009). Two years later (in 2008), ELISA tests were conducted for all of the six potato viruses (PVY, PLRV, PVX, PVM, PVS and PVA) on 120 tubers from Meru, Nakuru, Narok and Nyandarua counties. The most prevalent viruses were PVS (99\%), PLRV (80\%) and PVY (70\%). PVX, PVA and PVM were found with a lower prevalence of $45 \%, 40 \%$ and $26 \%$ respectively (Muthomi et al. 2009). These percentages also indicate that many tubers contained more than one virus. A more recent survey was done in 2011 in Meru, Nyandarua, Kiambu, Narok, Nakuru, Bomet, Uasin Gishu, Trans Nzoia, Elgeyo Marakwet and West Pokot counties on 493 symptomatic potato leaf samples. The samples were tested only for PVY in ELISA. Highest PVY prevalence was found in Meru $(77.8 \%)$, followed by $73.3 \%$ in Kiambu and 64.0\% in Nyandarua (Nyamwamu et al. 2014). All these previous surveys indicated that PVY is one of the most important viruses in Kenya due to the high prevalence reported over the past decades. Virus surveys in the neighboring countries like Tanzania (Chiunga 2013), Uganda (Gildemacher et al. 2009; Priegnitz et al. 2019) and Ethiopia (Gildemacher et al. 2009) similarly report PVY as one of the major viruses in the potato production systems in these countries.

One of the long-term, efficient, cost effective and sustainable methods of controlling PVY is the use of resistant cultivars. PVY resistance is either classified as extreme resistance (ER) or hypersensitive resistance (HR). Such types of PVY resistance have been discovered by breeding programs around the world and have been introgressed in several commercial cultivars (Cockerham 1970; CelebiToprak et al. 2002; Szajko et al. 2008). ER genes ( $\left.R y^{\prime} s\right)$ are durable, effective and comprehensive against all known strains of PVY and were sourced from Solanum chacoense, S. hougasii, S. stoloniferum ssp andigena and hence are referred to as Rychc, Rysto and Ryadg genes (Cockerham 1943; Munoz et al. 1975, Sato et al. 2006). When a potato plant with ER is infected with PVY, the virus can replicate within the cell, but the plant responds by effectively killing the infected cell, and nearly eliminating cell-to-cell spread of the virus, and thus its systemic spread throughout the plant. This ER results in very tiny necrotic spots or lesions, which 
are often too small to be seen by eye (Solomon-Blackburn and Barker 2001). Such ER genes have been introgressed in many commercial cultivars and successfully used to control PVY in Europe and America (Quenouille et al. 2013). The Nytbr and Nctbr genes, which elicit HR in potato cultivars, have however been broken by some PVY strains like PVYZ, PVYE, PVYN, PVYNTN and PVYN-Wi but have remained effective against $P V Y^{\circ}$ and $P V Y^{C}$ (Jones 1990; Kerlan 1999). Since some of the new PVY strains can break some but not all known sources of PVY resistance, some of the cultivars which were previously screened using the traditional PVY strains may not be resistant to the new recombinant strains of PVY. To define the goals of PVY resistance breeding, it is important to understand the local and current most prevalent strains and use them to screen, identify and recommend cultivars with resistance to farmers.

\subsection{The scope of the thesis}

This thesis is about the epidemiology and control of PVY in Kenya. The idea was conceived by the fact that PVY causes major yield losses in potato crop and control of the virus is of worldwide concern. In Kenya, past prevalence surveys indicate that PVY is one of the most prevalent viruses. To effectively control this virus, this thesis focused on generating information that gives a wider understanding of the whole potato growing situation in the country to make well-informed decisions on virus control. The main aim of the thesis was to provide virus control measures that can be applicable to the local potato growing conditions awaiting long term solutions. Towards this, the study had the following specific objectives:

1) To identify gaps in farmer's perceptions and practices in relation to potato virus control and to propose appropriate virus control methods based on the Kenyan potato growing situation.

2) To describe prevalence, distribution and relative importance of the six major potato viruses and suggest cultivars, regions and viruses that should be given priorities in potato virus control.

3) To determine the present status of prevalence of the various PVY strains in cultivars grown in different potato growing regions in Kenya and deduce information on PVY resistance from the prevalence of PVY strains.

4) Identify cultivars resistant to the current most prevalent PVY strain within the Kenyan potato germplasm. 
To introduce the above objectives, this chapter described potato as an important crop with potential to improve food and nutritional security of the people of Kenya. However, the national average yields of this crop are very low and immediate measures are needed to be put in place to improve potato yields. Based on previous research and the recent challenges in potato production in the world today, PVY was identified as one of the major constraints that needs to be addressed to improve potato yields in Kenya. In Chapter 2 the gaps in farmer knowledge were identified in the individual aspects of virus control and from regions where potatoes are grown. This knowledge was then packaged and moderated by a team of experts to propose a framework of priority setting in virus control. The use of virus resistant cultivars was identified as an aspect that would address the virus problem with the greatest impact considering the current challenges in Kenyan farming systems. The occurrence and distribution and seasonal changes in prevalence of the six major potato viruses in the five-major potato growing regions was analysed in Chapter 3. Based on the extent of the virus problems in cultivars as deduced from prevalence surveys, cultivars tolerant to the viruses were identified and recommended for use by the farmers to lower virus prevalence. Similarly, specific regions and cultivars with serious virus problem were identified and recommended for immediate intervention in virus control. Chapter 4 focuses more specifically on the different strains of PVY, their occurrence and distribution in potato cultivars and in two main potato growing regions in Kenya. Levels of resistance of cultivars to the PVY strains as deduced from their prevalence in the field and used to recommend cultivars with field resistance to particular PVY strains. The commonly grown cultivars in Kenya were screened in Chapter 5, under controlled as well as under field conditions, to identify the levels of resistance of the cultivars to the most prevalent recombinant PVY ${ }^{\mathrm{N}-\mathrm{Wi}}$ strain. Early generation potato clones with $\mathrm{PVY}^{\mathrm{N}-\mathrm{Wi}}$ resistance were also identified for future evaluation and release to respond to the diverse needs of farmers and consumers in the Kenyan potato production systems. Chapter 6 summarizes and discusses the major findings in relation to each of the above objectives. Implications and impacts of the findings were then put in the perspective of the present and future of potato growing in Kenya. 


\section{Chapter 2}

\section{Farmer knowledge in potato virus epidemiology and control in Kenya}

\section{John Onditi ${ }^{1,}{ }^{2}$, Nancy Ng'anga ${ }^{2}$, Moses Nyongesa ${ }^{2}$ and René van der Vlugt ${ }^{1}$}

${ }^{1}$ Laboratory of Virology, Wageningen University and Research, Droevendaalsesteeg 1

6708PB Wageningen, The Netherlands.

${ }^{2}$ Kenya Agricultural and Livestock Research Organization, Horticultural Research Institute, KALRO Tigoni, P.O. Box 338 Limuru 00217 Kenya

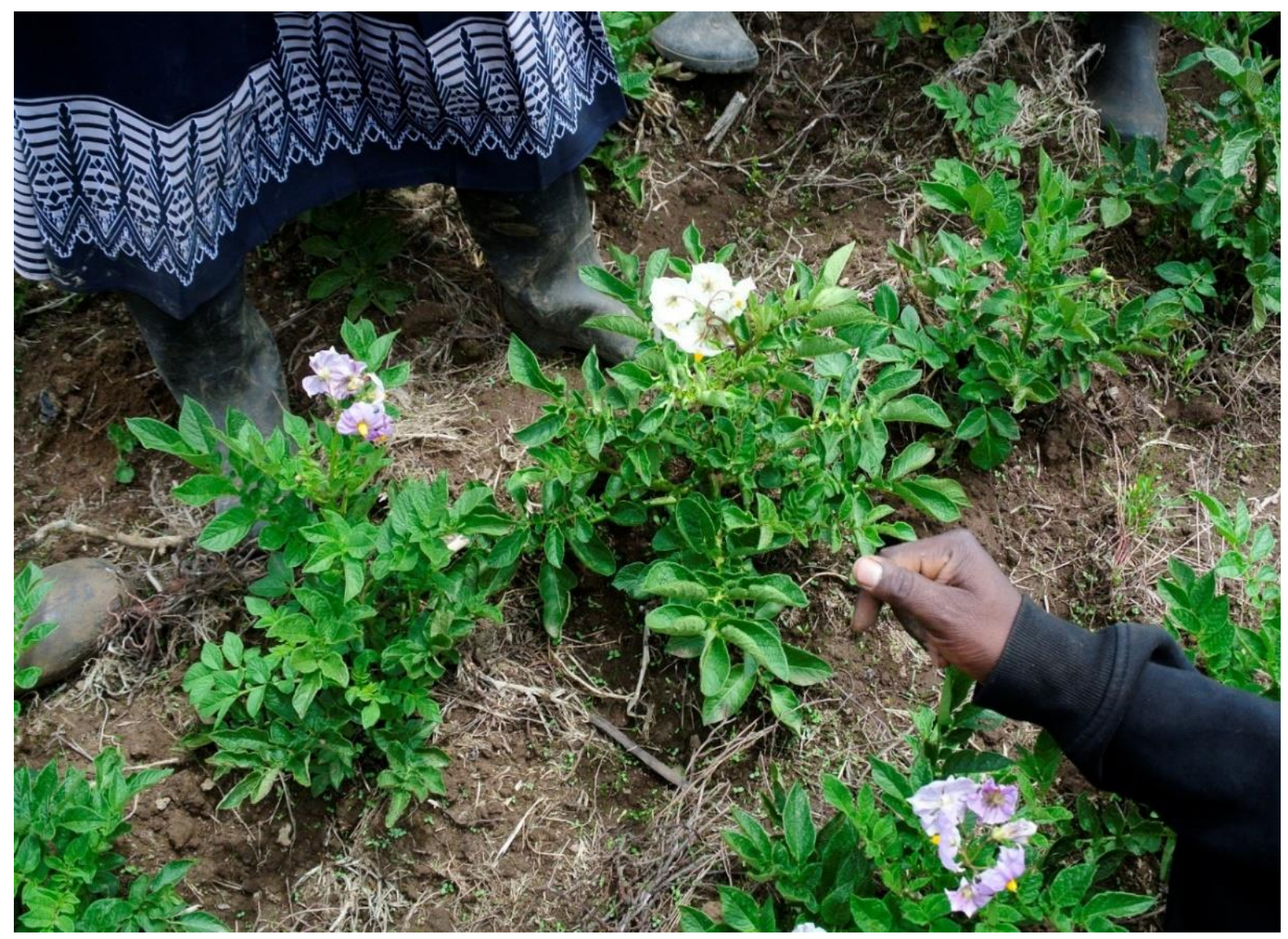

This chapter has been submitted for publication in Potato Research 


\section{Abstract}

Potato is an important food security crop in Kenya. High prevalence of potato viruses is one of the major causes of low potato yields. Implementation of effective virus management strategies requires information on farmer's perceptions and practices on virus epidemiology and control. To better understand farmer's knowledge and practices in virus control and set possible pathways for intervention, a farmer household survey involving 147 respondents was conducted in two major potato growing regions in Kenya. Lack of sufficient technical information on potato virus symptoms, vectors and modes of transmission were found to be the major hindrances to farmer's efforts towards virus control. In addition, the farmers did not have sufficient knowledge of locally available methods of potato virus control. A spider diagram approach was used as a decision-making tool to determine the aspect of virus control that required the highest prioritization for immediate intervention by policy makers. Use of virus resistant cultivars was found to require the most urgent attention compared to other aspects of virus control and was expected to have greater impact in lowering virus prevalence in farmer's fields. This study showed that enhancing farmer knowledge need to be prioritized as this is a key determinant of the success of the virus control strategy to be selected for implementation.

\subsection{Introduction}

Potato (Solanum tuberosum L.) is the second most important food crop in Kenya after maize (FAOSTAT 2017). The crop is considered a major staple food and an income earner for rural households in the potato producing regions majority of whom practice small scale farming (Janssen et al. 2013). Potato is mainly cultivated in high-altitude areas (1,500-3,000 $\mathrm{m}$ above sea level), in regions around Mt. Kenya and around the highlands surrounding the Rift Valley (NPCK 2017). Despite the increasing demand for potato and potato products across the Kenyan potato value chain (Janssen et al. 2013), potato yields are low with an average of $8.7 \mathrm{~T} / \mathrm{Ha}$ (FAOSTAT 2017) compared to a potential of over $35 \mathrm{~T} / \mathrm{Ha}$ under improved potato cultivation conditions (Lungaho et al. 2006; Onditi et al. 2012).

Potato viruses are among the major constraints to potato production in Kenya (Onditi et al. 2013). Six potato viruses, namely; potato leaf roll virus (PLRV), 
potato virus $Y(P V Y)$, potato virus $X(P V X)$, potato virus $M(P V M)$, potato virus $A$ (PVA) and potato virus S (PVS) have been reported in farmer's fields at high prevalence levels (Machangi et al. 2003; Muthomi et al. 2009; Were et al. 2013). Once a mother plant is infected, the virus is transmitted to the next cropping generation through seed tubers (Chandla et al. 2001; Rahman et al. 2010; Khurana 1998; Thomas-Sharma et al. 2016). Potato crops infected with viruses are commonly found with symptoms such as leaf roll, leaf vein necrosis, leaf mosaic, tuber necrosis and stunted growth each with varying levels of incidence and severity (Beemster and de Bokx 1987). In susceptible potato cultivars, PLRV and PVY can cause yield losses of 80 to $100 \%$ while PVX, PVM, PVA and PVS typically causes mild mosaic symptoms resulting in yield loses of 10 to $20 \%$ (Salazar 1996).

Potato viruses can be controlled by avoiding farming practices that increase chances of virus transmission. Such practices include: maintaining volunteer potato plants in or around the farm (Wright and Bishop 1981; Jones et al. 1996); cutting tubers prior to planting without following proper disinfection procedures; bruising seed tubers after harvest or mechanical injury to haulms during farm operations (Fageria et al. 2015); lack of a proper crop rotation/intercropping plan or overlap of potato growing seasons in same or neighbouring farms (Ragsdale et al. 2001) and maintaining alternative host plants of potato viruses in the field (Syller and Kaliciak 2009). Some of the potato virus control methods that have been proposed include use of certified seed tubers (Almekinders et al. 2019), positive seed selection (Gildemacher et al. 2011; Schulte-Geldermann et al. 2012; Priegnitz et al. 2019), control of aphids (virus vectors) by use of various forms of pesticides (Olubayo et al. 2010), use of virus resistant varieties (Onditi et al. 2013) and use of border barriers crops to control aphids (Olubayo et al. 2010). Virus control using resistant cultivars which can withstand virus degeneration can be a long-term, cost-effective solution to potato virus problems in this region because over $95 \%$ seed tubers planted by farmers are not certified (Gildemacher et al. 2011; NPCK 2017) and farmers may be having limited knowledge on virus control. Development and implementation of an effective virus control strategy based on the cropping system is one of the ways in which yield losses associated with viruses can be reduced (Islam 2017). Farmer's knowledge, perceptions and practices can be used in developing a package for control of various pest and diseases in developing countries and in improving capacity of farmers to managing pests and 
diseases (Florin et al. 2012; Midega et al. 2016; Mendesil et al. 2016). This study was therefore conducted to identify gaps in farmer's' perceptions and practices in relation to potato virus control and to suggest aspects of virus control in order of priority for implementation.

\subsection{Methodology}

\subsubsection{A description of survey sites}

A farmer household survey was conducted in Nyandarua and Kiambu counties in Kenya. The two counties were selected because they are among the leading potato producing regions in the country and potato is central to their economic activities (Kaguongo et al. 2008). In addition, a recent virus survey (Chapter 3 of this thesis) showed difference in virus prevalence and cultivar choice between Nyandarua County and other counties. Nyandarua County was found to have the lowest virus prevalence and to have a unique preference for one potato variety (Shangi) while Kiambu County had a higher virus prevalence with a preference for different cultivars. These findings triggered an inquiry into cultural perceptions and farming practices that may influence potato virus epidemiology and control.

\subsubsection{Sampling method, data collection and analysis}

A representative sample of 147 farmers interviewed in the survey was calculated as previously described by Singh and Masuku 2014 as:

$\mathrm{N}=\frac{2 \mathrm{Zpq}}{e^{2}}$

Where $Z$ is the normal variate (1.96), $p$ is an estimated proportion of measured attribute, $q$ is $(1-p)$ and $e$ is the desired precision $=5 \%$. Farmers (farms) were identified using simple random sampling in August 2018 from all the potato growing regions of each county. Data were collected by administering a semistructured questionnaire to individual farmers. Open-ended questions allowed farmers to express themselves fully allowing collection of as much information as possible. Answers were collected into open data kit (ODK; www.opendatakit.org) an android (Google Inc.) smart phone application while taking the GPS (global positioning system) position of the farms (Maduka et al. 2017). The GPS coordinates were used to generate the map (Fig 1) showing the survey points using QGIS software (QGIS 2019). To describe the present status of farmer 
knowledge and practice in potato virus control, data obtained were analysed to obtain descriptive statistics in Microsoft Excel (2013).

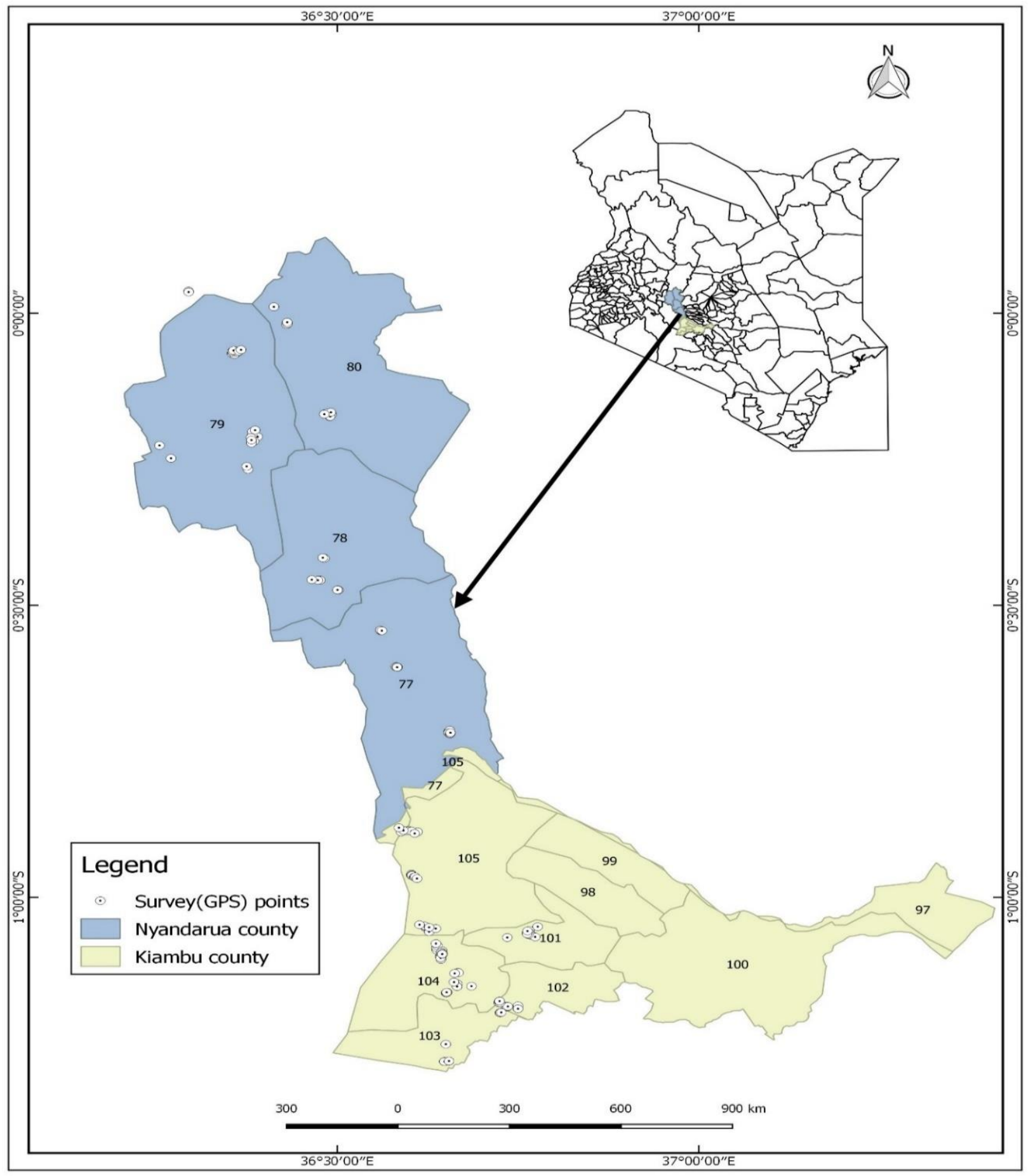

Fig 1: Administrative map of Nyandarua and Kiambu counties in Kenya with questionnaire survey GPS points

To set up a basis for decision making for potato virus control, a system approach using spider diagram (De Olde et al. 2016) was adopted to the potato (virus) growing situation in Kenya. The first step was to set the overall goal, defined as 
the 'principal' (Florin et al. 2014) which for this case was to effectively control potato viruses in the Kenyan potato farming systems. To achieve the overall goal, there are set conditions or general rules that govern the outcome of the overall goal called the 'criteria' (Florin et al. 2014). For this case the criteria for potato virus control were to improve farmer knowledge and practice in reducing: -

1. Aphid (vector) virus transmission.

2. Virus transmission through seed tubers.

3. Mechanical or contact virus transmission to the potato crop.

4. Sources of virus inoculum around the potato crop.

5. Lack of use of host resistance in virus control by the farmers.

6. Lack of effective use of pesticides in virus vector control by farmers.

These measurable parameters under each of the above criteria are called the 'indicators' (Florin et al. 2014). A conceptual framework of the relationship between principals, criteria and the indicators in relation to the Kenya potato virus situation is presented in Fig 2. The indicator scores were assigned based on the level of farmer knowledge and practice in potato virus epidemiology and control from the farmer's response during the survey and is represented on a scale of 010 (Marinus et al. 2018). For example, if $20 \%$ of farmers know about vector transmission of potato viruses, a score of 2 out of 10 was assigned. Since indicators under each criterion in an agricultural system may have different weights based on the relative potential impact on overall sustainability of a system (Struik et al. 2014), indicators were assigned different weights in a matrix of $0-100 \%$ under each criterion (Marinus et al. 2018). Expert opinion on the relative weight of each indicator in the Kenyan potato farming systems was used to assign the indicator weights. Expert opinions were sourced from a panel of four potato scientists with specialty and experience in potato virus epidemiology and control under the local (Kenyan) potato cultivation conditions and comprised of pathologist, breeder, socio-economist and virologist. The final scores were calculated as the sum of the product of each indicator and the corresponding indicator weighted and the final value visualized in the spider diagrams (Fig 5 and 6). 


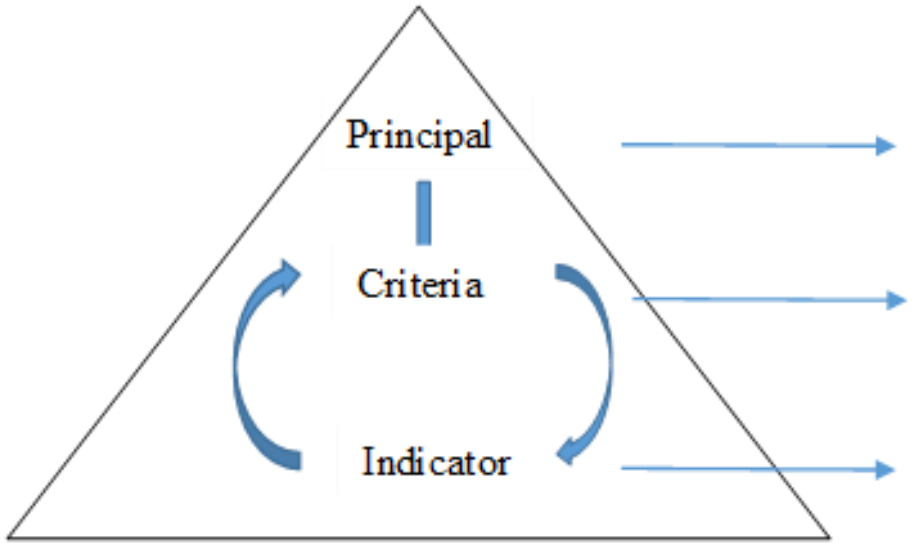

Effective control potato viruses in the Kenyan potato farming systems

Conditions that have to be met for effective virus control

Specific aspects of virus management e.g. $\%$ of farmers spraying against aphids

Fig 2: An illustration of the casual relationship between principal, criteria and indicator (Florin et al. 2014) in relation to potato virus epidemiology and control situation in Kenya

A score of zero in the spider diagram represented a situation which required more urgent intervention compared to a score of ten which indicated that viruses were perfectly controlled, and farmers did not need any support in virus control.

\subsection{Results}

\subsubsection{A general description of survey sites}

Average farm sizes in Kiambu and Nyandarua regions in Kenya were small (1.0 $\mathrm{Ha}$ ) and typical of a small-scale farming system. Farmers in both counties used $70 \%(0.7 \mathrm{Ha})$ of their total farm area for growing crops. Potato was planted in $35.7 \%(0.25 \mathrm{Ha})$ of the total area under crops $(28.6 \%$ in Kiambu and $42.8 \%$ in Nyandarua). There was a higher number of male respondents in Nyandarua (53.2\%) but there was a higher number of female respondents in Kiambu (67.1\%).

\subsubsection{A description of farmer's knowledge and practice in potato virus control}

\subsubsection{Farmer's knowledge of virus symptoms and vector virus transmission}

To understand farmer's knowledge of virus symptoms and vector transmission of potato viruses, farmers were shown images of aphids on the underside of potato leaves and images of common potato virus symptoms (mosaic, stunted growth, necrosis, chlorosis and leaf roll). They were asked to name the insect vector/pest 
and the plant disease characterized by the symptoms in the images respectively. The majority of respondents (63.9\%) did not know what aphids were $(60.0 \%$ in Kiambu and $67.8 \%$ in Nyandarua). Similarly, a high number of respondents $(81.8 \%)$ were unable to correctly identify potato virus symptoms $(76.5 \%$ in Kiambu and $87.1 \%$ in Nyandarua). Farmer's understanding of the role of aphids in virus transmission was very poor (Table 1 ). A clear majority of farmers $(94.5 \%)$ who did not identify aphids correctly also did not identify the correct virus symptoms (86.5\% in Kiambu and $97.6 \%$ in Nyandarua). Regarding the role of aphids in potato virus transmission, only $8.0 \%$ (4.7\% in Kiambu and $11.3 \%$ in Nyandarua) of farmers associated aphids with potato virus transmission while the rest associated aphids with other constraints of potato production.

\subsubsection{Use of insecticides to control aphids}

To understand the level of farmer knowledge in pesticides use for effective potato virus vector control, farmers were asked about their knowledge and practices in pesticide application (Table 1 ). Over half the farmers (55.1\%) did not apply any pesticide (including insecticides to control aphids) on their potato crop (58.8\% in Kiambu and $51.4 \%$ in Nyandarua). Farmer's responses on why they did not apply pesticides are summarized in Table 1. Farmer's lack of necessary information required for effective vector control using pesticides was the main reason they did not apply pesticides. Respondents were asked if they scouted for pests and diseases in their crop and almost half of them (50.7\%) did not (52.9\% in Kiambu and $48.4 \%$ in Nyandarua). Among farmers who scouted for pests and diseases, only a small fraction (20.5\%) checked specifically for aphids and viruses $(28.2 \%$ in Kiambu and $12.9 \%$ in Nyandarua) on their potato crop. Farmers who scouted for aphids in their crop did so at an average of 18 days interval (16 days interval in Kiambu and 20 days interval in Nyandarua counties respectively).

\subsubsection{Use of host resistance to control potato viruses and improve potato yields}

Table 3 lists the most important potato cultivars grown in the two counties. Among the farms visited in both counties, Shangi was the most popularly grown $(90.5 \%)$ potato and was the only cultivar in Nyandarua county. Even though farmers in Kiambu grew 11 different cultivars, Shangi was still their main (83.5\%) potato cultivar. Area under potato and the yields as reported by farmers during the survey interview over the cropping season of long rains 2018, (April to August 2018) were used to calculate average potato yield of the varieties grown (Table 3). 
Table 1: Description of farmer knowledge and practice in potato virus transmission and vector control

\begin{tabular}{llccc}
\hline Question & Farmer response (s)/practice (s) & \multicolumn{3}{c}{ Percentage of farmers (\%) } \\
\hline & & Kiambu & Nyandarua & Mean \\
\hline Farmers & Farmer doesn't know & 68.2 & 72.6 & 70.4 \\
knowledge of & Transmit potato viruses & 4.7 & 11.3 & 8.0 \\
the role of & Suck plant sap & 0.0 & 11.3 & 5.6 \\
aphids in & Lower yields & 7.1 & 3.2 & 5.1 \\
potato virus & Wilting of leaves & 9.4 & 0.0 & 4.7 \\
transmission & Farmer sees no effect on the crop & 3.5 & 1.6 & 2.6 \\
& Causes late blight & 3.5 & 0.0 & 1.8 \\
& Feeds on the leaves & 3.5 & 0.0 & 1.8 \\
\cline { 2 - 5 } Why farmers & Aphids have no effect on the potato crop & 41.2 & 2.6 & 21.9 \\
do not apply & Lack of technical information & 29.4 & 24.4 & 26.9 \\
pesticides on & No reason & 15.7 & 24.4 & 20.1 \\
their crop & Not available & 7.8 & 48.5 & 28.2 \\
& Not effective & 3.9 & 0.0 & 2.0 \\
& Too costly & 2.0 & 0.0 & 1.0 \\
\hline
\end{tabular}

Table 2: Characteristics that farmers prefer in potato varieties grown in Kiambu and Nyandarua counties in Kenya

\begin{tabular}{lccc}
\hline Farmer response (s)/practice (s) & \multicolumn{3}{c}{ Percentage of farmers (\%) } \\
\cline { 2 - 4 } & Kiambu & Nyandarua & Mean \\
\hline High yields & 44.3 & 47.7 & 46.0 \\
Big (large sized) tubers & 16.1 & 12.6 & 14.4 \\
High market demand & 5.4 & 13.5 & 9.4 \\
Good mix of large and medium size tubers & 13.4 & 3.6 & 8.5 \\
Early maturity & 4.0 & 11.7 & 7.9 \\
Well adapted to local cultivation conditions & 0.0 & 5.4 & 2.7 \\
Lack of better alternative varieties & 2.7 & 2.7 & 2.7 \\
Good taste & 5.4 & 0.0 & 2.7 \\
Late blight tolerance & 3.4 & 0.0 & 1.7 \\
Bacterial wilt tolerance & 2.0 & 0.0 & 1.0 \\
Virus tolerance & 2.0 & 0.0 & 1.0 \\
Medium size tubers & 1.3 & 0.0 & 0.7 \\
Availability of seed & 0.0 & 0.9 & 0.5 \\
Drought tolerance & 0.0 & 0.9 & 0.5 \\
Short dormancy & 0.0 & 0.9 & 0.5 \\
\hline
\end{tabular}


Table 3: Cultivars grown and average potato yield (T/Ha) among potato farmers Kiambu and Nyandarua counties in Kenya

\begin{tabular}{lllllll}
\hline \multirow{2}{*}{ Variety name } & \multicolumn{2}{l}{$\begin{array}{l}\text { Percentage of farmers growing } \\
\text { the cultivar }(\%)\end{array}$} & \multicolumn{2}{l}{ Average yield (T/Ha) } \\
\hline & Kiambu & Nyandarua & Mean & Kiambu & Nyandarua & Mean \\
\hline Shangi & 83.5 & 100.0 & 90.5 & 2.8 & 7.3 & 5.1 \\
Unica & 1.2 & Not Grown & 0.7 & 6.9 & Not grown & 3.5 \\
Tigoni & 3.5 & Not Grown & 2.0 & 5.9 & Not grown & 3.0 \\
Kenya Karibu & 3.5 & Not Grown & 2.0 & 5.1 & Not grown & 2.6 \\
Nyayo & 2.4 & Not Grown & 1.4 & 3.1 & Not grown & 1.6 \\
Thimathuti & 1.2 & Not Grown & 0.7 & 1.8 & Not grown & 0.9 \\
Kagosi & 1.2 & Not Grown & 0.7 & 1.6 & Not grown & 0.8 \\
Kerr's Pink & 1.2 & Not Grown & 0.7 & 1.5 & Not grown & 0.8 \\
Ndera Mwana & 7.1 & Not Grown & 4.1 & 1.4 & Not grown & 0.7 \\
Desiree & 2.4 & Not Grown & 1.4 & 1.3 & Not grown & 0.7 \\
Kalucy & 3.5 & Not Grown & 2.0 & 0.9 & Not grown & 0.5 \\
\hline Mean & & & 2.9 & 7.3 & 1.8 \\
\hline
\end{tabular}

Average potato yields during the season were very low $(1.8 \mathrm{~T} / \mathrm{Ha})$. The most popular cultivar (Shangi) was also the highest yielding. Highest yields (7.3 $\mathrm{T} / \mathrm{Ha})$ were realized in Nyandarua County, where all the farmers grew Shangi cultivar. In Kiambu where farmers grew 11 different cultivars the yields were lower (1.8 - 6.9 $\mathrm{T} / \mathrm{Ha}$ ). To understand if farmers considered potato virus tolerance an important factor during variety choice and selection. Farmers were therefore asked about the important characteristics that they preferred in the potato varieties they grew (Table 2). Tolerance to viruses was among the traits which attracted the least attention $(1.0 \%)$ during farmer potato variety selection. Instead, the most preferred characteristics included high yields (46.0\%), large sized tubers $(14.4 \%)$, high market demand $(9.4 \%)$, good mix of large and medium size tubers $(8.5 \%)$ and early maturity (7.9\%).

\subsubsection{Virus transmission through seed tubers}

Farmer's knowledge on virus transmission through seed tubers was limited. Majority $(77.4 \%)$ of the farmers (72.6\% in Kiambu and $82.3 \%$ in Nyandarua) were not aware that re-using their own (non-certified) virus infected seed tubers is one of the major pathways of virus transmission into their potato crop. A large proportion $(79.0 \%)$ of farmers have never replaced seed tubers of their potato crop ( 72.6 and $85.5 \%$ in Kiambu and Nyandarua respectively). The few farmers who replaced their seed tubers did so after an average of 4.5 years or 
approximately 9 cropping seasons (4.9 and 4.1 years in Kiambu and Nyandarua, respectively). Few farmers (10.2\% with $19.0 \%$ in Kiambu and $1.4 \%$ in Nyandarua) planted certified seed potato either from KALRO or other formal certified seed producers. Most farmers used ware potatoes bought from local markets $(45.2 \%$ with $41.9 \%$ in Kiambu and $48.6 \%$ in Nyandarua) while others obtained seed tubers from neighbours (38.8\% with $27.6 \%$ in Kiambu and $50.0 \%$ in Nyandarua) and from own saved seed (5.7\% with $11.4 \%$ in Kiambu and $0.0 \%$ in Nyandarua).

\subsubsection{Mechanical transmission of potato viruses}

A clear majority of the farmers interviewed (99.5\% with $98.9 \%$ in Kiambu and $100.0 \%$ in Nyandarua) were aware that cutting seed tubers can spread diseases in potato. As a result, very few farmers (1.9\% with $2.2 \%$ in Kiambu and $1.5 \%$ in Nyandarua) were cutting seed tubers. In addition, farmers did not $(0.5 \%$ with $1.1 \%$ in Kiambu and $0.0 \%$ in Nyandarua) consider it profitable to cut seed tubers. Some farmers (31.1\% with $33.0 \%$ in Kiambu and $29.2 \%$ in Nyandarua) cut the haulms of their potato crop shortly before harvesting but very few $(4.4 \%$ with $8.8 \%$ in Kiambu and $0.0 \%$ in Nyandarua) of them used sharp objects that could transmit potato viruses instead they uprooted plants gently, leaving the tubers in the soil. After dehaulming, farmers did not take too long before harvesting. Farmers took an average of 9 days (12 days in Kiambu and 6 days in Nyandarua) from dehaulming to harvesting.

\subsubsection{Role of alternative host plants and other sources of virus inoculum virus} transmission

Nine plant species, which are potential alternative hosts for potato viruses from the family Solanaceae were found in or around $19.7 \%$ of potato farms (Table 4). Sodom apple (Solanum incanum) (21.5\%), Datura spp (16.1\%) and Black night shade (Solanum nigrum) (31.8\%) were found more frequently while pepper (Capsicum annuum) (0.6\%) and angels trumpet (Brugmansia spp) (1.0\%) were least common. The average duration of three Solanaceous plants (sodom apple, Datura spp and Black night shade) were found to be long enough (10.1, 8.5 and 6.6 months respectively) to overlap two potato cultivation seasons of the year and act as source of virus inoculum for transmission from one season to another. Although intercropping (37.0\% with $42.4 \%$ in Kiambu and $31.7 \%$ in Nyandarua) and crop rotation ( $86.0 \%$ with $81.2 \%$ in Kiambu and $90.8 \%$ in Nyandarua) were commonly practiced by farmers, only $(3.2 \%$ with $3.6 \%$ in Kiambu and $2.8 \%$ in 
Nyandarua) intercropped or rotated their potato crop (5.9\% with $7.1 \%$ in Kiambu and $4.7 \%$ in Nyandarua) with Solanaceous plants which would have acted as potential source of virus inoculum to their crop.

A large proportion of farmers (79.8\%) had volunteer potato plants in their fields. Over half the farmers $(57.7 \%)$ deliberately left tubers in the field at harvest to produce a bridging crop that many farmers (41.5\%) were tending by weeding and controlling pests and diseases. Tubers harvested from the volunteer crop provided food early in the season before the main potato crop matured in most farms (52\%) and this was the main reason why the practice was common among the farmers and was difficult to eradicate. Farmer knowledge that growing volunteer potatoes can maintain and spread viral and other seed borne diseases in the farm was largely limited (6.4\%). Many farmers (78.0\%) did not know of any disadvantages of having volunteer potatoes while only a few (15.6\%) considered them as weeds in the farm. 
Table 4: Farmer's perception of the potential of alternative (Solanaceous plants) host plants in or around potato farms in contributing to spread of viruses to their potato crop

\begin{tabular}{|c|c|c|c|c|c|c|c|c|c|}
\hline \multirow[t]{2}{*}{$\begin{array}{l}\text { Solanaceous } \\
\text { crop/weed }\end{array}$} & \multicolumn{3}{|c|}{$\begin{array}{l}\% \text { of farmers with weeds } \\
\text { in/around their potato farms }\end{array}$} & \multicolumn{3}{|c|}{$\begin{array}{l}\text { Average duration of the plants } \\
\text { in/around potato farms (months) }\end{array}$} & \multicolumn{3}{|c|}{$\begin{array}{c}\% \text { of farmers knowing weeds can be } \\
\text { source of inoculum for virus } \\
\text { transmission }\end{array}$} \\
\hline & Kiambu & Nyandarua & Mean & Kiambu & Nyandarua & Mean & Kiambu & Nyandarua & Mean \\
\hline S. incanum & 11.9 & 31.1 & 21.5 & 9.4 & 7.5 & 8.5 & 25.0 & 4.5 & 14.8 \\
\hline Datura spp & 26.7 & 5.5 & 16.1 & 3.0 & 6.3 & 4.6 & 22.8 & 25.0 & 23.9 \\
\hline S. nigrum & 32.9 & 30.6 & 31.8 & 3.4 & 3.4 & 3.4 & 28.6 & 5.5 & 17.1 \\
\hline S. muricatum & 11.8 & 32.3 & 22.0 & 7.4 & 5.8 & 6.6 & 10.0 & 5.0 & 7.5 \\
\hline S. betaceum & 10.6 & 12.9 & 11.7 & 8.8 & 11.4 & 10.1 & 33.3 & 0.0 & 16.7 \\
\hline S. lycopersicun & 17.6 & 1.6 & 9.6 & 3.8 & 3.0 & 3.4 & 26.7 & 0.0 & 13.4 \\
\hline Physalis spp & 7.1 & 3.2 & 5.1 & 6.0 & 0.8 & 3.4 & 0.0 & 5.0 & 2.5 \\
\hline Brugmansia spp & 2.0 & 0.0 & 1.0 & 2.0 & 2.0 & 2.0 & 0.0 & 0.0 & 0.0 \\
\hline C. annuum & 1.2 & 0.0 & 0.6 & 3.0 & 3.0 & 3.0 & 0.0 & 0.0 & 0.0 \\
\hline
\end{tabular}




\subsubsection{Overlap of potato cultivation seasons and potato virus transmission}

To understand if the duration of the two potato cropping seasons overlap in the field in a year (a situation that can lead to transmission of viral diseases from one season to another), farmers were asked the months of the year when they planted and harvested their crop (Fig 3 and 4) and this was used to establish the duration of potato crops in the field. Potato crops in the field overlapped all through the year both in Kiambu and Nyandarua counties. Farmers planted potatoes in almost all the months of the year. When the farmers were asked how many times in a year they planted potatoes, most farmers (78.0\%) grew potatoes twice a year (88.2\% in Kiambu and $67.7 \%$ in Nyandarua) and another $15.6 \%$ planted them three times a year (7.1\% in Kiambu and $24.2 \%$ in Nyandarua). Very few farmers (6.4\%) with only $4.7 \%$ in Kiambu and $8.1 \%$ Nyandarua planted potatoes only once a year.

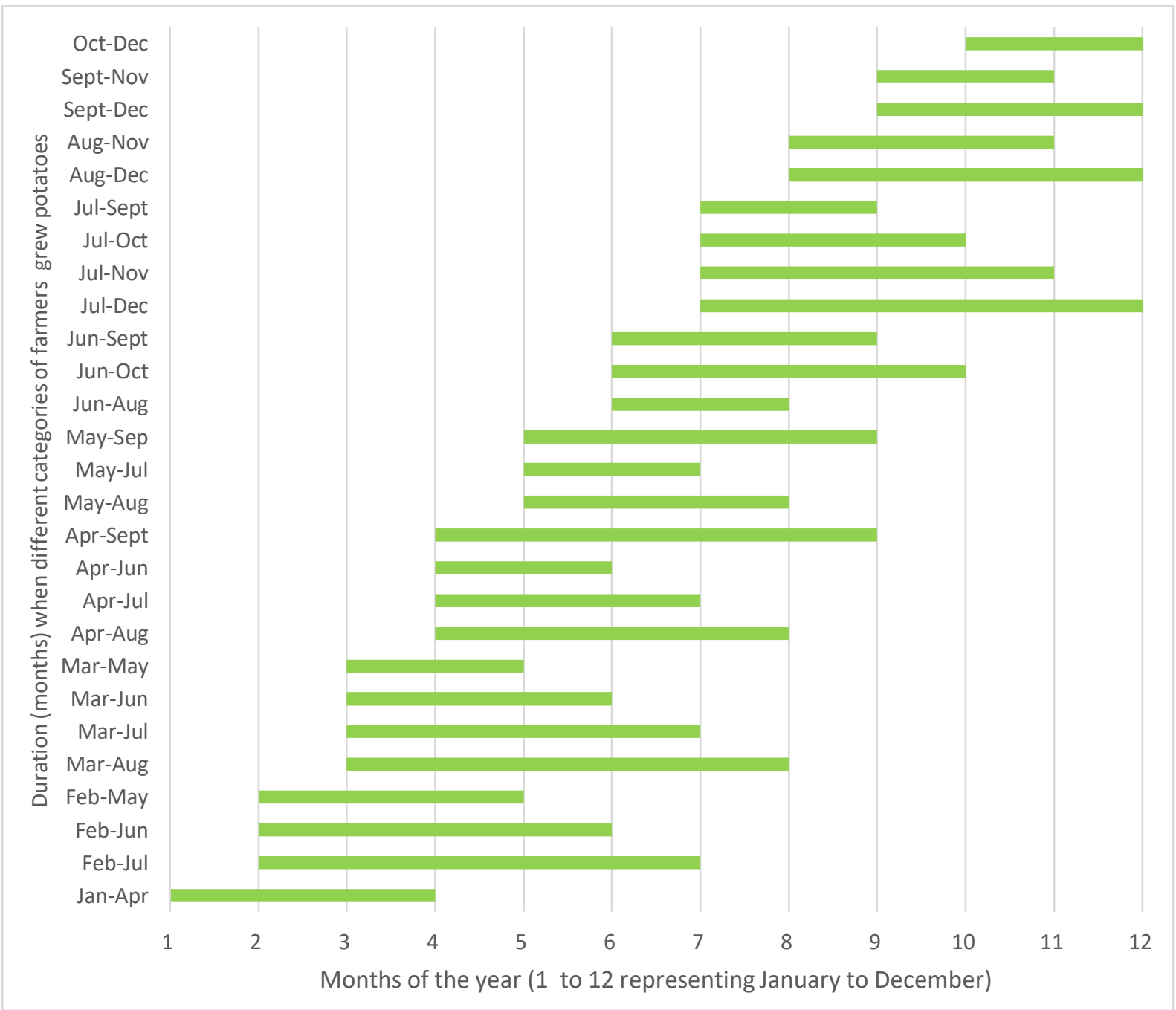

Fig 3: Overlap of potato cultivation periods in Kiambu County, Kenya in the year prior to the survey (2017) 


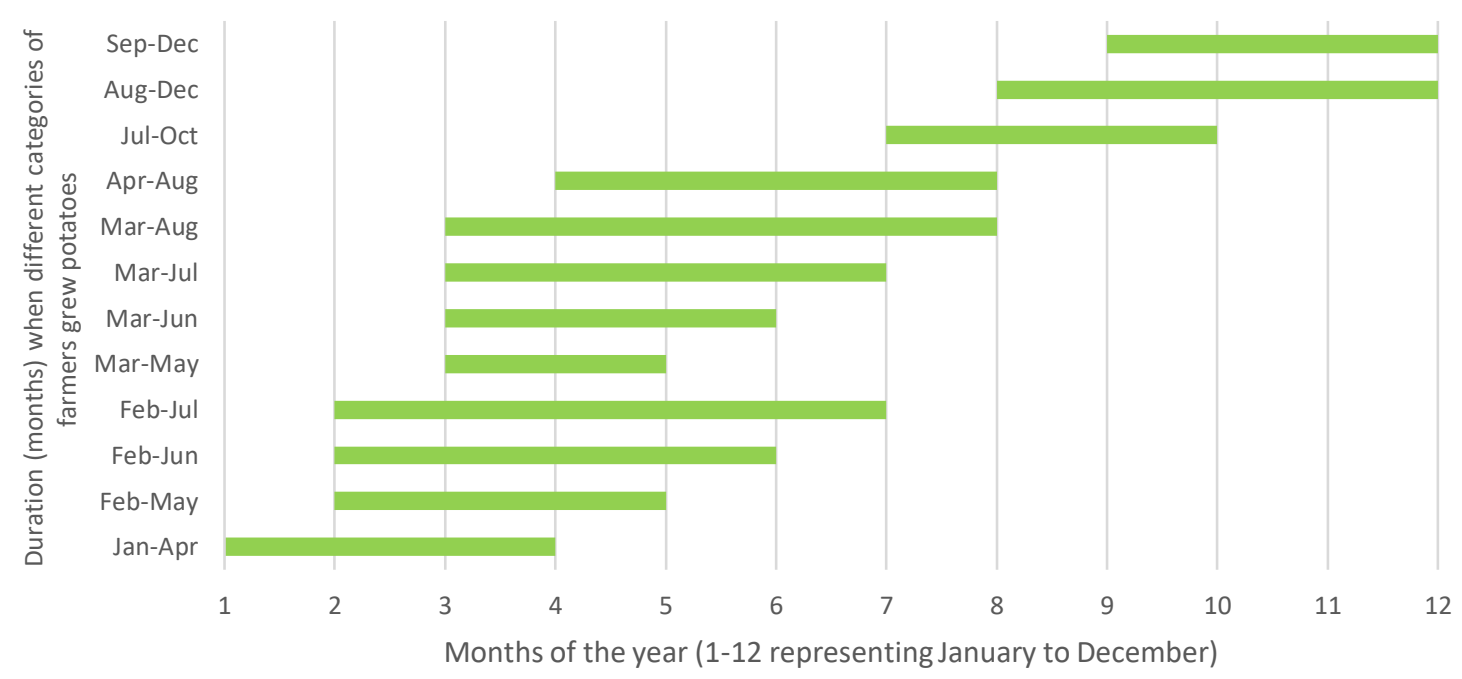

Fig 4: Overlap of potato cultivation periods in Nyandarua County, Kenya in the year prior to the survey (2017)

\subsubsection{Analysis of order of priority in intervention in potato virus control using spider diagrams}

Individual scores on the different aspects of virus control (criteria) and ranking of the orders of priority of different aspects of virus control from the spider diagram of the two counties are presented in Fig 5. In Kiambu county, the order of priority in virus control based on the respective scores in the spider diagram starting with the one that requires highest priority was:

1. Using host resistance in virus control (0.2).

2. Avoiding sources of virus inoculum (1.6).

3. Avoiding mechanical transmission of viruses (3.3).

4. Avoiding vector transmission of viruses (4.6).

5. Avoiding virus transmission through seed tubers (5.0).

6. Knowledge of effective use of pesticides in virus vector control (6.3).

In Nyandarua county, the scores and the order of priority were ranked as follows respectively:

1. Using host resistance in virus control (0.0).

2. Avoiding sources of virus inoculum (1.2). 
3. Avoiding vector transmission of viruses (1.9).

4. Avoiding mechanical transmission of viruses (3.4).

5. Avoiding virus transmission through seed tubers (5.2).

6. Knowledge of effective use of pesticides in virus vector control (7.0).

In both counties, the use of host resistance in virus control and avoiding sources of virus inoculum were the two aspects of virus control that had the lowest scores ranging from 0.0 to 1.6 . Improving farmer knowledge on effective use of pesticides in virus vector control and avoiding virus transmission through seed tubers gave the highest scores ranging from 5.0 to 7.0 in both counties but the scores were still lower than the maximum 10 needed for effective control of potato viruses. Under each of the above six criteria, the indicators (specific things that need to be done to control the viruses) used to generate the criteria are displayed in the spider diagram (Fig 6). These too had scores which varied under each criterion and had different orders of priority based on the scores in the two counties.

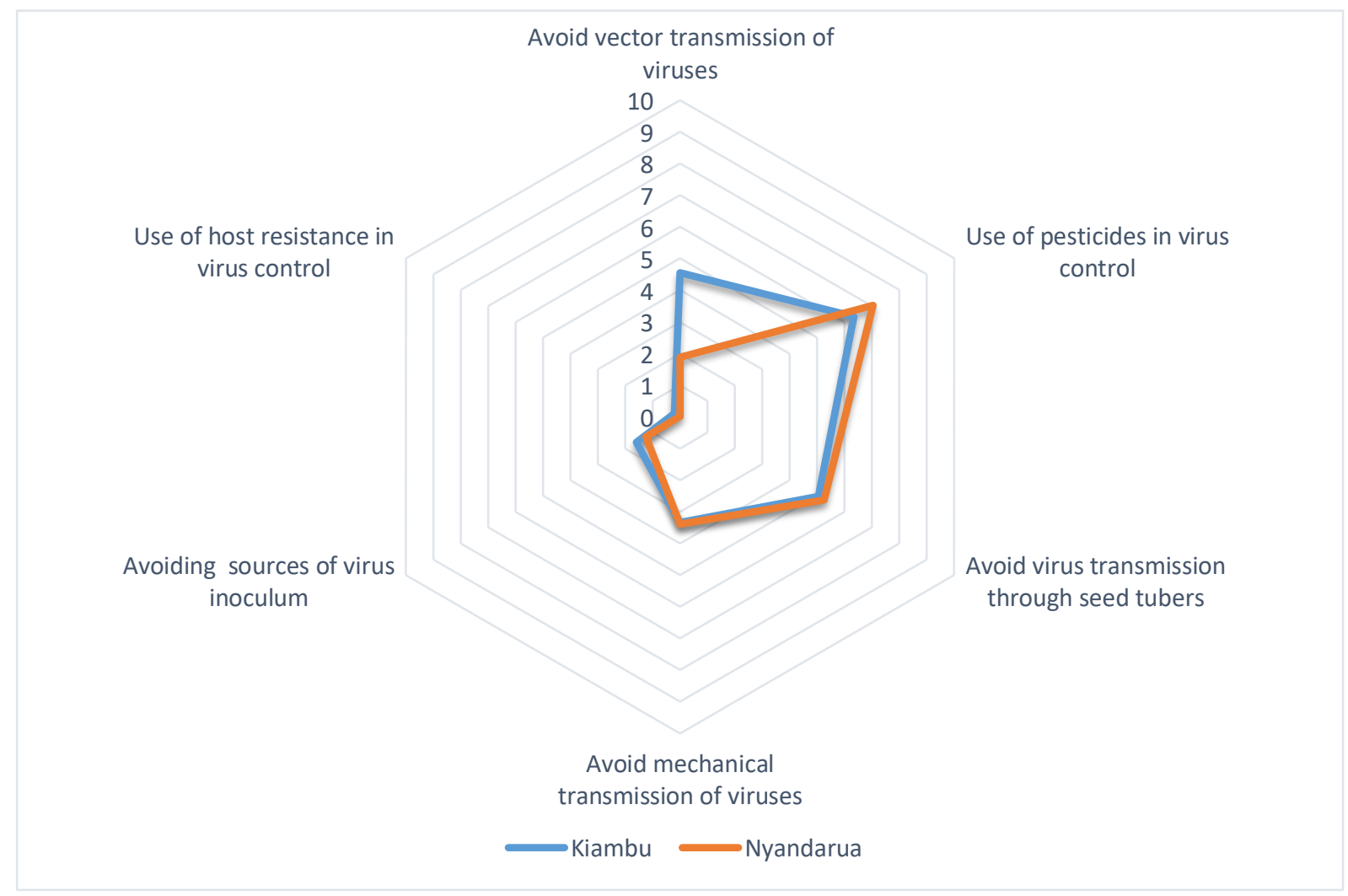

Fig 5: Spider diagram showing principal scores of what the farmers are doing to control potato viruses in Kiambu and Nyandarua counties in Kenya 


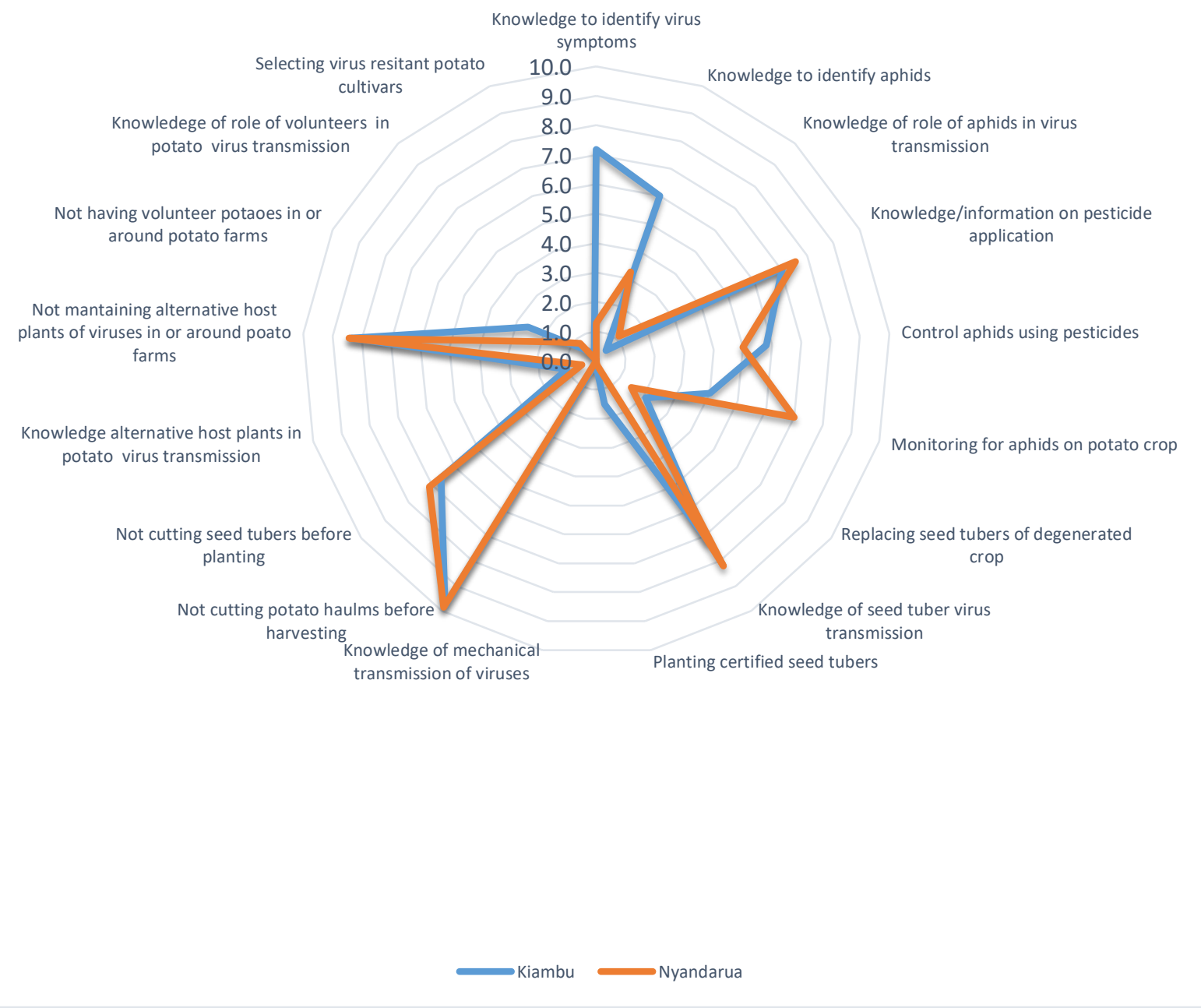

Fig 6: Spider diagram showing indicator scores of what the farmers are doing to control potato viruses in Kiambu and Nyandarua counties in Kenya 
Table 5: Scores on the principals and indicators of potato virus control by farmers in Kiambu and Nyandarua counties of Kenya

\begin{tabular}{|c|c|c|c|c|c|}
\hline Principals and indicators of virus control & Indicato & values & Indicator weights & Principal & cores \\
\hline & Kiambu & Nyandarua & & Kiambu & Nyandarua \\
\hline Vector transmission of viruses & & & & 4.6 & 1.9 \\
\hline Knowledge to identify virus symptoms & 7.2 & 1.3 & 0.33 & & \\
\hline Knowledge to identify aphids & 6.0 & 3.2 & 0.33 & & \\
\hline Knowledge of role of aphids in virus transmission & 0.5 & 1.1 & 0.33 & & \\
\hline Using pesticides in virus vector control & & & & 6.3 & 7.0 \\
\hline Knowledge/information on pesticide application & 7.1 & 7.6 & 0.67 & & \\
\hline Control aphids using pesticides & 5.8 & 5.0 & 0.17 & & \\
\hline Monitoring for aphids on potato crop & 4.0 & 7.0 & 0.17 & & \\
\hline Virus transmission through seed tubers & & & & 5.0 & 5.2 \\
\hline Replacing seed tubers of degenerated crop & 2.1 & 1.5 & 0.20 & & \\
\hline Knowledge of seed tuber virus transmission & 7.2 & 8.2 & 0.60 & & \\
\hline Planting certified seed tubers & 1.5 & 0.1 & 0.20 & & \\
\hline Mechanical transmission of viruses & & & & 3.3 & 3.4 \\
\hline Knowledge of mechanical transmission of viruses & 0.1 & 0.0 & 0.60 & & \\
\hline Not cutting potato haulms before harvesting & 9.8 & 9.8 & 0.20 & & \\
\hline Not cutting seed tubers before planting & 6.6 & 7.1 & 0.20 & & \\
\hline Avoiding sources of virus inoculum & & & & 1.6 & 1.2 \\
\hline Knowledge alternative host plants in potato virus transmission & 1.0 & 0.5 & 0.35 & & \\
\hline Absence of alternative host plants of viruses in/around farms & 8.4 & 8.4 & 0.05 & & \\
\hline Absence of volunteer potatoes in or around potato farms & 2.6 & 1.5 & 0.25 & & \\
\hline Knowledge of role of volunteers in potato virus transmission & 0.5 & 0.8 & 0.35 & & \\
\hline Using host resistance in virus control & & & & 0.2 & 0.0 \\
\hline Selecting virus resistant potato cultivars & 0.2 & 0.0 & 1.0 & & \\
\hline
\end{tabular}




\subsection{Discussions and conclusions}

\subsubsection{Farmer's knowledge of virus symptoms and vector virus transmission}

The concept of potato virus, virus symptoms and mode of transmission of viruses was not well understood by farmers in Kiambu and Nyandarua counties. Farmers were not able to clearly distinguish viruses as a separate biotic entity from other constraints to potato production. This is likely to have a negative impact on potato production because improving potato yields largely depends on control of potato viruses and their vectors (Syller 1996) and to do this, farmers need to have a basic knowledge and ability (Waqar 2017) to correctly identify virus diseases and the aphids which act as virus vectors. This lack of knowledge can be one reason for the high virus prevalence reported in previous surveys (Gildemacher et al. 2009; Muthomi et al. 2009). Just like in this study, limited knowledge of plant viruses as opposed to other pathogens has been reported by other authors working on different crops elsewhere (Colvin et al. 2012; Adam et al. 2015). Virus symptoms have proven difficult to differentiate from other biotic and abiotic stress on the crop, a fact that can be a major hindrance to virus management. Diagnosis of virus infection through observation of visual symptoms is a challenge to farmers because virus symptom expression in plants usually depends on changing virus strains/types (García-Arenal et al. 2001); multiple infection of the host with different strains/types, host plant level of resistance and changing climatic conditions (Mendez-Lozano et al. 2003). Knowledge of virus symptoms can help farmers know when their crop is infected so that they can take appropriate actions like negative selection, positive selection (Priegnitz et al. 2019) or replace infected seed tubers with disease free certified seed tubers among other methods.

\subsubsection{Use of insecticides to control aphids}

Insufficient farmer knowledge in pesticide application to control aphids that transmit potato viruses as found in this study can hinder efforts to minimize potato virus transmission in potato fields. Application of pesticides without following action guidelines as found among Kenyan farmers may lead to development of resistance in aphid populations which may cause further outbreaks (Ragsdale et al. 2001). Farmers in such situations are at a risk of exposure to hazardous chemicals with possibilities of environmental pollution (Islam et al. 2017) resulting 
in health risks and economic losses arising from ineffective control of pest and diseases (Rahman et al. 2013). In addition, weekly monitoring of aphids or even at shorter interval (3-4 days) reduces exponential spread of viruses if aphids are controlled in time. Improving farmer's knowledge on safe and effective use of insecticides is therefore essential to reducing aphid populations which may cause virus transmission.

\subsubsection{Use of host resistance to control potato viruses and improve potato yields}

Farmers normally grow and maintain potato varieties with traits they consider important in their cropping system (Crissman 1993; Kaguongo et al. 2008). High yield is one of the most important traits that farmers consider in variety selections (Semagn et al. 2017) without knowing the underlying factors that contribute to high potato tuber yields. In the Kenyan potato cultivation situation with high potato virus prevalence and yield losses associated with virus infections (Muthomi et al. 2009; Were et al. 2013), potato virus resistance could be among the important traits associated with high potato yields (Onditi et al. 2013). Virus resistance should therefore be among the main characteristics that farmers need to consider in selecting cultivars which can withstand yield and crop quality degeneration which occurs over seasons of replanting virus infected seed tubers (Hide and Lapwood 1992; Jayashige et al. 1989; Beukema and van der Zaag 1990).

Low average yields found among farmers in Kiambu and Nyandarua counties of Kenya could be due to farmer's limited knowledge in managing viruses and other related seed borne diseases found on farms as reported in this study. Varieties Shangi, Unica and Tigoni with considerable higher yields could have higher levels of resistance to locally important seed borne diseases including potato viruses. Since most farmers considered higher yields as the most important factor in potato variety choice and selection, selecting high yielding cultivars under high virus pressure could be an indirect way of selecting cultivars with tolerance to viruses (Cooper and Jones 1983; Valkonen et al. 1994).

\subsubsection{Virus transmission through seed tubers}

When farmers plant own farm saved seed tubers, which in many cases has significant amounts of virus infections, potato viruses are transmitted from one season to the next, especially in susceptible cultivars and sometimes with increased severity. This results in successive loss of yield and crop quality. In this 
study, most farmers did not plant certified seed tubers, a practice that would be contributing to high virus prevalence in farmer's fields. In previous studies, the use of own seed and seed from neighbours or from local markets is a common practice which contributes to low potato yields not only among farmers in Kenya but also among farmers in neighbouring Uganda and Ethiopia (Gildemacher et al. 2011; Priegnitz et al. 2019). Lack of sufficient quantities of certified seed tubers at affordable prices is one reason that hinders efforts to use certified seed tubers which would reduce potato virus transmission (Kaguongo et al. 2008). In Kenya, formal sources of certified seed tubers can only satisfy $5 \%$ of the national demand in Kenya (NPCK 2017).

\subsubsection{Mechanical transmission of potato viruses}

Most potato viruses (except PLRV) can be transmitted mechanically through contact with plant sap or tissue that is infected with viruses during farm operations like cutting tubers before planting and cutting haulms before harvesting (Woodford 1992). In the Kenyan situation, there was an indication that spread of potato viruses based on practices that cause mechanical transmission of viruses was of minimal impact because farmers did not follow practices that favour virus transmission in this manner.

\subsubsection{Role of alternative host plants and other sources of virus inoculum virus transmission}

Abundance of sources of virus inoculum (virus infected plants) as reported in this study coupled with high incidence of virus vectors and alternative virus host plants around potato fields can aid spread of aphid borne potato viruses. In this study, only $10.7 \%$ of farmers knew about the potential threat of alternative host plants of viruses in their potato farms. Plant species belonging to the same family as potato (Solanaceae) or other families like Asteraceae, Brassicaceae, Chenopodiaceae, Commelinaceae and Fabaceaea can act as potential alternative host plants for viruses around the potato farms and increase chances of virus transmission to potato fields. Alternative virus host plants (weeds and crops) which grow for longer periods on the farm can increase chances of virus transmission from one cropping season to the next when this period overlaps with the next potato season, because most farmers grow potatoes more than once a year. Farmers can avoid virus transmission from infected plants is by using a crop rotation plan whereby a host plant of a potato virus does not follow a potato crop 
during the subsequent seasons of rotation (Thresh 1982). Similarly, the potential host plants of viruses should not be intercropped with a potato plant to avoid virus transmissions (Duffus 1971). However, low numbers of farmers practicing this as found in this study is an indication that virus spread through improper practice of crop rotation and intercropping is likely to be low.

Farmer's practice of maintaining volunteers in Kiambu and Nyandarua regions of Kenya can make it difficult to eliminate viruses from the crop especially if varieties grown by farmers are susceptible to viruses (Wright and Bishop 1981; Koepke-Hill et al. 2010). Even if farmers plant certified seed tubers with low virus loads, the clean seed would after a short while succumb to the high virus pressure on farms and force farmers to replace seed tubers after a shorter period.

Overlapping cropping periods could allow crops in neighbouring farms to maintain aphids and allow for vector migration and virus transmission considering the high prevalence of potato viruses in the region. When there is a potato crop in the farm or in neighbouring farms all year round, the crop can maintain aphid species that could play an important role in virus transmission (DiFonzo et al. 1994). Survival of such aphid species depends upon suitable host plants some of which are potato crops in neighbouring fields. In such farming systems, virus control can be a challenge due to proximity to a constant source of virus inoculum.

\subsubsection{Analysis of order of priority in intervention in potato virus control using spider diagrams}

The use of farmer knowledge and experiences has been reported to be effective in setting up a control strategy for pest and disease problems in farming systems (Florin et al. 2012; Midega et al. 2016; Mendesil et al. 2016). Virus control among farmers can therefore be more effective if their knowledge is improved. For policy makers it is important to be able to prioritize different aspects of virus control based on the order of priority to attend to farmer's needs that would bring greatest impact in virus control. In addition, policy makers can focus on specific regions with specific needs in lack of knowledge to cut cost of intervention logistics in virus control. Farmer knowledge further moderated by expert knowledge and experience in potato virus epidemiology and control is a special aspect of the spider diagrams because not all aspects of virus control have the same impact on potato virus epidemiology and control. Marinus et al (2018) discussed in detail the different challenges and questions that arise when using spider diagrams when analysing 
different aspects of a farming system. His conclusion was that the best spider diagram is that which answers to the objective of the study. In our case, we wanted to know if farmer needs in virus control vary between regions and to rank farmers needs based on priority which was well answered by the spider diagrams.

\subsection{Recommendations}

Compared to other forms of farmer knowledge on good agricultural practices, knowledge on virus epidemiology and control in potato is largely low and confusing to farmers. Special attention should be given to improving farmer's knowledge on viruses. Making decisions about virus control should be region or sub region specific since different regions may have different needs. This can be achieved by regular farmer surveys to understand farmer knowledge and needs in different aspects of virus control. This needs to be supported by (local) knowledge on occurrence and relative importance of the different potato viruses. Development and local testing of new improved methods of potato virus control through engagement of farmers and experts is vital for virus control. This however should be followed by a proper framework of dissemination of information to farmers.

\subsection{Acknowledgements}

We are very grateful to the farmers and farmer groups in Nyandarua and Kiambu counties in Kenya for providing information willingly and being a valuable asset to us during data collection. Similarly, we thank the County agricultural officers in the two regions who helped us to co-ordinate the data collection process. We also thank the data enumerators and the Kenya Agricultural and Livestock Research Organization (KALRO), Information Technology department for helping with ODK data management. 


\title{
Chapter 3
}

\section{Prevalence, distribution and relative importance of the six major potato viruses in Kenya}

\author{
John Onditi ${ }^{1,2}$, René van der Vlugt $^{2}$ and Moses Nyongesa ${ }^{1}$ \\ ${ }^{1}$ Kenya Agricultural and Livestock Research Organization, Horticultural Research \\ Institute, KALRO Tigoni, P.O. Box 338 Limuru 00217 Kenya; \\ ${ }^{2}$ Laboratory of Virology, Wageningen University and Research, Droevendaalsesteeg 1 \\ 6708PB Wageningen, The Netherlands.
}

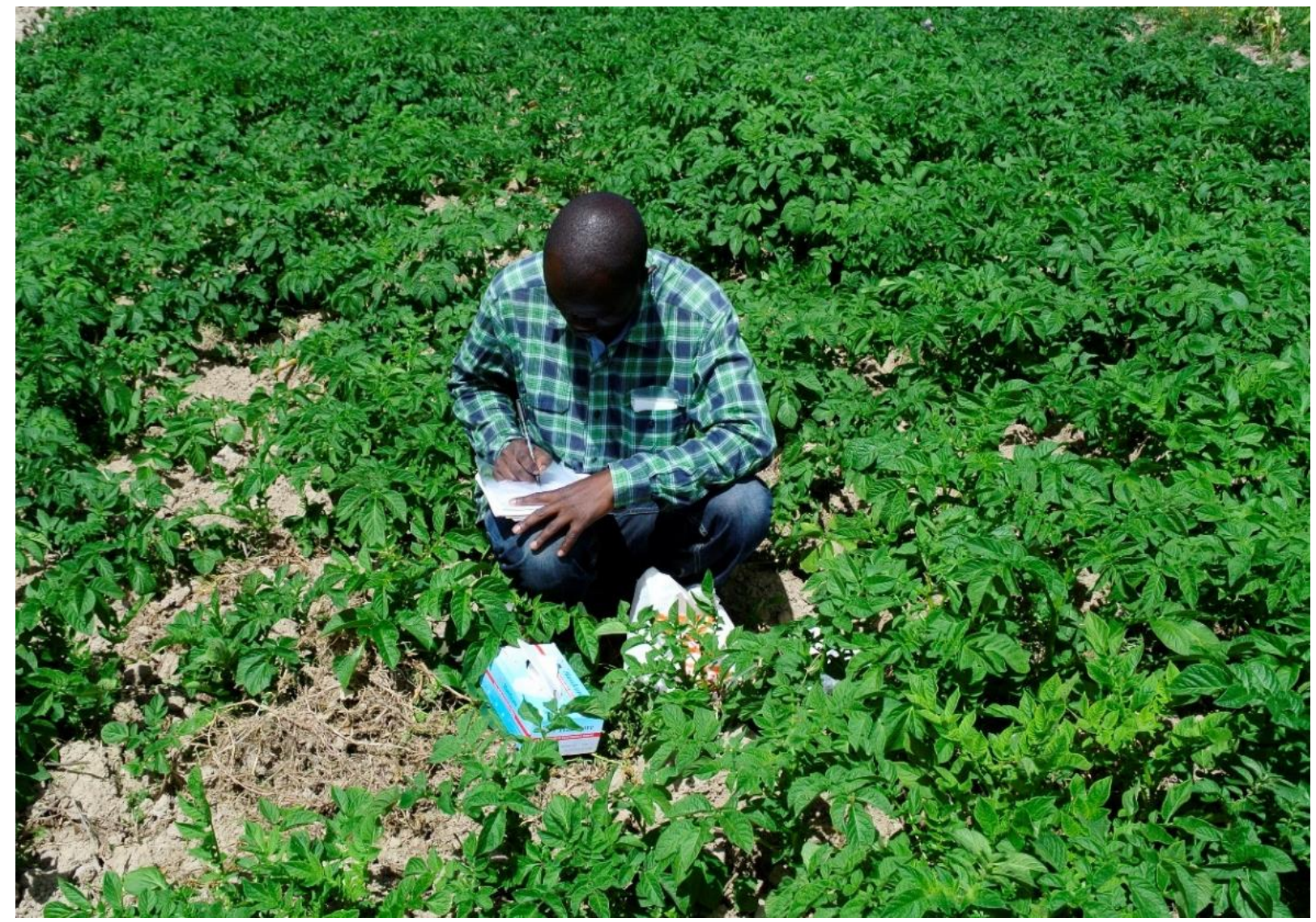

This chapter has been submitted for publication in the Tropical Plant Pathology 


\section{Abstract}

Knowledge of virus prevalence and distribution in cultivars grown in a particular region is essential in setting priorities for virus control. To investigate the present status of six potato viruses and their patterns of distribution in the cultivars grown in five major potato growing regions in Kenya, 354 potato leaf samples were randomly collected and tested for six viruses, namely; potato leaf roll virus (PLRV), potato virus $Y(P V Y)$, potato virus $X(P V X)$, potato virus $M(P V M)$, potato virus $A$ (PVA) and potato virus $S$ (PVS) in a DAS-ELISA assay. The viruses were detected in $72.9 \%$ of the samples. PVX was the most prevalent virus (54.8\%) followed by PVS (47.5\%), PVM (13.0\%), PVY (8.2\%), PLRV (6.8\%) and PVA (2.5\%). Multiple infections occurred in $55.9 \%$ of the samples. Virus distribution maps were used to locate viruses occurring only in particular geographic regions indicating that any effective approach in virus control should be region specific. Among the 13 cultivars grown, four cultivars, Sherekea, Shangi, Kenya Karibu and Asante were identified with the lowest average ELISA absorbance (OD) values of the six viruses which was used as an indication of field resistance to the viruses. This study demonstrated that knowledge of prevalence can be used to identify and recommend virus resistant cultivars to replace virus susceptible cultivars in regions identified with high virus prevalence.

\subsection{Introduction}

Potato (Solanum tuberosum L.) is a food crop globally ranking fourth after wheat, rice and maize. The crop is distributed worldwide in over 100 countries and is considered an important crop in all continents (Birch et al. 2012). Over the past five decades, the crop has been increasing in importance in East and Central Africa (Scott et al. 2013). In Kenya, potato is the second most important food crop after maize and plays an important role in ensuring food security of the country (MoALF 2016). Despite its importance, average potato yields in the farmer's fields is low $(8.7 \mathrm{~T} / \mathrm{Ha})$ as compared to the leading potato producers in the world which produce between 40 - 60 T/Ha (FAOSTAT 2017) under well-established seed systems, pest and disease surveillance and effective virus control (Whitworth and Davidson 2008; Wang et al. 2011). High incidence of pests and diseases are a big challenge in potato production, causing low profitability and consequently threatening food security (Thomas Sharma et al. 2016). 
Viruses are also among the most important vector and seed borne diseases of the potato crop (Salazar 1996). Out of over 40 viruses which can infect potato (Whitfield et al. 2015), the six best known viruses; potato virus Y (PVY, genus Potyvirus), potato leaf roll virus (PLRV, Polerovirus), potato virus X (PVX, Potexvirus), potato virus A (PVA, Potyvirus), potato virus S (PVS, Carlavirus) and potato virus M (PVM, Carlavirus) have been reported to be most important in Kenya (Were et al. 2003; Muthomi et al. 2009; Were et al. 2013) and even in the neighbouring countries Ethiopia, Uganda and Tanzania (Gildemacher 2011; Chiunga 2013; Priegnitz et al. 2019). PVY, PLRV and PVX have attracted more attention than PVM, PVS and PVA because they cause higher yield losses (Taliansky et al. 2003) and generally cause more pronounced symptoms. Multiple infections commonly occur with an increased synergistic effect on the crop, subsequently leading to higher yield losses (Brandolini et al. 1992; Kerlan and Moury, 2008). In susceptible potato cultivars, the viruses cause general poor vegetative growth and loss in tuber yield, coupled with symptoms such as leaf roll, mosaic, leaf drop, chlorosis, stunted growth and necrosis and production of undersized tubers and sometimes death of the whole plant (Jayashige et al. 1989; Beukema and van der Zaag 1990).

All six potato viruses are transmitted by various aphid species except PVX which is transmitted through contact (Salazar 1996; Whitfield et al. 2015). Some of the aphid species that transmit potato viruses have been found to occur with high incidence in potato growing regions in Kenya (Olubayo et al 2010; Muthomi et al. 2009; Were et al. 2013). Existence of alternative weed host plants of the viruses in or around potato fields are among the factors that contribute to further spread of the viruses (Were et al. 2003; Nyamwamu et al. 2014; Smith et al. 2012). Among the seed producers, viruses lower the quality standards of the various classes of seed potato and in cases where virus prevalence exceeds legal limits of the phytosanitary authorities, the seed lot is normally rejected and seed producers loose profitability (Soliman et al. 2012; Kim and Kwon 2019). In Kenya, certified seed tubers are scarce ( $<5 \%$ of seed tubers planted), a fact that may be contributing to high virus prevalence in the farmer's fields (NPCK 2017). Low quality and quantities seed tubers to the farmers lead to yield losses resulting from degeneration of tubers over seasons (Onditi et al. 2013), a practice that also contributes to further spread of the viruses. To make an effort towards virus control, knowledge of prevalence, geographical distribution and relative economic 
impact of the different potato viruses is essential in implementation of control strategies (Tesfaye et al. 2011). This is because high prevalence and rapid spread of potato viruses normally occur in cases where there is insufficient application of virus diagnostics and phytosanitary surveillance (Frost et al. 2013; Yadav and Khurana 2015). This study was therefore conducted to (a) describe prevalence and distribution of the six major viruses and (b) deduce virus resistance resistant cultivars from virus prevalence surveys and (c) suggest cultivars, regions and viruses that should be given priorities in potato virus control in Kenya.

\subsection{Material and methods}

A survey was conducted in farmer's fields in the five major potato growing regions in Kenya administratively demarcated as Bomet, Nakuru, Kiambu, Nyandarua and in Meru counties ( $F i g$ 3, 4, 5, 6, 7 and 8). In these regions, there are two main potato growing seasons in a year; the short rains (October-December) and long rains (April -July). Potato leaf samples were collected from a total of 354 farms (80 in Bomet, 65 in Nakuru, 64 in Kiambu, 65 in Nyandarua and 80 in Meru) during the main potato growing season of 2016 (long rains 2016). To compare virus prevalence over the consecutive seasons, sampling continued in two of the five potato growing regions (Nyandarua and Meru) during the short rains 2016 and long rains 2017 with the same number of samples from the same field per region every season.

The sampling sites (farms) were randomly selected within the potato growing regions. Four samples (tested as a composite) were taken randomly from within each farm without bias on symptomatic or asymptomatic plants. Leaf samples were collected from the third leaf from the top of the plant and at a time when the potatoes were at early vegetative stage towards flowering (30 to 60 days after planting). Data were collected on the cultivar sampled and the geographic positioning systems (GPS) coordinates (longitudes and latitudes) of the farms using the Universal Transverse Mercator (UTM) geo map android application. The GPS coordinates were used to generate virus distribution maps using Quantum GIS (QGIS) software (QGIS Development Team 2019) to visualize the virus distribution pattern.

Leaf samples were analysed by Double Antibody Sandwich Enzyme Linked Immuno-Sorbent Assay (DAS-ELISA) (Clark and Adams 1977). The antibodies for 
the potato six viruses (PVY, PLRV, PVX, PVM, PVA and PVS) the kit and instructions for ELISA detection were obtained from the International Potato Centre (CIP), Lima, Peru. The samples were tested at Kenya Agricultural and Livestock Research Organization (KALRO), Potato Research Centre, Tigoni, Kenya.

ELISA coating solution was prepared by diluting the coating antibody for each if the six viruses (PVY, PLRV, PVX, PVM, PVS and PVA). Coating solution consisted of $35 \mu \mathrm{l}$ of the antibodies ( $\mathrm{IgG})$ in $10 \mathrm{ml}$ of coating buffer $\left(0.2 \mathrm{~g} \mathrm{Na}_{2} \mathrm{CO}_{3}, 0.44 \mathrm{~g}\right.$ NaHCO3, $0.03 \mathrm{~g} \mathrm{NaN3} \mathrm{pH} 9.6$ in $120 \mathrm{ml}$ of distilled water). Wells of the ELISA plates (Thermo Scientific, Denmark) were loaded with $100 \mu$ of the coating solution and incubated overnight at $4{ }^{\circ} \mathrm{C}$. The plates were washed three times using washing buffer consisting of $8.0 \mathrm{~g} \mathrm{NaCl}, 0.2 \mathrm{~g} \mathrm{KH}_{2} \mathrm{PO}_{4}, 0.2 \mathrm{~g} \mathrm{KCL}, 1.13 \mathrm{~g}$ $\mathrm{NaH}_{2} \mathrm{PO}_{4}, 0.29 \mathrm{~g} \mathrm{NaN}_{2}$ and $0.05 \%$ of Tween 20 in 1 litre of distilled water, pH7.4 (PBS-T). Leaf samples were macerated in $1: 2 \mathrm{w} / \mathrm{v}$ ratio with ELISA extraction buffer $(0.2 \%$ egg ovalbumine, 2\% PVP40, 0.05\% Tween-20 and $0.05 \%$ NaN3 in $0.01 \mathrm{M}$ PBS). Samples $(100 \mu \mathrm{l})$ were loaded in duplicates in the ELISA plate including three positive and six negative controls and incubated overnight at $4{ }^{\circ} \mathrm{C}$. Positive controls were potato leaf samples previously tested in ELISA and found infected with each of the six viruses respectively for each test plate. Negative controls were potato leaf samples confirmed to be without infection of any of the six viruses. After three plate washings, alkaline phosphatase (IgG-AP) conjugate antibody (1000 times diluted in extraction buffer) for each of the respective six viruses was added $(100 \mu \mathrm{l})$ and incubated overnight at $4^{\circ} \mathrm{C}$. Colour development was done by adding $100 \mu \mathrm{l}$ of substrate solution $\{0.75 \mathrm{mg} / \mathrm{ml}$ of paranitrophenylphosphate (pNPP) in substrate buffer $(97 \mathrm{ml}$ of diethanolamine, $\mathrm{pH}$ 9.8 in $1000 \mathrm{ml}$ of distilled water)\} and incubating at room temperature for 60 minutes.

An ELISA reader (Biotek 88TS, Vermont, USA) was used to take optical density (OD) reading at a wavelength of $405 \mathrm{~nm}$. ELISA positive samples were calculated as those with values equal or greater than the mean of the negative controls plus three times the standard deviation. Potato virus prevalence was calculated from the ELISA positive and negative samples as the percentage of the proportion of the number of virus positive samples against the total number of samples tested. Analysis of variance (ANOVA) was done on the ELISA OD values and a least significant difference (LSD) of $5 \%$ was used to compare means using the $R$ statistical package. This was also used to summarize the differences in means of 
cultivars, regions and viruses and to make decision on the relative importance of the viruses.

\subsection{Results}

\subsubsection{Prevalence of the six viruses}

The virus prevalences in five major potato growing counties (Nyandarua, Kiambu, Nakuru, Meru and Bomet) based on 354 potato leaf samples analysed in an ELISA assay for six viruses are summarised in Fig 1 . Virus infections were found in $72.9 \%$ of all the samples analysed, while the rest $(27.1 \%)$ were totally free of all the six viruses. Each of the six viruses were detected in all the counties with the exception of Nakuru where PVY was not detected. The virus prevalences varied from within one county to another. In the total of all the samples analysed, PVX was the most prevalent virus (54.8\%) followed by PVS (47.5\%) while PVM (13.0\%). PVY (8.2\%), PLRV (6.8\%) and PVA (2.5\%) occurred at lower prevalences. Within each of the five counties, PVX and PVS were the most prevalent viruses while the rest of the viruses occurred at lower prevalences. In Nyandarua county, there was $86.2 \%$ PVS, 66.2\% PVX, 6.2\% PVM, 3.1\% PVY, 1.5\% PLRV and 1.5\% PVA.

In Nakuru county, PVX (67.9\%) and PVS (52.3\%) were the most prevalent viruses followed by PVM (18.5\%), PLRV (1.5\%) and PVA (1.5\%) while PVY was not detected. Viruses prevalences in the other three counties were as follows; $83.8 \%$ PVX, 35.0\% PVS, 18.8\% PVY, 11.3\% PLRV, 5.0\% PVM and 2.5\% PVA in Meru county, 50.8\% PVS, 38.5\% PVX, 29.2\% PVM, 7.7\% PVY, 3.1\% PVA and 1.5\% PLRV in Kiambu county and 17.5\% PVX, 21.3\% PVS, 8.8\% PVY, $15.0 \%$ PLRV, 8.8\% PVM and 3.8\% PVA in Bomet county. 


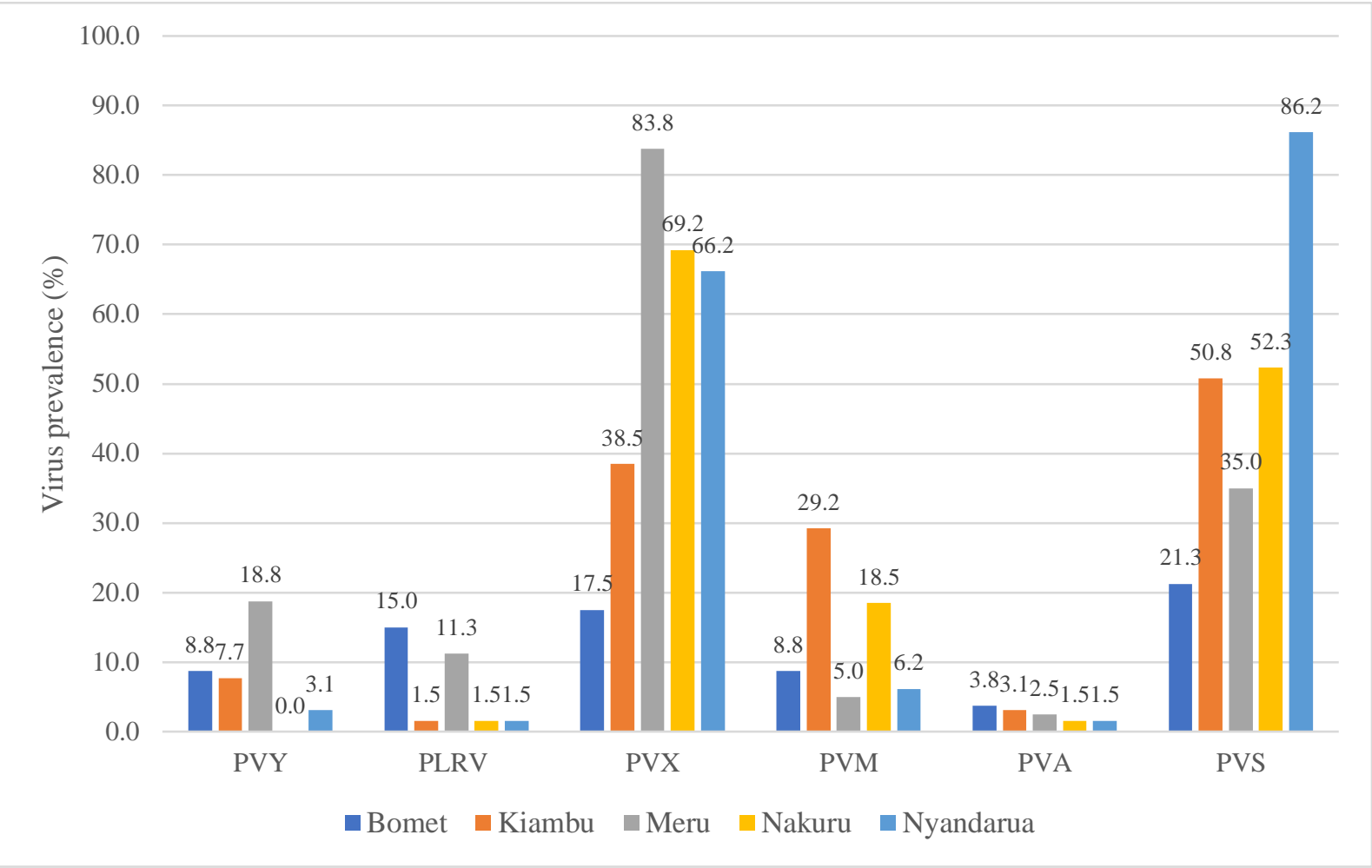

Fig 1: Prevalence in percentages of potato virus $Y(P V Y)$ potato leaf roll virus ( $P L R V)$, potato virus $X(P V X)$, potato virus $M(P V M)$, potato virus $A$ (PVA) and potato virus $S$ (PVS) within each of the five major potato growing areas in Kenya as based on DAS-ELISA assays on a total of 354 potato leaf samples randomly collected from these regions

\subsubsection{Potato virus prevalence across the consecutive seasons}

Prevalence of the six viruses were analysed for three consecutive seasons in two (Meru and Nyandarua) of the five counties. Potato leaf samples (65 in Nyandarua and 80 in Meru) were collected in the same farms during long rains 2016, short rains 2016 and long rains 2017 (Fig 2). Virus prevalence was found to be changing over time especially with PVX and PVS which were found to occur with the highest overall prevalence. There was an overall decreasing trend in PVX prevalence from $37.7 \%$ to $28.1 \%$ to $22.8 \%$ over the three seasons. Even though PLRV prevalence were relatively lower than that of PVX there was still a decreasing trend prevalence from $3.4 \%$ to $3.1 \%$ to $2.8 \%$. In contrast, there was an increase in PVS prevalence from $29.0 \%$ to $33.1 \%$ to $36.9 \%$ over the seasons. Though with a lower prevalence than that of PVX, there was an increase in PVY from $4.1 \%$ to $4.7 \%$ to $7.2 \%$ over the seasons. PVA and PVM occurred at lower prevalence than the rest of the viruses with small variations in prevalence between the seasons and without any clear trend of increase or decrease. 


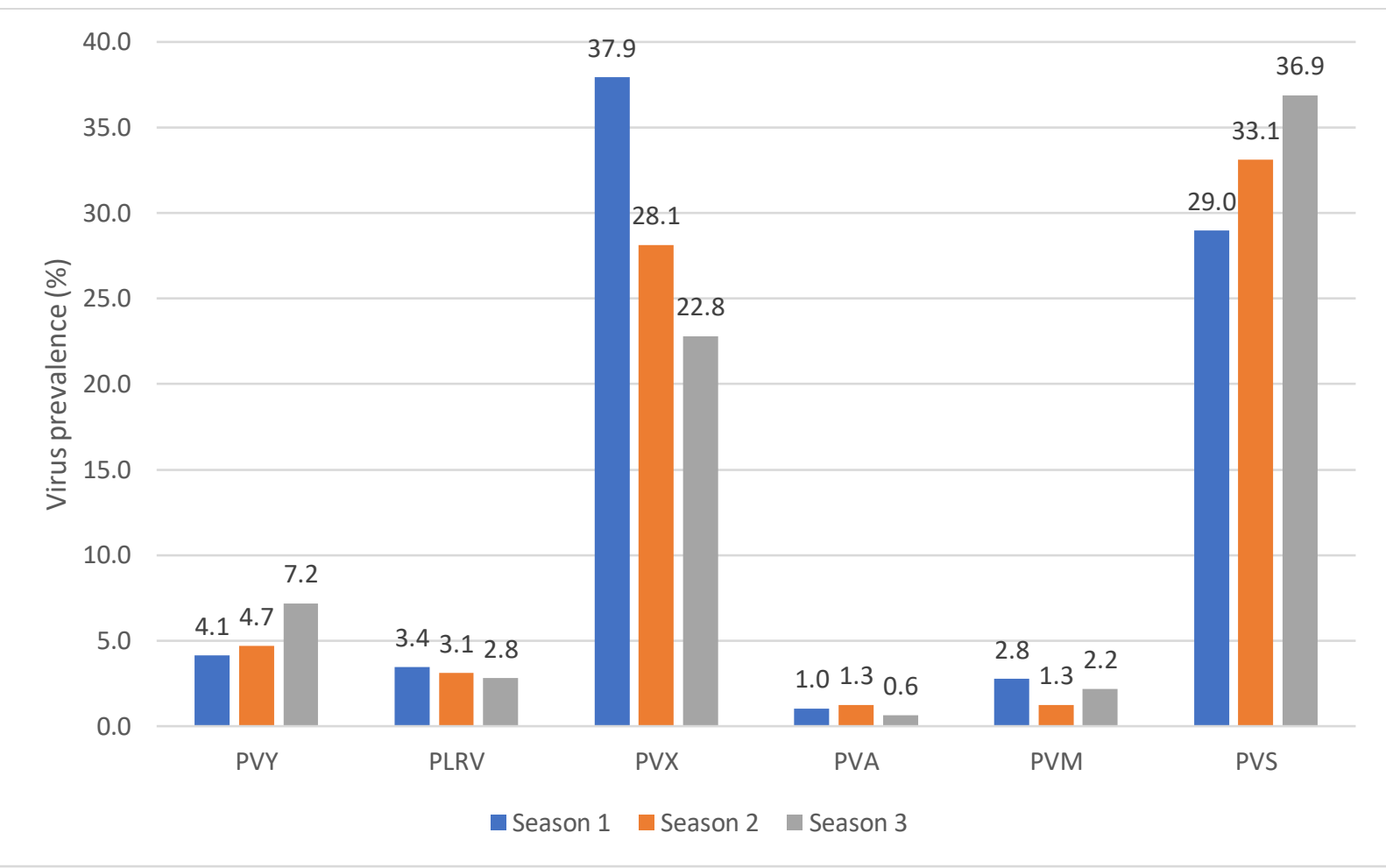

Fig 2: Prevalence in percentages of potato virus $Y(P V Y)$ potato leaf roll virus ( $P L R V)$, potato virus $X(P V X)$, potato virus $M(P V M)$, potato virus $A(P V A)$ and potato virus $S$ (PVS) in Meru and Nyandarua counties over 3 consecutive seasons of long rains 2016, short rains 2016 and long rains 2017 (seasons 1, 2 and 3 respectively)

\subsubsection{Occurrence of multiple infections}

The different combinations of infections of six viruses that occurred in the 354 samples from the five potato growing counties are presented in Table 1 . Three categories of the samples analysed were found, namely; multiple infections, single infection and those samples which were free of all the six viruses (Table 1). Multiple infections occurred in 24 different combinations of the six viruses in $55.9 \%$ of the samples. The most common type of multiple infection was that involving a mixture of PVX and PVS which occurred in $23.4 \%$ of the samples. Other types of multiple infections included a mixture of PVX, PVM and PVS (6.2\%), PVM and PVS (2.5\%), PVY and PVS (1.1\%), PLRV and PVX (1.1\%) while the rest occurred at lower prevalence of less than $1.0 \%$. Single infections were found in $27.7 \%$ of the samples and only for PVX (19.8\%) and PVS (9.0\%). 
Table 1: Prevalence of potato virus $Y$ (PVY) potato leaf roll virus (PLRV), potato virus $X$ $(P V X)$, potato virus $M(P V M)$, potato virus $A(P V A)$ and potato virus $S$ (PVS) in single and mixed infections in the total of 354 potato leaf samples collected from five major potato growing regions in Kenya

\begin{tabular}{|c|c|c|}
\hline Type of multiple infection & No. of samples & Virus prevalence (\%) \\
\hline Virus free & 96 & 27.1 \\
\hline$P V X+P V S$ & 83 & 23.4 \\
\hline PVX & 70 & 19.8 \\
\hline PVS & 32 & 9.0 \\
\hline$P V X+P V M+P V S$ & 22 & 6.2 \\
\hline PVM+PVS & 9 & 2.5 \\
\hline$P V Y+P V S$ & 4 & 1.1 \\
\hline$P L R V+P V X$ & 4 & 1.1 \\
\hline$P V Y+P V X+P V S$ & 3 & 0.8 \\
\hline$P V Y+P L R V+P V X$ & 3 & 0.8 \\
\hline$P V Y+P L R V$ & 3 & 0.8 \\
\hline$P V Y+P L R V+P V X+P V M$ & 2 & 0.6 \\
\hline$P V Y+P L R V+P V S$ & 2 & 0.6 \\
\hline$P V Y+P L R V+P V M+P V S$ & 2 & 0.6 \\
\hline$P V Y+P L R V+P V M+P V A$ & 2 & 0.6 \\
\hline$P V Y+P V M+P V X$ & 2 & 0.6 \\
\hline$P V Y+P V M$ & 2 & 0.6 \\
\hline$P V X+P V A$ & 2 & 0.6 \\
\hline PLRV+PVM+PVS & 2 & 0.6 \\
\hline$P V Y+P L R V+P V M+P V S$ & 2 & 0.6 \\
\hline$P V Y+P V X$ & 1 & 0.3 \\
\hline$P V Y+P L R V+P V X+P V M+P V S$ & 1 & 0.3 \\
\hline$P V Y+P L R V+P V X+P V A+P V S$ & 1 & 0.3 \\
\hline$P V X+P V M+P V A+P V S$ & 1 & 0.3 \\
\hline $\mathrm{PLRV}+\mathrm{PVX}+\mathrm{PVM}+\mathrm{PVA}+\mathrm{PVS}$ & 1 & 0.3 \\
\hline PLRV+PVM+PVA+PVS & 1 & 0.3 \\
\hline PVA+PVS & 1 & 0.3 \\
\hline Total & 354 & 100 \\
\hline
\end{tabular}




\subsubsection{Distribution patterns of six potato viruses in five potato growing regions}

Fig 3, 4, 5, 6, 7 and 8 shows the distribution of the six potato viruses in the five major potato growing areas as plotted from the geographical coordinates of the sampling sites. PVY, PLRV and PVX were found to be localized only in specific subcounties within the counties surveyed. PVY (Fig 3) and PLRV (Fig 4) were mainly localized to one sub-county (Imenti South) in Meru County and in Konoin subcounty in Bomet. PVY was detected in Kiambu and Nyandarua counties but sparsely distributed. PVY was not found in Nakuru County. Apart from being localized in Bomet and Meru counties, PLRV was very sparsely distributed in the rest of the counties.

PVX occurred in almost all counties although it was more densely localized in some particular counties than others and also within some sub-counties than others (Fig 8). PVX was densely localized in Molo sub-county in Nakuru County and in Kinangop and Kipipiri sub-counties of Nyandarua County. Meru County, PVX was found mainly in Imenti south just like in the case of PVY and PLRV. PVX was randomly distributed in Bomet county and in other regions of Meru county. Dense PVX distribution in Kiambu county was skewed towards the western side of the county cutting across different counties.

PVM (Fig 5) was sparsely distributed all over the five counties and even within the sub-counties. It however, occurred densely towards the western region of Kiambu county. PVS (Fig 6) was found to be randomly distributed in all counties and within the sub-counties of the potato growing regions. PVA (Fig 7) had a similar random distribution across the counties but very more sparsely distributed unlike PVS. 


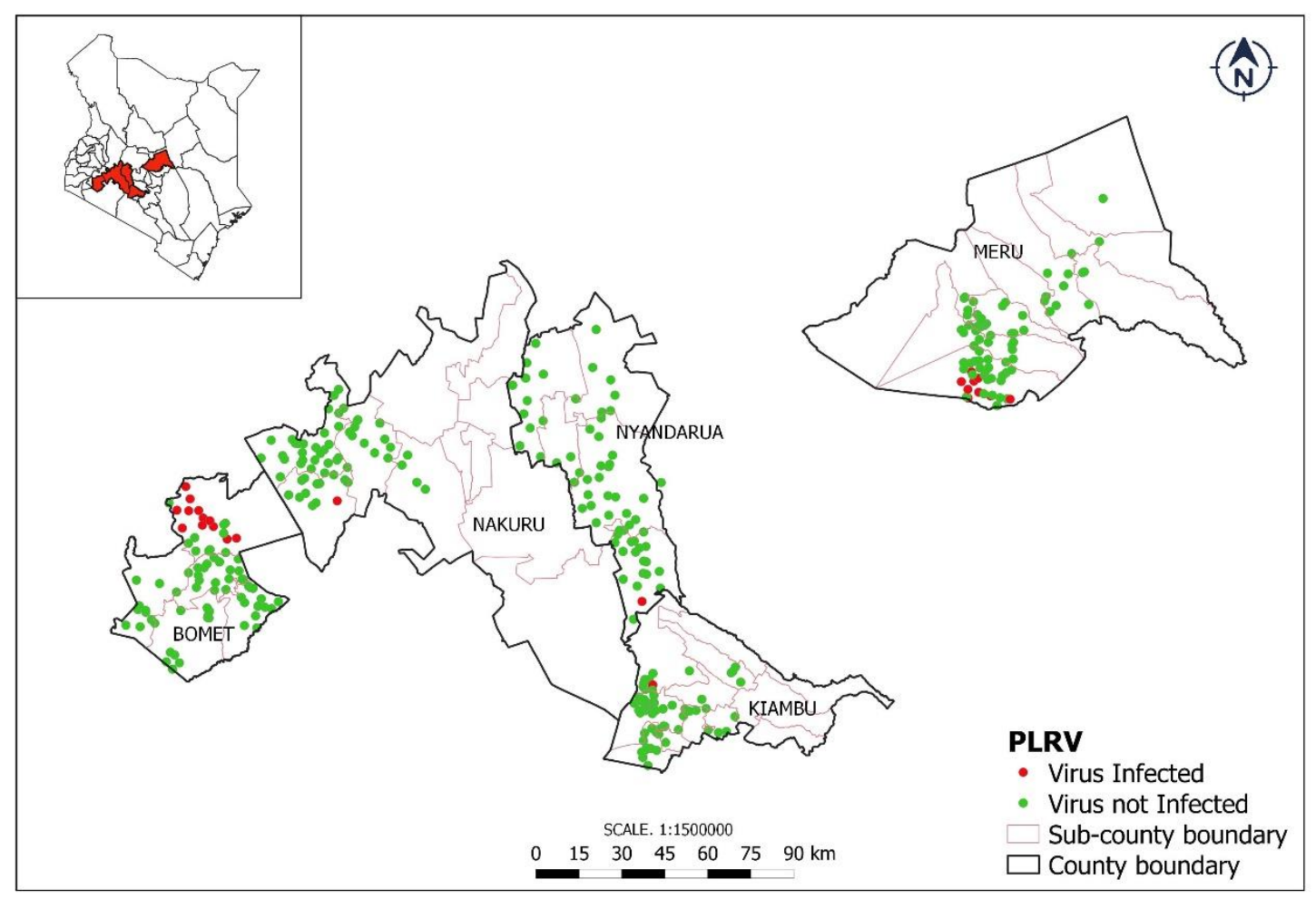

Fig 3: Map of the distribution pattern of potato virus $Y(P V Y)$ in five potato growing counties in Kenya

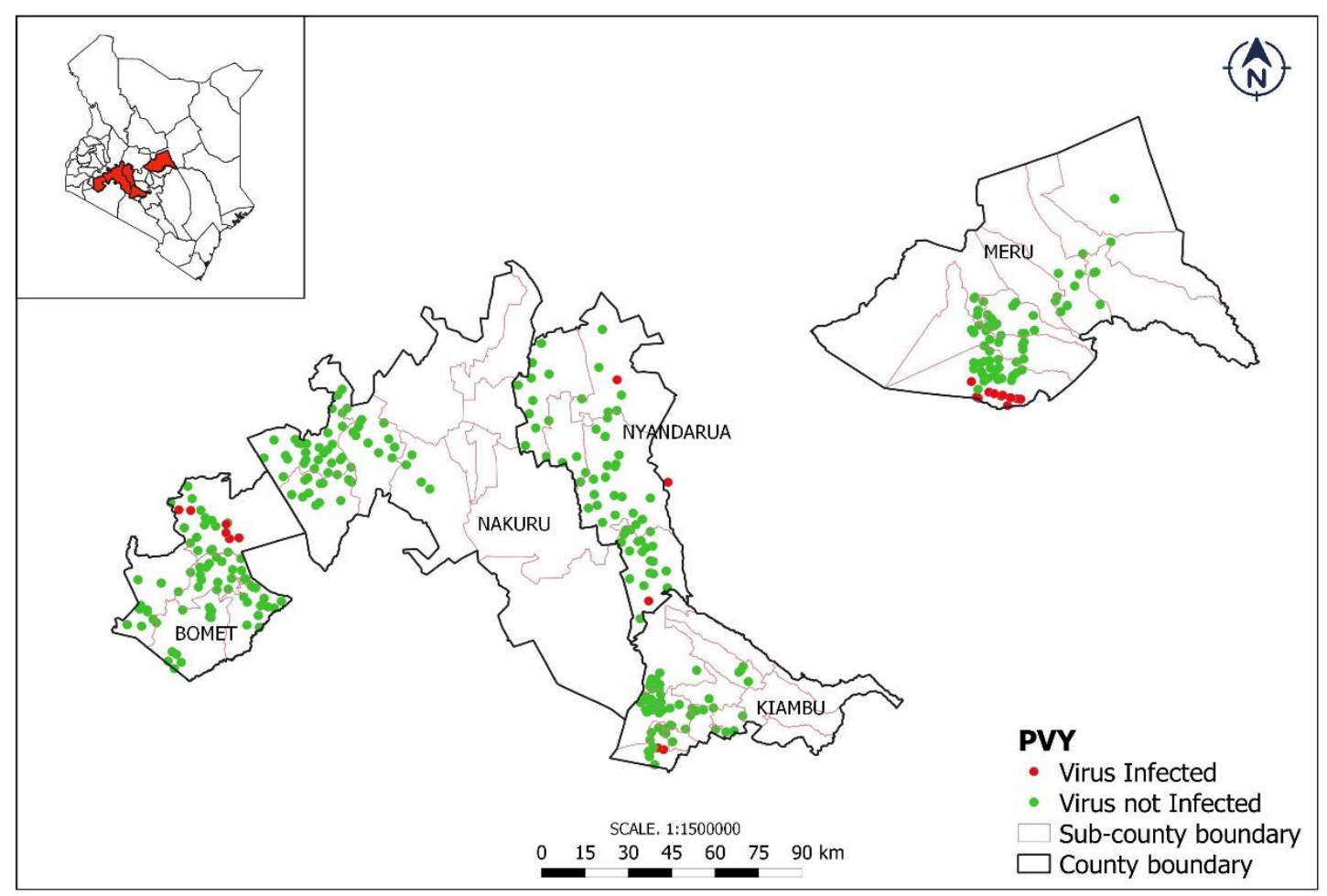

Fig 4: Map of the distribution pattern of potato leaf roll virus (PLRV) in five potato growing counties in Kenya 


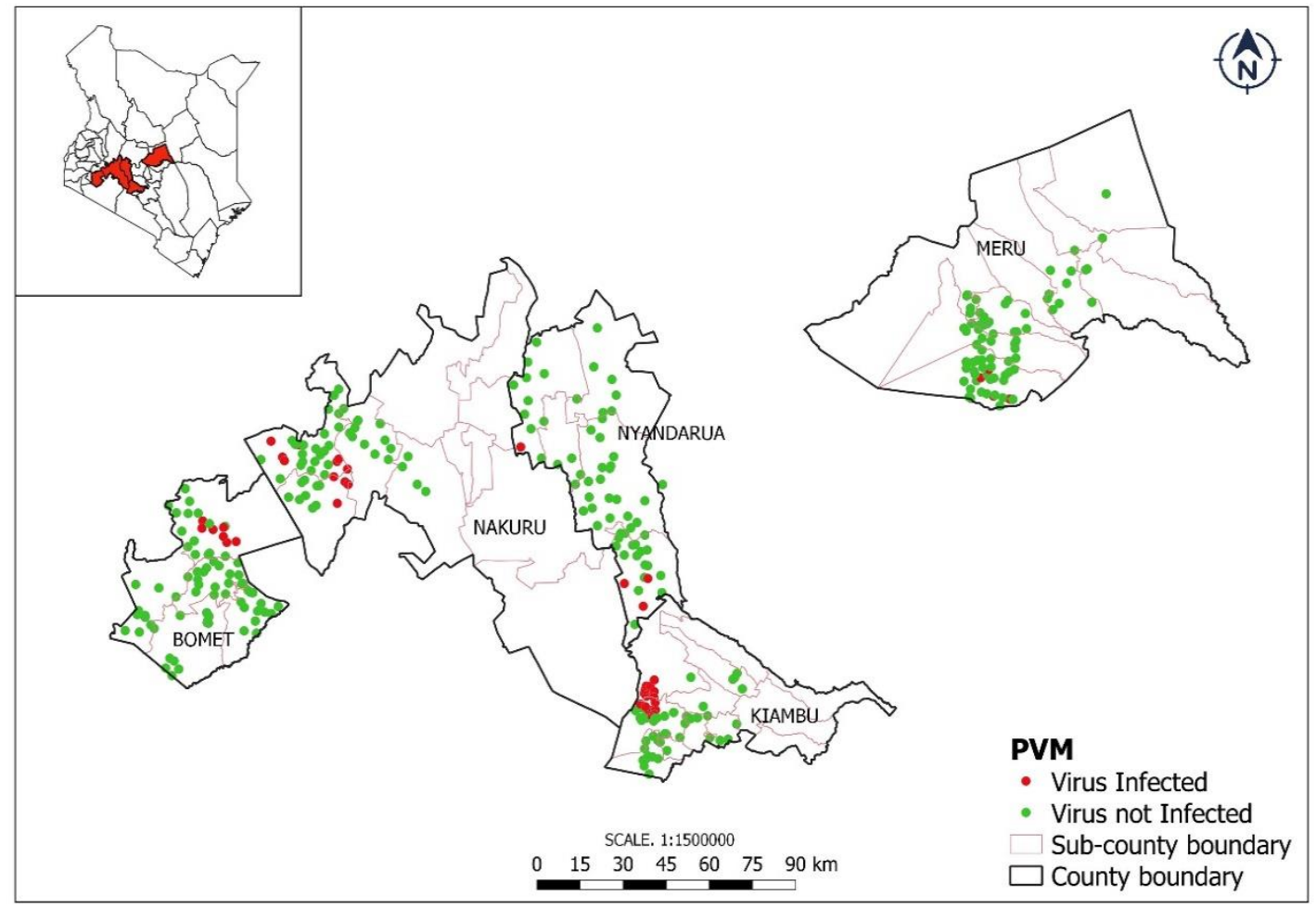

Fig 5: Map of the distribution pattern of potato virus $M$ (PVM) in five potato growing counties in Kenya

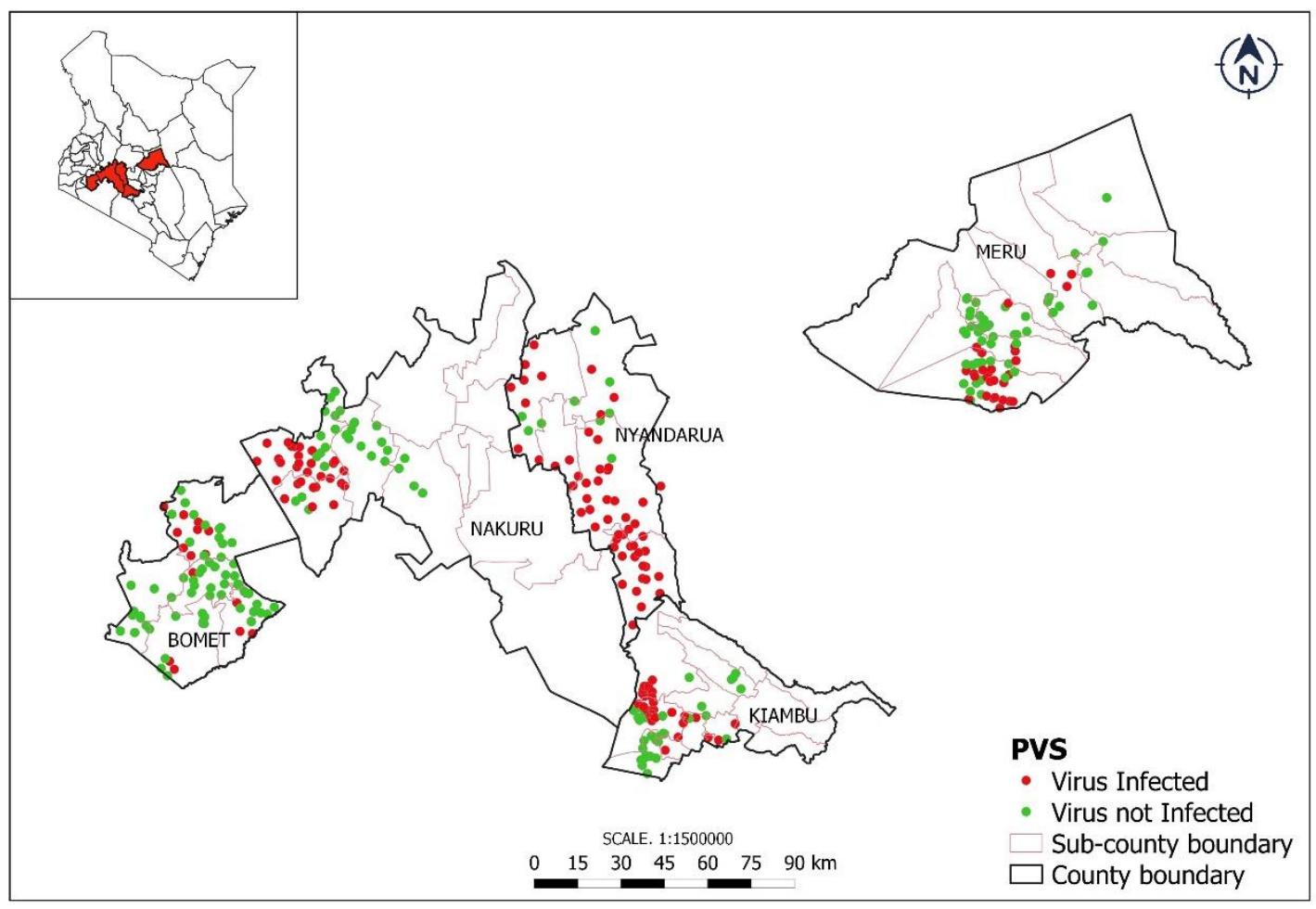

Fig 6: Map of the distribution pattern of potato virus S (PVS) in five potato growing counties in Kenya 


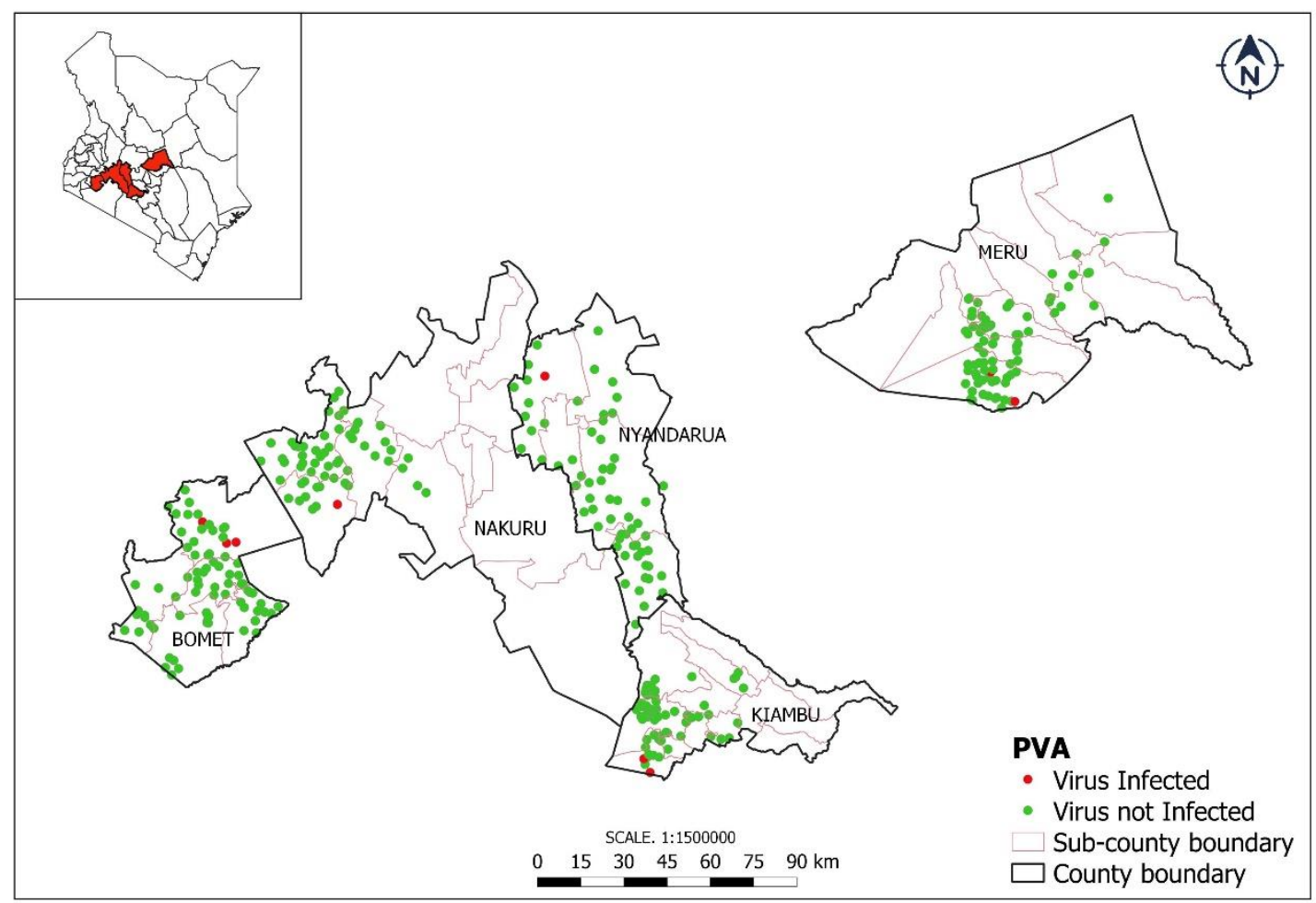

Fig 7: Maps of the distribution pattern of potato virus $A$ (PVA) in five potato growing counties in Kenya

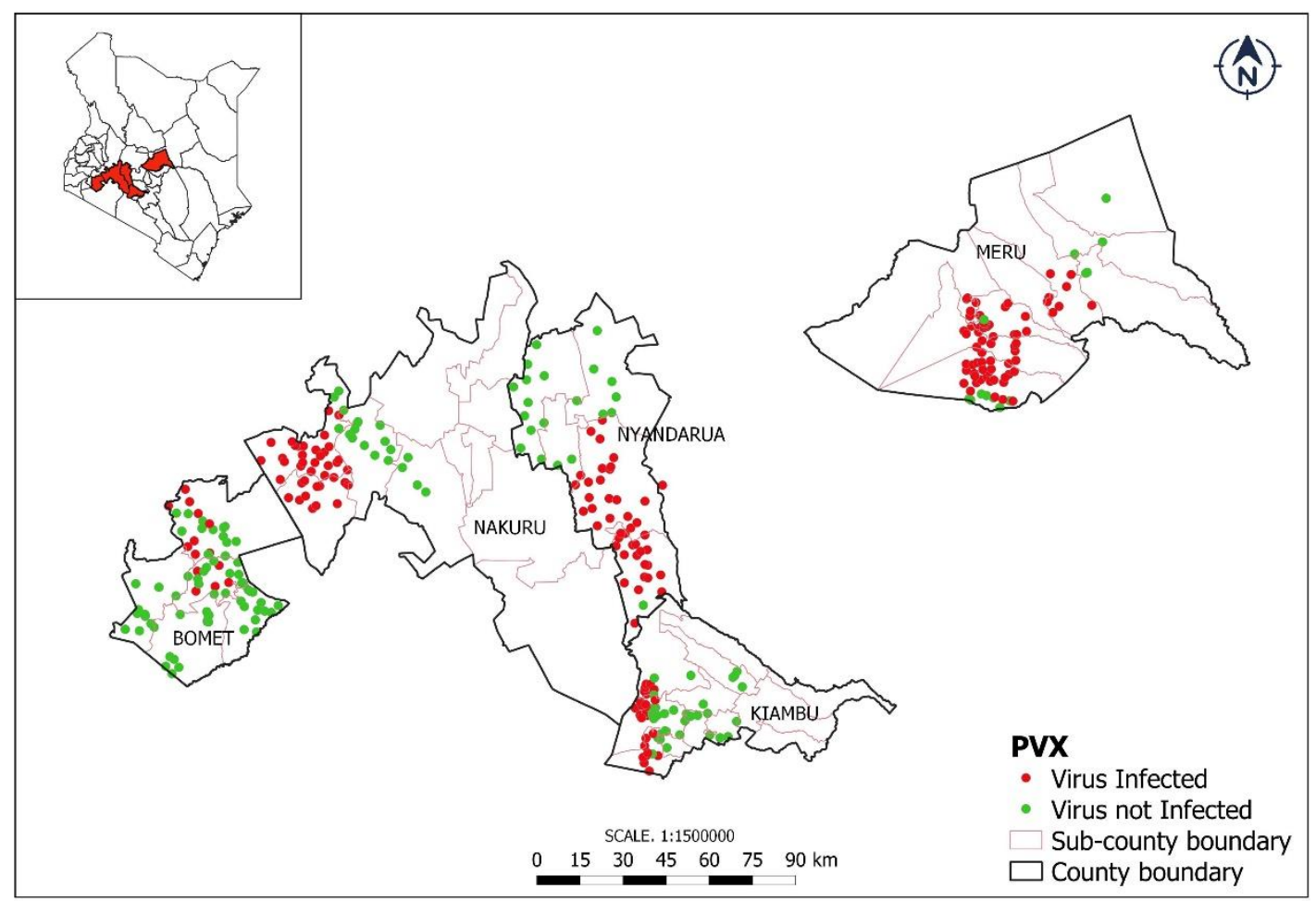

Fig 8: Maps of the distribution pattern of potato virus $X(P V X)$ in five potato growing counties in Kenya 


\subsubsection{Prevalence of the six potato viruses in different potato cultivars}

Prevalences of the six potato viruses in each of the 13 different potato cultivars grown in five major potato growing counties in Kenya are summarised in Table 3. The majority of the potato crops in the farmer's fields were mainly from cultivars Shangi $(60.5 \%)$ and Kombere (15.5\%). The rest of the cultivars were found only in a few farms (each at $<5 \%$ ). Cultivars Sherekea, Asante, Kenya Karibu, Unica, Thimathuti, Tigoni and Kalucy were not infected with PLRV and PVY. Shangi was found with a low prevalence $(1.4 \%$ and $1.9 \%$ respectively) of both viruses. The highest PVY prevalence was found in cultivars Nyayo (66.7\%), Dutch Robyjn (50.0\%) and Nderamwana (50.0\%), Kombere (27.3\%) and Desiree (14.3\%). The same cultivars (Dutch Robyjn, Nderamwana, Nyayo, Kombere and Desiree) were also found with high PLRV prevalence of $57.1 \%, 50.0 \%, 33.3 \%, 16.4 \%$ and $14.3 \%$ respectively. PVX infections were found in 11 out of the 13 cultivars with the exception of Thimathuti and Nyayo. All the samples collected from cultivars Tigoni and Kalucy were $100 \%$ infected with the virus. Other cultivars found with high PVX prevalence included Asante (92.9\%) Kombere (85.5\%), Unica (80\%), Sherekea (57.1\%), Nderamwana (50.0\%), Shangi (45.8\%), Kenya Karibu (40.0\%), Desiree (28.6\%) and Dutch Robyjn (28.6\%).

Sherekea was the only cultivar that was not found with any PVM infection. The rest of 12 cultivars were all infected with PVM with varying prevalences. This virus was detected in $100 \%$ of the samples collected from cultivars Nderamwana, Nyayo, Kalucy and Thimathuti. PVM infections occurred in Dutch Robyjn, Tigoni, Kombere, Unica, Desiree, Kenya Karibu, Asante, Sherekea and Shangi with prevalences of $78.6 \%, 54.5 \%, 7.3 \%, 20 \%, 14.3 \%, 40.0 \%, 14.3$ and $4.2 \%$ respectively. PVS was found in all the cultivars with $100 \%$ infection in cultivars Nderamwana, Kalucy, Nyayo Thimathuti. PVS prevalence in almost all cultivars was relatively high with $64.3 \%, 54.5 \%, 43.6 \%, 60.0 \%, 71.4 \%, 50.0 \%, 14.3 \%, 42.9 \%$, and $46.7 \%$ in Dutch Robyjn, Tigoni, Kombere, Unica, Desiree, Kenya Karibu, Asante, Sherekea and Shangi respectively. Out of the 13 cultivars, PVA occurred in the least number of cultivars (only in four) and at relative lower prevalence with $21.4 \%$ in Dutch Robyjn, $20 \%$ in Unica $14.3 \%$ in Desiree and $3.6 \%$ in Kombere. 
Table 3: Virus prevalence in percentages in the 354 samples tested for potato virus $Y$ (PVY) potato leaf roll virus (PLRV), potato virus $X(P V X)$, potato virus $M(P V M)$, potato virus $A$ $(P V A)$ and potato virus $S$ (PVS) in 13 potato cultivars grown in Kenya

\begin{tabular}{lccllllll}
\hline \multicolumn{1}{c}{ Cultivar } & $\begin{array}{c}\text { Number of } \\
\text { samples }\end{array}$ & $\begin{array}{c}\text { \% of } \\
\text { samples }\end{array}$ & PVY & PLRV & PVX & PVM & PVA & PVS \\
\hline Nderamwana & 2 & 0.6 & 50.0 & 50.0 & 50.0 & 100.0 & 0.0 & 100.0 \\
Dutch Robyjn & 14 & 4.0 & 50.0 & 57.1 & 28.6 & 78.6 & 21.4 & 64.3 \\
Kalucy & 2 & 0.6 & 0.0 & 0.0 & 100.0 & 100.0 & 0.0 & 100.0 \\
Nyayo & 3 & 0.8 & 66.7 & 33.3 & 0.0 & 100.0 & 0.0 & 100.0 \\
Tigoni & 11 & 3.1 & 0.0 & 0.0 & 100.0 & 54.5 & 0.0 & 54.5 \\
Thimathuti & 1 & 0.3 & 0.0 & 0.0 & 0.0 & 100.0 & 0.0 & 100.0 \\
Kombere & 55 & 15.5 & 27.3 & 16.4 & 85.5 & 7.3 & 3.6 & 43.6 \\
Unica & 5 & 1.4 & 0.0 & 0.0 & 80.0 & 20.0 & 20.0 & 60.0 \\
Desiree & 7 & 2.0 & 14.3 & 14.3 & 28.6 & 14.3 & 14.3 & 71.4 \\
Kenya Karibu & 10 & 2.8 & 0.0 & 0.0 & 40.0 & 40.0 & 0.0 & 50.0 \\
Asante & 14 & 4.0 & 0.0 & 0.0 & 92.9 & 14.3 & 0.0 & 14.3 \\
Sherekea & 16 & 4.5 & 0.0 & 0.0 & 57.1 & 0.0 & 7.1 & 42.9 \\
Shangi & 214 & 60.5 & 1.4 & 1.9 & 45.8 & 4.2 & 0.5 & 46.7 \\
\hline Total & 354 & 100.0 & & & & & & \\
\hline
\end{tabular}

\subsubsection{ELISA OD values of the six potato viruses in the cultivars}

The average ELISA OD values representing concentrations of each of the six potato viruses in the 13 potato cultivars are presented in Fig 9. Cultivars with the lowest ELISA OD values considering all the six potato viruses were; Sherekea, Kenya Karibu, Shangi, Asante and Unica as compared to the rest of the cultivars. Thimathuti, Dutch Robyjn, Nyayo, Kombere, Desiree, Kalucy and Tigoni had moderate concentrations of the viruses.

The average ELISA OD values in samples found infected were highest for PVS (0.73) followed by PVX (0.57), then PVM (0.42), PLRV (0.16), PVY (0.12) and PVA (0.06) was lowest. The cultivar-virus combinations with the highest average ELISA OD value was found in cultivar Kalucy with PVX (1.99). This was followed by Nderamwana with PVS (1.84), Thimathuti with PVM (1.77, Thimathuti with PVS (1.431), Kombere with PVX (1.408), Nyayo with PVS (1.19), Dutch Robyjn with PVS (1.20), Desiree with PVS (1.06) and Nderamwana with PVM (1.02). 


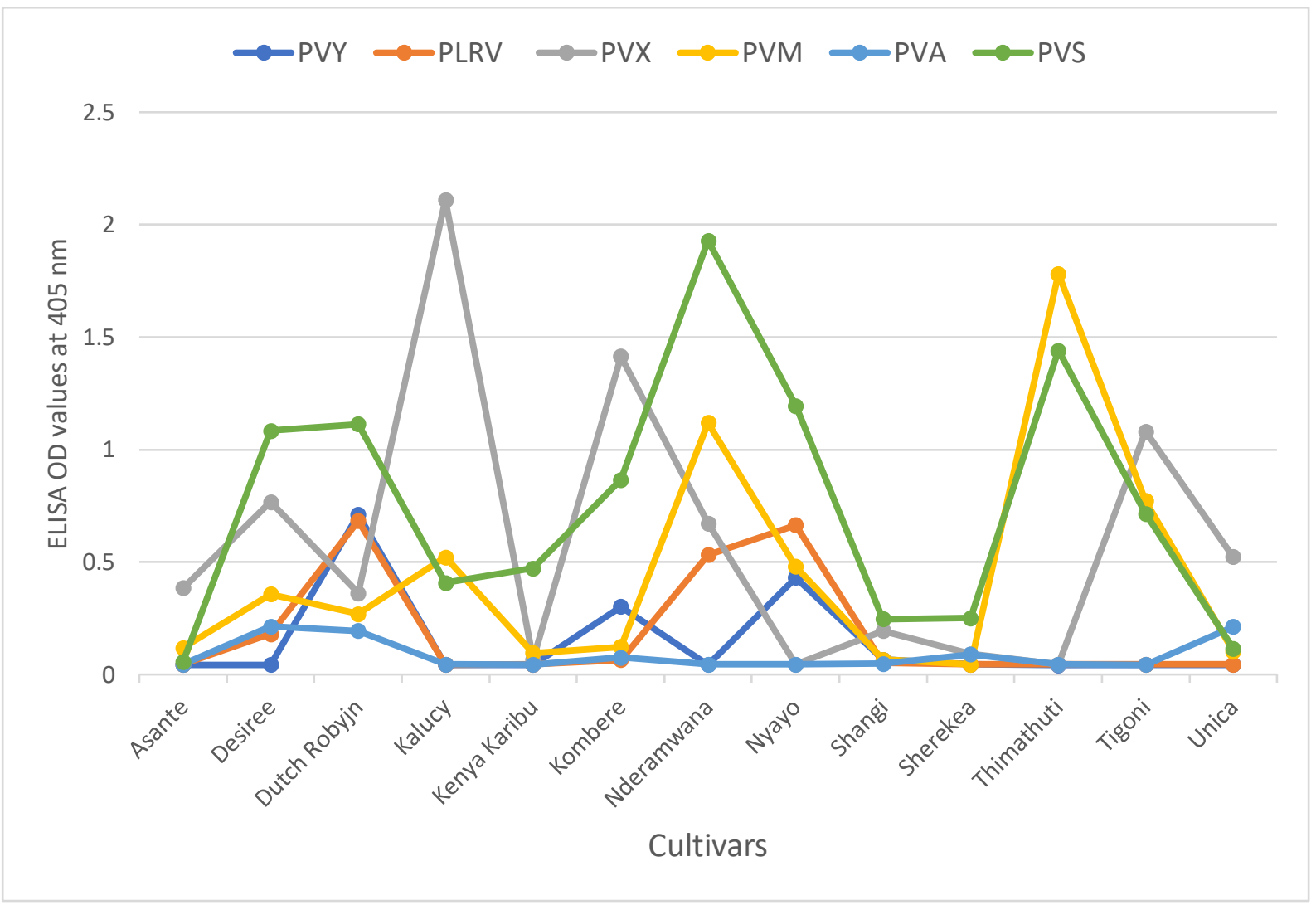

Fig 10: The average ELISA OD values for potato leaf-roll virus (PLRV), potato virus $Y(P V Y)$, potato virus $X(P V X)$, potato virus (PVM), potato virus $S$ (PVS), potato virus $A(P V A)$ and potato virus $S$ (PVS) in samples collected from 13 potato cultivars grown in five major potato growing counties in Kenya

\subsection{Discussions and conclusions}

In Kenya, the first organized field survey on potato viruses was conducted during the potato-growing seasons of 1996 and 1998 in four regions (Nyamira, Kisii, Meru and Kiambu) on 80 leaf samples which were tested in ELISA only for PLRV. PLRV prevalence was $7.7 \%$ based on ELISA and $8.9 \%$ based on virus symptoms (Were et al. 2003). Almost a decade later (in 2006), another field survey was conducted in Nakuru, Kirinyaga, Nyeri, Laikipia, Meru, Nyeri and Nyandarua regions, but on only on four viruses; PVY, PLRV, PVX and PVA. In this survey PVY was the most prevalent virus with $77.6 \%$ followed by PLRV (74.0\%), PVX (57\%) and PVA (42\%) (Gildemacher et al. 2009). Two years later (in 2008), another survey was conducted involving all the six potato viruses (PVY, PLRV, PVX, PVM, PVS and PVA) for the first time. The most prevalent viruses were PVS (99.0\%), PLRV $(80.0 \%)$ and PVY (70.0\%). PVX, PVA and PVM were found with a lower prevalence of $45 \%$, $40 \%$ and $26 \%$ respectively (Muthomi et al. 2009). A more recent survey was done 
in 2011 and only one virus (PVY) was tested for in ELISA. Highest PVY prevalence was found in Meru (77.8\%), followed by $73.3 \%$ in Kiambu and $64.0 \%$ in Nyandarua (Nyamwamu et al. 2014).

Organization and implementation of previous surveys was not the same in all the surveys in terms of the number of samples collected, types of samples (tubers or leaves), number of regions surveyed, method of virus diagnosis (visual or serological), time intervals of conducting the surveys, types of sampling (whether on all plants or on only symptomatic plants). This makes their results difficult to compare. This present study provides the status in 2016 of all the six most important potato viruses in all the important potato growing region in Kenya. In addition, it linked the overall virus prevalence figures to actual virus distribution patterns in these regions and also investigated the relative importance of the viruses in agronomically important cultivars in these regions.

From the past reports on virus prevalence, it was evident that PVY, PLRV and PVS have been a major problem of potato production in Kenya. In this study, two viruses were found to occur more commonly in cultivars and in the different regions (PVX with an overall prevalence of $54.8 \%$ and PVS with a prevalence of $47.5 \%$ ). These two viruses often occur asymptomatic in the field though in some cases mosaic can be seen and can cause minimal yield losses of not more than $10-20 \%$ (Salazar 1996). PVS and PVX usually occur as multiple infection in real life situation just as portrayed by $23.4 \%$ of samples analyzed in this study. When such mild viruses like PVS and PVX occur in combination with other viruses there may be a synergistic increase in their pathogenicity resulting to even higher crop losses (Brandolini et al. 1992; Kerlan and Moury 2008). Due to the high prevalence of multiple infections, we recommend breeding for multiple resistance to viruses rather than focusing on only one virus. PVY and PLRV are known to show more visible symptoms and to cause major yield losses of up to $90 \%$. In this study, they were found with lower prevalences of $8.2 \%$ and $6.8 \%$ respectively.

The practice of positive selection is among the factors that can reduce prevalence of viruses which show visible symptoms like PVY and PLRV by selecting healthy looking plants as planting materials for the subsequent seasons. Over the past decade the practice has been promoted among the farmer groups in Kenya to improve quality of the seed tubers among the farmers (Gildemacher et al. 2009; Schulte-Geldermann et al. 2012; Kaguongo et al. 2014; Onduru et al. 2019). In addition, the most commonly grown cultivar Shangi $(60.5 \%)$ was among the 
cultivars found with the lowest infection levels of PLRV (1.9\%) and PVY (1.4\%). This could be an indication of high levels of resistance to these viruses, a fact that could be contributing to their low prevalence as discussed below.

This study intended to contribute towards potato virus control in Kenya by first determining the virus distribution in the potato growing counties and identifying viruses found only in specific geographic localities. For instance, in this study, we identified PVY and PLRV to occur primarily in specific sub-counties of Meru and Bomet counties. This knowledge can help in targeting virus control in those specific regions to cut the cost and logistics of virus's control. One of the things that can be done in those regions is to advice farmers to avoid growing cultivars identified with high virus prevalence and replace them with resistant ones. In absence of resistant cultivars farmers can still practice positive selection to improve quality and health of the tubers they plant over seasons (Gildemacher et al. 2009; Schulte-Geldermann et al. 2012; Kanguoungo et al. 2014; Onduru et al. 2019; Priegnitz et al. 2019) and subsequently improve potato tuber yields. Training of farmers and dissemination of such virus control technologies can be targeted specifically to regions with high virus problem as identified in this study. Because certified seed tubers available to the farmers in Kenya is scarce (only $5 \%$ of the total demand is currently produced; NPCK 2017), the little available certified seed tubers can be targeted for distribution to specific regions identified with high virus prevalence in this study.

This being the first time the map of the prevalence of the six viruses in the region was constructed, it would be useful to conduct similar surveys in the future to trace and contain virus spread. Considering the significant differences in virus infection levels found in comparison to earlier surveys and the changes in virus prevalence over seasons as observed in our surveys in Nyandarua and Meru counties over three consecutive seasons, it is advisable to survey more regularly. In absence of an organized and consistent virus detection and surveillance system, it would be a difficult to manage the virus problem (Frost et al. 2013; Yadav and Khurana 2015; Okonya et al. 2019) and this can be a predisposing factor for further virus spread and expose Kenyan farmers to more virus problems.

This study identified virus resistant cultivars by deducing from variation in levels of virus infection in cultivars in farmer's fields. The screening for resistance from virus prevalence surveys was based on the fact that the majority (95\%) of Kenyan famers do not plant certified seed tubers implying that they replant their own 
saved seed tubers over several seasons (NPCK 2017). This practice exposes the cultivars grown in the field to both aphid and seed transmission of virus (Thomas Sharma et al. 2016) and simulates a field exposure trial for screening for virus resistance (Davies et al. 1975). In addition, the farmers do not have sufficient knowledge and capacity for potato virus control (Chapter 2 of this thesis).

This implies that differences in virus prevalence as observed in these surveys are more cultivar based rather than on specific virus control measures as possibly implemented by the farmers. Virus resistant cultivars under such field exposure trials are normally found without or with very low prevalence of the viruses (Davies et al. 1975; Solomon-Blackburn 2001). In this study we identified four cultivars with fairly low average concentration of all the six viruses (Fig 9): Unica, Sherekea, Shangi and Kenya Karibu. Three of these cultivars (Unica, Sherekea and Kenya Karibu) were also found without infection of the two viruses (PVY and PLRV) that causes major yield losses, an indication of high level of resistance in these cultivars. Shangi was found with very low prevalence of $1.4 \%$ and $1.9 \%$ of the two viruses. These results are confirmed in experiments described in Chapter 5 of this thesis which investigates the resistance of common Kenyan and experimental potato cultivars against the N-Wilga $\left(P V Y^{N-W i}\right)$ and $O\left(P V Y^{-O}\right)$ strains of PVY under screen-house and field conditions.

Cultivars with virus resistance are known to withstand degeneration of crop quality resulting from virus infections in the field (Davies et al. 1975) and can give fairly high yields despite exposure to different sources of virus infections like in the Kenyan situation. Such virus resistant cultivars can be recommended to lower virus prevalence among the Kenyan farmers. Further research however needs to be conducted to provide further information on the reasons for the dynamics in virus prevalence, distribution and relative importance as identified in this study. This kind of information can be useful in implementing a more effective virus control in Kenya.

\subsection{Acknowledgement}

We sincerely thank all those directly or indirectly involved in the process of this study both from WUR and KALRO. Sincere thanks to Deo-Gratias Hougni of Plant Production Systems, (WUR) for advice on data analysis and Kevin Waweru from the University of Nairobi for helping me in sample collection and serological assays. 
Chapter 3

I also thank the Kenyan famers and the staff from the Ministry of Agriculture Livestock and Fisheries for their guidance during sample collection. 


\title{
Chapter 4
}

Prevalence of potato virus $Y$ strains in Kenyan potato cultivars

\author{
John Onditi ${ }^{1,2}$, Moses Nyongesa ${ }^{1}$ and René van der Vlugt ${ }^{2}$ \\ ${ }^{1}$ Kenya Agricultural and Livestock Research Organization, Horticultural Research \\ Institute, KALRO Tigoni, P.O. Box 338 Limuru 00217 Kenya; \\ ${ }^{2}$ Laboratory of Virology, Wageningen University and Research, Droevendaalsesteeg 1 \\ 6708PB Wageningen, The Netherlands.
}

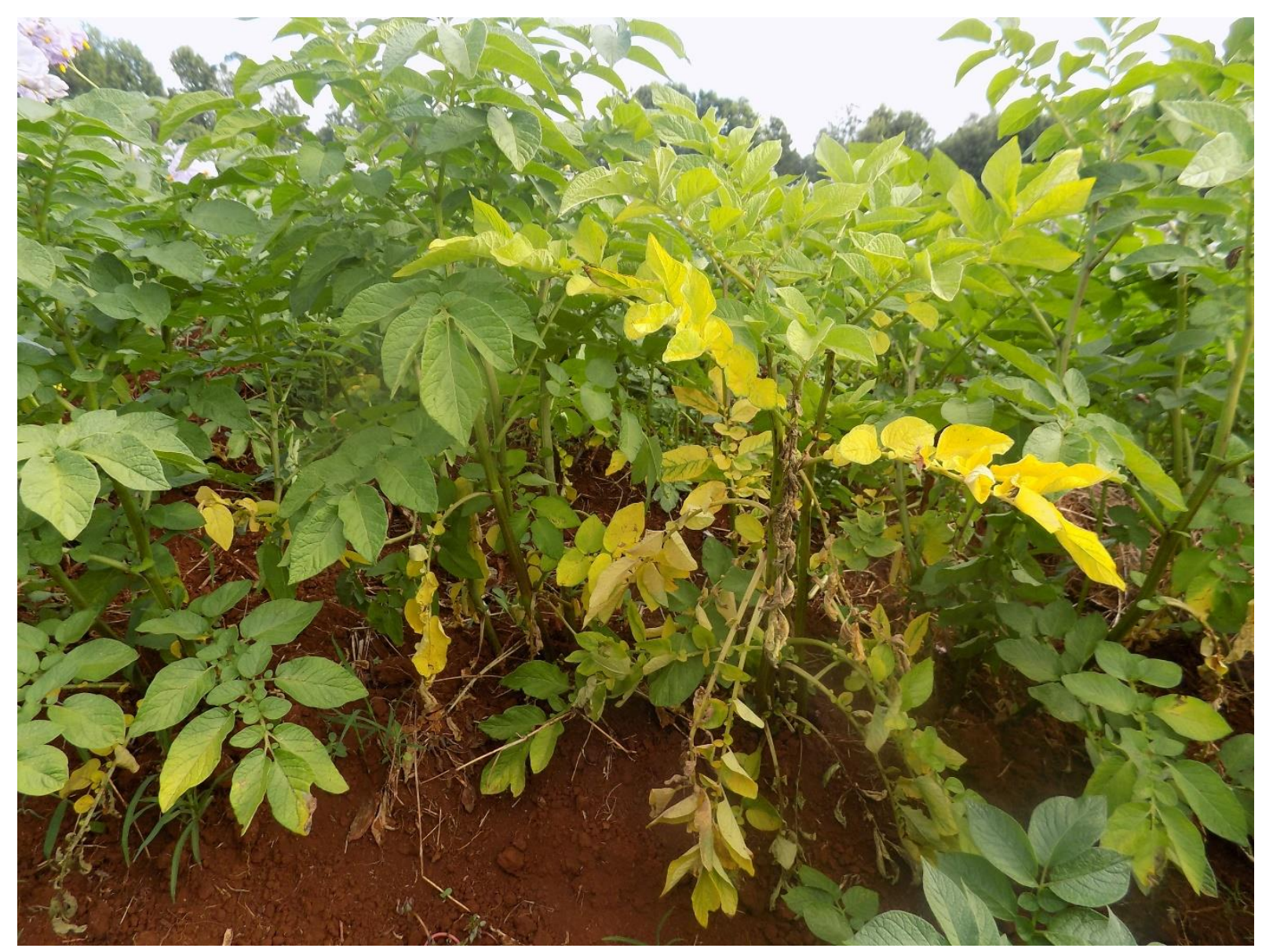

This chapter has been submitted for publication in Potato Research 


\section{Abstract}

Potato virus $\mathrm{Y}$ (PVY) is the most important virus of potato (Solanum tuberosum L.). Over the past few decades, there have been worldwide reports of increased prevalence of PVY resistance breaking strains, mainly PVY ${ }^{N-W i}$ and PVY ${ }^{N T N}$ with the ability to compromise some of the known types of PVY resistances, creating the need for new PVY resistant cultivars. In Kenya, there is scanty information about cultivar resistance to the different PVY strains. A survey of 354 potato leaf samples taken from 13 different cultivars was conducted in five major potato growing counties with follow up surveys in two of the five counties for two more seasons to deduce PVY prevalence and resistance in these cultivars. Samples were tested using DAS-ELISA and those found to be infected with PVY were subjected to reverse transcription polymerase chain reactions (RT-PCR) to determine the PVY strains. Overall PVY prevalence was generally low (8.2\%). PVY ${ }^{\mathrm{N}-\mathrm{Wi}}$ was the most prevalent strain $(7.3 \%)$ followed by $\mathrm{PVY}^{\mathrm{O}}$ (2.3\%) and PVYNTN $(1.4 \%)$ while PVYN was not detected (with mixed infections). The PVYN-Wi strain occurred across the three seasons and across the counties but only on specific cultivars. Three cultivars were identified as PVY resistant and the most widely grown cultivar Shangi (60.2\%), had only a low PVY prevalence of $0.6 \%$. This is an indication that this cultivar may have already been useful minimizing virus prevalence in farmer's fields. This being the first prevalence survey of PVY strains and resistance, the results obtained provide a basis for major focus on PVY resistance breeding in Kenya.

\subsection{Introduction}

Potato virus $\mathrm{Y}(\mathrm{PVY})$ is a problem in all regions of the world where the potato (Solanum tuberosum L.) crop is grown. The virus is transmitted mainly through infected seed tubers and by over 50 species of non-colonizing aphids in a nonpersistent manner (Quenouille et al. 2013). Once a potato plant is infected, there is a successive increase in severity of the infection coupled with reduction in size and number of tubers and crop quality over seasons of replanting virus infected tubers (Jayashige et al. 1989; Beukema and van der Zaag, 1990). The virus is the type member of the genus Potyvirus within the family Potyviridae and has a genome of about 9700 nucleotides. In an infected plant, the PVY genome is 
translated into a large polyprotein which is then cleaved into ten functional proteins by three proteases encoded by the virus (Adams et al. 2012).

The virus occurs as different strains which can be distinguished biologically, serologically and on specific differences in their genome nucleotide sequences. Historically, the description of PVY strains started in the 1930's based on the symptoms they elicited either on potato (Solanum tuberosum L.) cultivars with specific PVY resistance genes or the symptoms on tobacco (Nicotiana tabacum) plants (Smith 1931; De Bokx and van der Want 1987; Jones 1990). This led to the distinction of three different PVY strains called PVY ${ }^{\circ}, P^{\prime N} Y^{N}$ and PVYC. Later, enzyme linked immune-sorbent assay tests (ELISA) were developed to detect and differentiate PVY isolates either as ' $\mathrm{O}$ ' or ' $\mathrm{N}$ ' serotypes using specific monoclonal antibodies (Rose and Hubbard, 1986; Ellis et al. 1996; Crosslin et al. 2005). Due to the limitations of ELISA in differentiating PVY strains, different types of reverse transcription polymerase chain reaction (RT-PCR) assays were developed to simultaneously detect and differentiate PVY strains, in particular between the PVY ${ }^{\circ}$, PVYN strains and the new PVYNTN and PVY ${ }^{N-W i l g a}$ strains, which resulted from genetic recombination between $\mathrm{PVY}^{\mathrm{N}}$ and $\mathrm{PVY} \mathrm{Y}^{\circ}$ (Nie and Singh, 2002; Schubert et al. 2007; Lorenzen et al. 2006). Full or partial genome nucleotide sequence analysis is often used to confirm the genetic identity of specific PVY strains and the evolutionary relationships between and within the strain groups (Green et al. 2017). Over the years, there has been an evolutionary shift resulting from genome recombination of two of the traditionally known strains ( $P V Y^{O}$ and $P V Y^{N}$ ) to new recombinant strains, predominantly PVYNTN and PVYN-Wilga (Kehoe et al., 2016) leading to changes in prevalence of particular PVY strains in different regions in the world. Among the different ways of managing the virus, the use of host resistance is an effective long-lasting way of PVY control. Two types of resistance, extreme resistance (ER) and hypersensitive resistance $(H R)$ to the virus have been discovered in wild relatives of potato and have been introgressed into commercial cultivars (Hide and Lapwood 1992; Quenouille et al. 2013). The extreme resistance genes, Rychc, Rysto and Ryadg were sourced from Solanum chacoense, S. hougasiiand S. stoloniferum ssp andigena respectively (Cockerham 1943; Sato et al. 2006) and are known to be durable and effective against all known strains of PVY (Bradshaw and Mackay 1994). Cultivars with this kind of resistance show very low virus titres and only low PVY infection levels of $2-8 \%$ when tested in ELISA in 
field exposure experiments, unlike susceptible ones where up to $100 \%$ infection can occur (Davies et al. 1975). The hypersensitive resistance (HR) controlled by Nytbr and Nctbr genes from $S$. tuberosum limits virus movement within the plant by inducing systemic necrosis on virus infected tissues (Nie et al. 2012: Jones and Stuart 2018). This is a form of resistance which results in little or no virus translocation to the daughter tubers from the mother plant after initial infection (Bertschinger et al. 2017). Some of the sources of this type of resistance have however been broken by resistance breaking strains of PVY like PVYNTN and PVY ${ }^{N-W i}, P V Y^{Z}, P V Y^{E}$, and PVY ${ }^{N}$ (Jones 1990), creating the need to develop and screen new virus resistant cultivars.

In Kenya, potato is the second most important food crop after maize (NPCK 2017). Past PVY surveys in Kenya indicated high virus prevalence of $77.6 \%$ in $2006,70 \%$ in 2009 and 27.0\% in 2011 (Gildemacher et al. 2009; Muthomi et al. 2009; Nyamwamu et al. 2014). This could be one of the reasons for the low average potato tuber yields reported $(8.7 \mathrm{~T} / \mathrm{Ha})$ as compared to the expected potential yield of over $40 \mathrm{~T} / \mathrm{Ha}$ which can be achieved if the growing conditions are improved (Lung'aho et al. 2007; Onditi et al. 2012; FAOSTAT 2017). Studies indicate that the type and level of resistance in potato cultivars is one of the most important factors that determine relative abundance of different PVY strains in different countries (Dupuis et al. 2018). In Kenya, there is no information about occurrence of the different PVY strains and the levels of field resistance in cultivars grown by farmers. This study was therefore conducted to (a) determine the present status of prevalence and distribution of the different PVY strains in cultivars grown in different potato growing counties in Kenya and (b) to deduce PVY resistance from the prevalence of PVY strains in these potato cultivars.

\subsection{Materials and methods}

\subsubsection{Sampling survey}

A potato leaf sampling survey was conducted in 354 farms in five of the major potato growing counties in Kenya. Farms were selected randomly from within each of the five counties (Chapter 1 of this thesis) as follows: 65 in Nyandarua, 64 in Kiambu, 80 in Meru, 80 in Bomet and 65 in Nakuru. The counties are among the leading potato producing counties and potato is the main staple food for the people in these counties. The counties are basically in the highlands of Kenya at above 
1800 metres above sea level (m.a.s.l) where climatic conditions favour potato production in the two rainy seasons of the year (long rains in April to July and short rains from September to November). This survey was conducted during the long rains season of 2016. Two similar follow up sampling surveys were conducted in two of the five counties (Nyandarua and Meru) using the same number of samples and on the same farms in the short rains season in 2016 and finally the third season during long rains 2017.

Leaf samples were collected from four randomly selected potato plants within each farm and were tested as one composite. The samples were collected from among the first 3 leaves at the top of the potato plant. The survey was conducted at a time when crop was at the early vegetative stage between 30-60 days after planting. The samples were first subjected to double antibody sandwich enzyme linked immune-sorbent assay (DAS-ELISA) (Clark and Adams, 1977) test at Kenya Agricultural and Livestock Research Organization (KALRO), Tigoni. Samples confirmed to be infected with PVY were subjected to reverse transcription polymerase chain reaction (RT-PCR) at the laboratory at Kenya Plant Health Inspectorate Service (KEPHIS), Plant Quarantine and Biosafety Station (PBQS), Muguga to differentiate between the PVY strains. At the time of sample collection data were collected on the global position system (GPS) position of the farm using (UTM GEO MAP, Android app), the name of the cultivar and the PVY symptoms from the plants where the samples were collected from, severity of the symptoms scores where; 0 = no symptom, $1=$ very mild, $2=$ moderately mild, 3 = moderate, $4=$ severe and $5=$ very severe.

\subsubsection{Serological detection of PVY}

A DAS-ELISA kit with antibodies and instructions was obtained from the International Potato Center (CIP), Lima, Peru. ELISA plates (Thermo Scientific, Denmark) were coated with $100 \mu$ of coating solution consisting of $35 \mu$ of PVY polyclonal antibodies (PVY-IgG) in $10 \mathrm{ml}$ of coating buffer $\left(0.2 \mathrm{~g} \mathrm{Na}_{2} \mathrm{CO}_{3}, 0.44 \mathrm{~g}\right.$ $\mathrm{NaHCO} 3,0.03 \mathrm{~g} \mathrm{NaN}_{2}$ in $120 \mathrm{ml}$ of distilled water, $\left.\mathrm{pH} 9.6\right)$ and incubated overnight at $4^{\circ} \mathrm{C}$. All plate washings after incubations were done in triplicate using the washing buffer consisting of $8.0 \mathrm{~g} \mathrm{NaCl}, 0.2 \mathrm{~g} \mathrm{KH}_{2} \mathrm{PO}_{4}, 0.2 \mathrm{~g} \mathrm{KCL}, 1.13 \mathrm{~g} \mathrm{NaH}_{2} \mathrm{PO}_{4}$, $0.29 \mathrm{~g} \mathrm{NaN}_{2}$ and $0.05 \%$ of Tween 20 in 1 litre of distilled water, pH 7.4 (PBS-T). One hundred $(100 \mu \mathrm{l})$ of $1 \mathrm{~g}$ of leaf material macerated in $2 \mathrm{ml}$ of sample extraction buffer (4.0 g PVP-40,000 and $2.0 \mathrm{~g}$ of egg ovalbumine in $200 \mathrm{ml}$ of PBS-T) was 
added to each well of the plate and incubated overnight at $4^{\circ} \mathrm{C}$. Three positive controls consisting of potato leaf samples previously tested in ELISA and found infected with PVY were included. Similarly, six negative controls were also included from potato leaf samples previously confirmed to be free of PVY in an ELISA test. After an overnight incubation and subsequent washing, $100 \mu$ of conjugate solution (35 $\mu \mathrm{l}$ of PVY IgG-AP in $10 \mathrm{ml}$ of the above extraction buffer) was added and incubated for 3 hours at $37^{\circ} \mathrm{C}$. After washing colour development was initiated by incubating the plates with $100 \mu$ l per well of $15 \mathrm{mg}$ paranitrophenylphosphate (pNPP) in $20 \mathrm{ml}$ substrate buffer (97 ml diethanolamine in $1000 \mathrm{ml}$ distilled water, $\mathrm{pH}$ 9.8) at room temperature. An ELISA reader (Biotek ELX800, Vermont, USA) was used to take ELISA optical density (OD) values at a wavelength $405 \mathrm{~nm}$ after 60 minutes of substrate incubation. The absorbance values obtained were used to quantity severity of the PVY infection in the plants collected and also to determine which samples were infected with PVY. PVY-infected samples per individual plate were considered as those with mean OD values equal or greater than the standard deviation of the mean of the negative controls plus three times the standard deviation of the negative controls.

\subsubsection{RT-PCR analysis}

\subsubsection{RNA extraction}

All samples confirmed to have PVY in ELISA were subjected to RT-PCR using previously described primers and protocols (Lorenzen et al. 2006; Schubert et al. 2007). RNA extraction was done by the TRizol method previously described by Chomcynski et al (1987) and Hummon et al. (2007). Five hundred $\mu l$ TRIzolßReagent (Life Technologies) was incubated for 15 minutes with $200 \mu$ of the virus samples macerated in ELISA extraction buffer after which $200 \mu$ of chloroform was added and shaken vigorously by hand for 15 seconds. The lower red phenol-chloroform phase was separated from an interphase and a colourless upper aqueous phase by spinning at $10,500 \mathrm{rpm}$ for 15 minutes at $4^{\circ} \mathrm{C}$. Five hundred $\mu$ of the upper aqueous phase was transferred to a clean Eppendorf tube and the RNA was precipitated by adding $500 \mu \mathrm{l}$ of isopropanol, mixing and then incubating for 10 minutes at room temperature. The samples were spun at 10,500 $\mathrm{rpm}$ for 10 minutes at $4^{\circ} \mathrm{C}$. Supernatant was carefully poured out of the tube leaving the RNA pellet at the bottom. The pellet was washed with $1 \mathrm{ml}$ of $75 \%$ ethanol and samples were mixed gently prior to centrifugation at 8,500 rpm for 5 
minutes at $4^{\circ} \mathrm{C}$. Washing ethanol was removed carefully and the RNA pellet was dried shortly in a speed-vac and re-suspended in $30 \mu \mathrm{l}$ of RNAse-free Milli-Q water and stored $-20^{\circ} \mathrm{C}$ awaiting the subsequent cDNA synthesis.

\subsubsection{2 cDNA synthesis}

For each individual sample a mix consisting of $1 \mu \mathrm{l}$ of $100 \mu \mathrm{M}$ of each of the three reverse primers (Table 1 ) and $2 \mu \mathrm{l}$ of the RNA sample and $5 \mu \mathrm{l}$ of MQ water was (total volume of $10 \mu \mathrm{l}$ ) incubated at $70^{\circ} \mathrm{C}$ for five minutes to denature the RNA and then snap cooled in ice water. This was followed by adding $10 \mu$ of reverse transcription mix consisting of $4 \mu \mathrm{l}$ of 5X AMV RT buffer (Promega), $0.25 \mu \mathrm{l}$ of 10 mM dNTP mix, $0.5 \mu \mathrm{l}$ of $2 \mathrm{mM}$ DTT and $0.5 \mu \mathrm{l}$ of $10 \mathrm{u} / \mu \mathrm{l}$ Reverse transcriptase (Promega) to make a total reaction volume $20 \mu \mathrm{l}$ and incubating for 1 hour at $42{ }^{\circ} \mathrm{C}$ to synthesize cDNA for the subsequent PCR process.

\subsubsection{PCR}

The PCR mixture consisted of $5 \mu$ of $5 X$ Taq reaction buffer (Promega), $2.5 \mu l$ of $25 \mathrm{mM}$ MgSO4, $0.5 \mu \mathrm{l}$ of $10 \mathrm{mM}$ dNTP mix, $0.5 \mu \mathrm{l}$ of $5 \mathrm{u} / \mu \mathrm{l}$ Taq polymerase (Promega), $8.5 \mu \mathrm{MQ}$ water and $1 \mu \mathrm{l}$ of each of the six forward and reverse PCRprimers $(100 \mu \mathrm{M})$ (Table 1$)$ and $2 \mu \mathrm{l}$ of cDNA to make at total reaction volume of $25 \mu \mathrm{l}$. The PCR reaction was started with 2 minutes of denaturation at $94^{\circ} \mathrm{C}$ followed by 12 cycles at $94^{\circ} \mathrm{C}$ for 10 seconds; 30 seconds at $66^{\circ} \mathrm{C}$ with minus $0.5^{\circ} \mathrm{C}$ for each cycle and $72^{\circ} \mathrm{C}$ for 60 seconds, followed by 20 cycles of $92^{\circ} \mathrm{C}$ for 10 seconds, $60^{\circ} \mathrm{C}$ for 30 seconds and $72^{\circ} \mathrm{C}$ for 60 seconds. The PCR ended with a final extension for $72^{\circ} \mathrm{C}$ for 7 minutes (Lorenzen 2006). The amplified PCR products were separated in $1 \%$ agarose gel electrophoresis and visualized using ethidium bromide. The expected PCR products and the different fragments sizes for the different PVY strains were identified according to the distinctive fragments size as shown in Table 2 and Fig 1.

\subsubsection{Data analysis}

Data were analysed using IBM SPSS Statistics (2017) for Windows, Version 25.0. Armonk, NY: IBM Corp to obtain descriptive means and percentages of the occurrence of the PVY strains on cultivars in the different counties and over the three consecutive seasons. 
Table 1: Primers used in the detection of the potato virus $Y$ (PVY) strains and their calculated melting temperature (Tm), length and genomic locations. The primer positions in the PVY genome were based on the full-length sequences of the following representative PVY isolates: (a) PVY ${ }^{N}-$ Mont (AY884983) and (b) PVYO-139 (U09509) and (c) NA-PVYNRRA-1 (AY884984) (Lorenzen et al. 2006)

\begin{tabular}{lllll}
\hline Name & Sequence 5'-3' & Tm & Length & Position in the genome \\
\hline PVY-A6032m & CTTGCGGACATCACTAAAGCG & 64 & 21 & 6033 reverse (c) \\
PVY-n 2258 & GTCGATCACGAAACGCAGACAT & 66 & 22 & 2258 forward(a) \\
PVY-n 2650 & TGATCCACAACTTCACCGCTAACT & 70 & 24 & 2650 reverse (a) \\
PVY-o 2172 & CAACTATGATGGATTGGCGACC & 68 & 23 & 2172 forward (b) \\
PVY-o 2439 & CCCAAGTTCAGGGCATGCAT & 62 & 20 & 2487 reverse (b) \\
PVY-s 5585m & GGATCTCAAGTTGAAGGGGAC & 64 & 21 & 5584 forward (c) \\
\hline
\end{tabular}

\subsection{Results}

\subsubsection{Overall prevalence of PVY strains five potato growing counties}

A total of 354 potato leaf samples collected randomly from five major potato growing counties in Kenya were tested for PVY infections by ELISA followed by differentiation of four PVY strains $\left(P V Y^{N-W i}, P V Y^{N T N}, P V Y^{O}\right.$ and $P V Y^{N}$ ) in an RT-PCR. The representative agarose gel visualisation of PCR products of each the four PVY strains are presented in Fig 1 and each of the primer combinations which gave rise to the PCR fragment sizes (bp) are presented in Table 1. Results of both the general PVY DAS-ELISA and RT-PCR strain detections are summarised in Table 3.The overall PVY prevalence observed in this survey was very low (8.2\%) in comparison to earlier reports (Gildemacher et al. 2009; Muthomi et al. 2011; Nyamwamu et al. 2014). PVYN-Wi was the most prevalent strain (7.3\%) followed by PVYO $^{\circ}(2.3 \%)$ and PVYNTN $(1.4 \%)$ while PVYN was not detected. Comparing the five counties, the highest PVY prevalence was in Meru (18.8\%) followed by $8.8 \%$ in Bomet, $7.8 \%$ in Kiambu and $3.1 \%$ in Nyandarua. PVY was not detected in the samples collected from Nakuru County.

\subsubsection{Overall prevalence of PVY strains in Kenyan potato cultivars}

In the five major potato growing counties a total of thirteen different cultivars were sampled (Table 3). Based on RT-PCR tests (results not shown), PVY ${ }^{\mathrm{N}-\mathrm{Wi}^{\mathrm{i}}}$ was the most prevalent PVY strain in each of the infected cultivars. Shangi, the cultivar grown by the majority of farmers $(60.5 \%)$ had only few ( 3 out of $214 ; 1.4 \%$ ) of its samples infected with PVY (0.9\% PVYN-Wi and 0.5\% PVY $\left.{ }^{N T N}\right)$. Almost a quarter $(27.3 \%)$ of the samples from Kombere, the second most popularly grown cultivar 
(15.5\%) were found with PVY infection. The most prominent strains were PVY $^{N-W i}(25.5 \%)$, PVY NTN $^{\text {(3.6\%) and PVYO }}$ (9.1\%). Dutch Robyjn was the third most popularly grown cultivar (4.0\%) and almost half $(50.0 \%)$ of this cultivar was PVY infected. The three PVY strains found in this cultivar included PVY ${ }^{\mathrm{N}-\mathrm{Wi}}(42.9 \%)$, PVYNTN $(14.3 \%)$ and PVYO (21.4\%). The rest of the PVY infected cultivars, Desiree, Nderamwana and Nyayo were each grown by very few farmers, $2.0 \%, 0.6 \%$ and $0.8 \%$ respectively, though a larger proportion $(14.2 \%, 50.0 \%$ and $66.7 \%$ respectively) of each were found to be infected only with the PVYN-Wi strain. PVY was not detected in seven cultivars (Sherekea, Asante, Kenya Karibu, Tigoni, Kalucy, Unica and Thimathuti) both in DAS-ELISA and RT-PCR (Table 3).

PVYN-Wi infections in cultivar Shangi were symptomless but those infected with PVY NTN had chlorosis and necrotic spots on the stem (Fig 3). All infections of PVYNWi, PVYNTN and PVY ${ }^{\circ}$ were found with mosaic symptoms in cultivar Kombere (Fig 2), Cultivars Nderamwana and Nyayo were infected only with PVYN-Wi strain and had mosaic symptoms. Dutch Robyjn was found with PVYN-Wi, PVYNTN and PVYO mixed infections and the symptoms observed included mosaic and crinkled leaves, stunted growth and leaf and stem necrosis. PVYN-Wi was the only PVY strain in cultivar Desiree with both mosaic and crinkled leaves. Mean ELISA OD values in samples that were found to be PVY infected in the test were lowest in cultivar Shangi (0.419), the most popularly grown cultivar. The OD values were higher in Desiree (1.048), Nyayo (1.427), Nderamwana (1.443), Dutch Robyjn (1.490) grown only by few farmers. The mean OD values were highest in Kombere (1.949), the second most popularly grown cultivar.

Table 2: Potato virus Y (PVY) primer combinations and expected fragment lengths in the multiplex PCR assay as modified from Lorenzen (2006)

\begin{tabular}{lll}
\hline Primer combinations & Size (bp) & Target PVY strain \\
\hline PVY-n 2258 + PVY-o 2439 & 181 & PVY $^{\text {N-Wilga }}$ \\
PVY-o 2172 + PVY-o 2439 & 267 & PVY $^{\circ}$ \\
PVY-n 2258 + PVY-n 2650 & 398 & PVY $^{N}$ \\
PVY-s 5585m + PVY-A6032m & 452 & PVY $^{\text {NTN }}$ \\
\hline
\end{tabular}




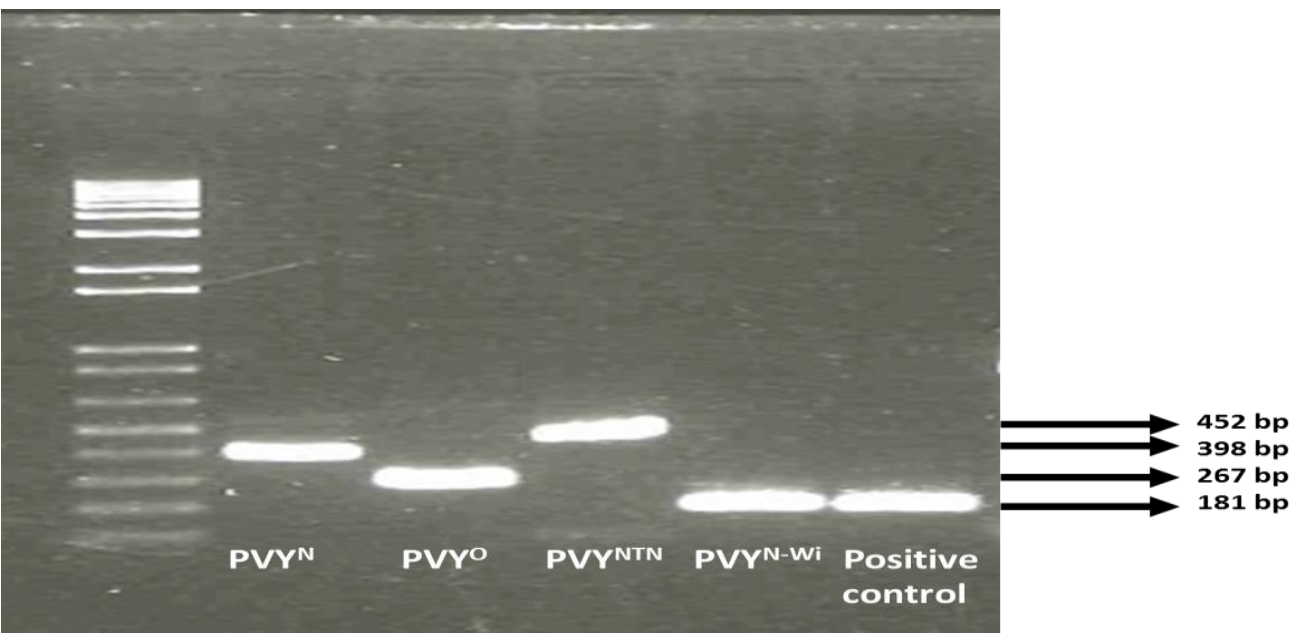

Fig 1: Visualisation of PCR products of each the four potato virus $Y(P V Y)$ strains in agarose gel electrophoresis according to the expected fragment sizes (bp) for each primer combinations as summarised in Table 2. PVY ${ }^{N-W i}$ was used as a positive control

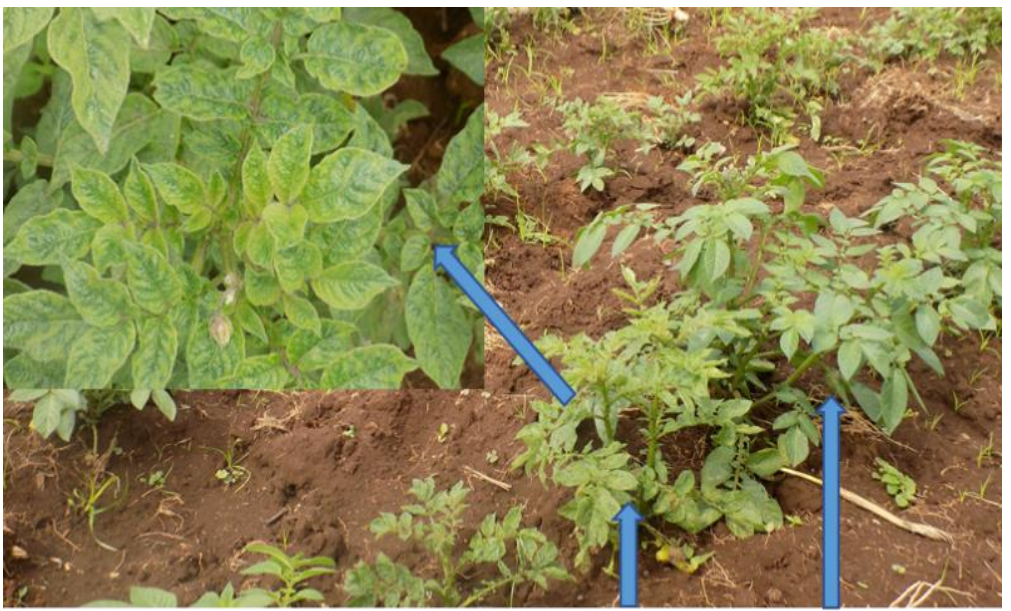

A

B

Fig 2: Potato virus $Y$ ( $\left.P V Y^{N-W i}\right)$ symptoms (mosaic) in Cultivar Kombere $(A)$ next to a healthy plant $(B)$ of the same cultivar in Meru County
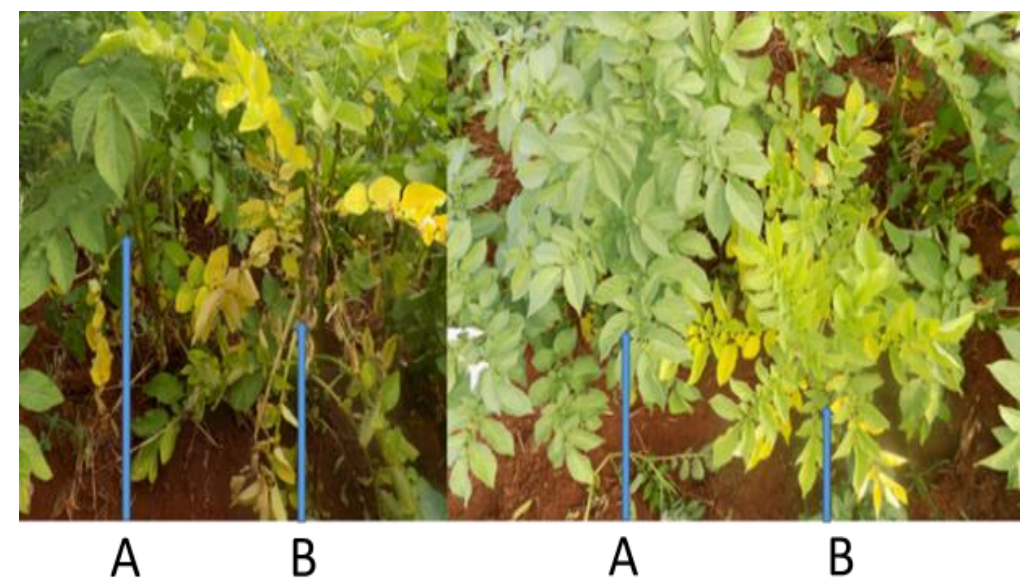

Fig 3: Potato virus Y (PVYNTN) symptoms (chlorosis and stem necrosis) in Cultivar Shangi $(B)$ next to a healthy plant $(A)$ of the same cultivar in Kiambu County 
Table 3: Proportions of potato virus Y (PVY) strain infections in positive samples of cultivars from 5 major potato growing counties in Kenya with their respective symptoms where, $N=$ total number of samples tested per cultivar with $\% N=$ percentage of cultivar in total of samples tested; \%Wi, \%NTN, \%YN, \%YO = Proportion of PVYN-Wi; PVYNTN; PVYN and PVYO respectively; OD = mean ELISA absorbance values (405 $\mathrm{nm}$ ); Symptoms = PVY symptoms recorded at the time of sample collection in the field in which ' $M$ ' is mosaic, 'Cr' is crinkled, 'St' is stunted, ' $\mathrm{Nec}^{\prime}$ is necrosis and 'Chl' is chlorosis; Sev* =Mean symptom severity among infected plants where $0=$ no symptom, $1=$ very mild, $2=$ moderately mild, $3=$ moderate, $4=$ severe and $5=$ very severe

\begin{tabular}{|c|c|c|c|c|c|c|c|c|c|c|}
\hline \multirow[t]{2}{*}{ Cultivar } & \multirow[t]{2}{*}{$\mathrm{N}$} & \multirow[t]{2}{*}{$\% \mathrm{~N}$} & \multicolumn{5}{|c|}{ Proportion of each cultivar infected (\%) } & \multirow[t]{2}{*}{ OD } & \multirow[t]{2}{*}{ Sev* } & \multirow[t]{2}{*}{ Symptoms } \\
\hline & & & \%PVY & $\% \mathrm{Wi}$ & $\%$ NTN & $\%$ YN & $\% \mathrm{O}$ & & & \\
\hline Kombere & 55 & 15.5 & 27.3 & 25.5 & 3.6 & 0 & 9.1 & 1.949 & 3.2 & $M$ \\
\hline Dutch Robyjn & 14 & 4 & 50.0 & 42.9 & 14.3 & 0 & 21.4 & 1.491 & 2.4 & $\mathrm{M}, \mathrm{Cr}, \mathrm{St}, \mathrm{Nec}$ \\
\hline Nderamwana & 2 & 0.6 & 50.0 & 50.0 & 0 & 0 & 0 & 1.443 & 2 & $M$ \\
\hline Nyayo & 3 & 0.8 & 66.7 & 66.7 & 0 & 0 & 0 & 1.427 & 2.5 & M \\
\hline Desiree & 7 & 2.0 & 14.2 & 14.2 & 0 & 0 & 0 & 1.048 & 2 & $\mathrm{M}, \mathrm{Cr}$ \\
\hline Shangi & 214 & 60.5 & 1.4 & 0.9 & 0.5 & 0 & 0 & 0.419 & 1 & $\mathrm{Ch}, \mathrm{Nec}$ \\
\hline Sherekea & 16 & 4.5 & 0 & 0 & 0 & 0 & 0 & 0.049 & 0 & None \\
\hline Asante & 14 & 4.0 & 0 & 0 & 0 & 0 & 0 & 0.046 & 0 & None \\
\hline Kalucy & 2 & 0.6 & 0 & 0 & 0 & 0 & 0 & 0.045 & 0 & None \\
\hline Kenya Karibu & 10 & 2.8 & 0 & 0 & 0 & 0 & 0 & 0.045 & 0 & None \\
\hline Tigoni & 11 & 3.1 & 0 & 0 & 0 & 0 & 0 & 0.044 & 0 & None \\
\hline Unica & 5 & 1.4 & 0 & 0 & 0 & 0 & 0 & 0.043 & 0 & None \\
\hline Thimathuti & 1 & 0.3 & 0 & 0 & 0 & 0 & 0 & 0.042 & 0 & None \\
\hline Total & 354 & 100 & & & & & & & & \\
\hline
\end{tabular}




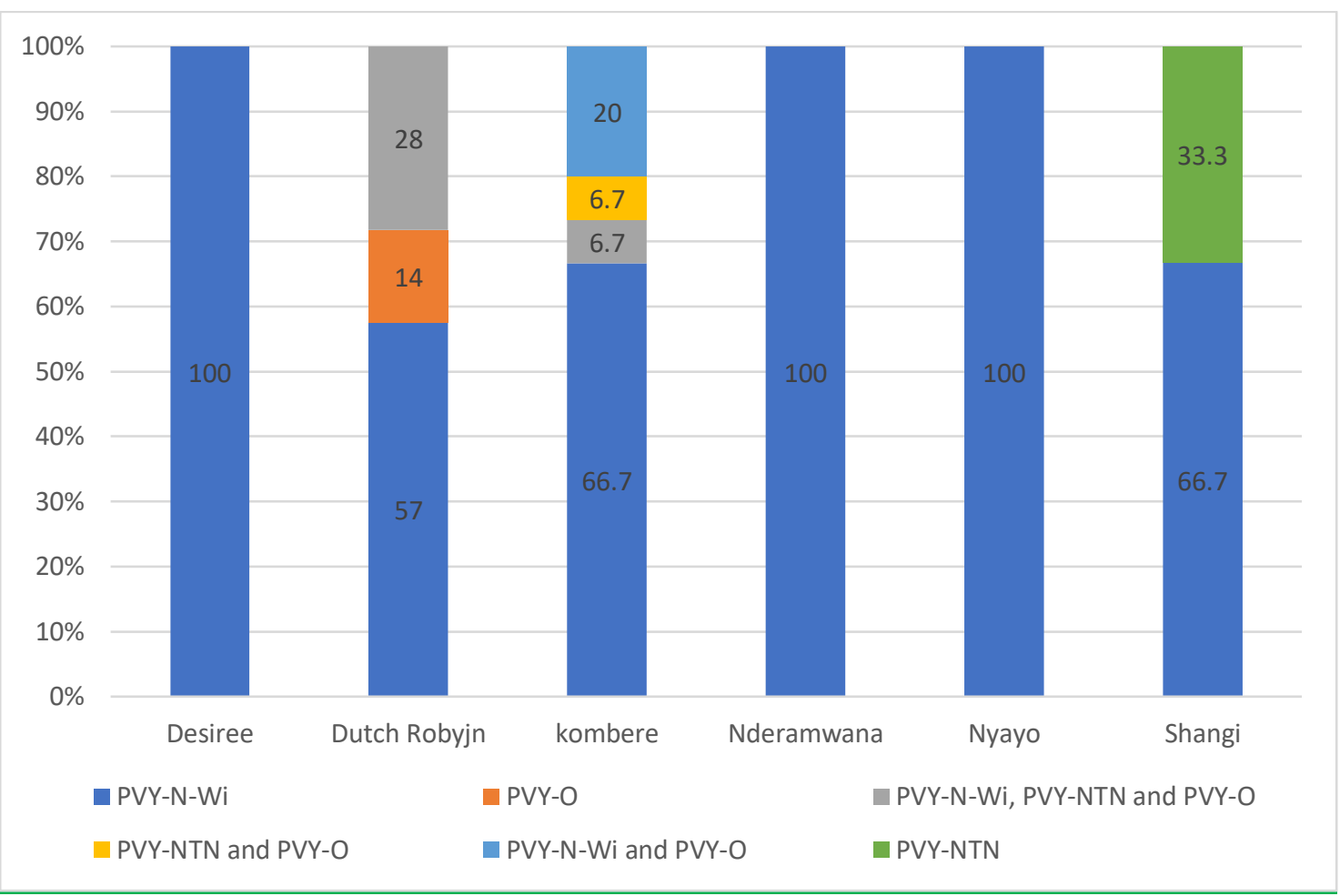

Fig 4: Proportion of single and multiple infections of the four potato virus $Y$ (PVY) strains in the total of the infected cultivars sampled in the five major potato growing counties in Kenya

\subsubsection{Occurrence of multiple infections PVY strains in potato cultivars}

Out of the PVY infected samples analysed, mixed infections of PVY strains occurred only in cultivars Kombere and Dutch Robyjn (Fig.4). In Kombere, 6.7\% of PVY infected samples had mixed infections with PVYN-Wi, PVYNTN and PVYO $6.7 \%$ with PVYNTN and PVYO and $20.0 \%$ with a mixture of PVYN-Wi and PVYO. A strain mixture of PVYN-Wi, PVYNTN and PVYO was found in $28.0 \%$ of the PVY positive samples in cultivar Dutch Robyjn. There were no mixed infections found in cultivars Desiree, Nderamwana, Nyayo and Shangi.

\subsubsection{Prevalence of PVY strains in cultivars grown within each County}

The prevalence of the different PVY strains was analysed in relation to the cultivars grown (Table 4). Among all the 354 samples analysed, the PVY ${ }^{\mathrm{N}-W i}$ had the highest overall prevalence of $7.5 \%$ in Dutch Robyjn in Bomet, $1.6 \%$ in Shangi in Kiambu, $17.5 \%$ in Kombere in Meru and $1.5 \%$ both in Shangi and Nyayo in Nyandarua. $\mathrm{PVY}^{\circ}$ was the second most prevalent strain, but it was found only in Kombere $(6.3 \%)$ in Meru and in Dutch Robyn (3.8\%) in Bomet. PVYNTN was the least 
prevalent PVY strain with $2.5 \%$ in Dutch Robyn in Bomet, $1.5 \%$ in Shangi in Kiambu and $2.5 \%$ in Kombere in Meru.

PVY infections were found only on particular cultivars grown across different counties. In Meru County, six cultivars were grown but PVY was found only in Kombere, the cultivar grown by the majority (67.5\%) of the farmers in this County. This cultivar had the highest overall PVY prevalence $(18.8 \%)$ and also the highest prevalence of the three PVY strains (17.5\% PVYN-Wi $2.5 \% \mathrm{PVY}^{\mathrm{NTN}}$ and $6.3 \% \mathrm{PVY}^{\mathrm{O}}$ ). Dutch Robyjn grown by $13.8 \%$ of the farmers in Bomet County was the only cultivar found infected with PVY among the four cultivars grown in the County. PVY prevalence in this cultivar was $8.8 \%$ (with $7.5 \% \mathrm{PVY}^{\mathrm{N}-\mathrm{Wi}}, 2.5 \% \mathrm{PVY}^{\mathrm{NTN}}$ and $3.8 \%$ $\mathrm{PVY}^{\circ}$ ). In Nyandarua County the majority of farmers (95.4\%) grew cultivar Shangi and PVY prevalence in this cultivar was very low (1.5\%). PVY was also found in cultivar Nyayo (1.5\%) from this County. Only PVY ${ }^{\mathrm{N}-\mathrm{Wi}}$ was detected in the two cultivars grown in this County. Kiambu County had the highest number of cultivars (11 cultivars) but Shangi was the main cultivar grown by more than a half $(53.1 \%)$ of the farmers. PVY infections were found only in three cultivars, Shangi $(3.1 \%)$, Nyayo $(1.5 \%)$ and Nderamwana (1.6\%). No PVY was detected in all the samples collected from Nakuru County.

\subsubsection{Prevalence of PVY strains over three consecutive growing seasons}

The prevalence of PVY strains in cultivars were followed over three consecutive potato growing seasons during the long rains 2016, short rains 2016 and long rains 2017 in Nyandarua and Meru County (Table 5). There was an overall PVY prevalence of $3.1 \%, 1.5 \%$ and $4.6 \%$ in Nyandarua County and $18.8 \%, 16.3 \%$ and $20.0 \%$ in Meru County over the three potato growing seasons respectively. Same cultivars were grown in the same farms in Nyandarua County while in Meru County some farmers changed the cultivars they grew over the seasons. Shangi was the most predominant cultivar (95.4\%) in farms in Nyandarua County while the other three cultivars Nyayo, Unica and Tigoni were each grown only in $1.5 \%$ of the farms. Cultivar Kombere was grown in the majority of the farms $(63.8 \%, 65.0 \%$ and $71.3 \%$ over the three seasons respectively) in Meru County. Shangi was also grown in Meru but as the second most popular cultivar with $12.5 \%$ in the first and the second seasons and $11.3 \%$ in the third season. 
Table 4: Potato virus $Y$ (PVY) strain infections in the different cultivars grown in each of the five major potato growing counties in Kenya where $N=$ Total number of samples tested per cultivar; $\% N=$ Percentage of each cultivars tested out of all the samples tested in each county; \%PVY= Proportion of samples detected with PVY out of all the samples analysed from each county and \%Wi, \%NTN, \%YN, \%YO = Proportion of PVYN-Wi; PVYNTN; PVYN and $P V Y^{O}$ infections respectively

\begin{tabular}{|c|c|c|c|c|c|c|c|c|}
\hline County & Cultivar & $\mathbf{N}$ & $\% \mathbf{N}$ & \% PVY & $\% \mathrm{Wi}$ & \%NTN & \%YN & $\% 0$ \\
\hline \multirow{5}{*}{ Bomet } & Sherekea & 2 & 2.5 & 0.0 & 0.0 & 0.0 & 0.0 & 0.0 \\
\hline & Shangi & 66 & 82.5 & 0.0 & 0.0 & 0.0 & 0.0 & 0.0 \\
\hline & Dutch & 11 & 13.8 & 8.8 & 7.5 & 2.5 & 0.0 & 3.8 \\
\hline & Robyjn & & & & & & & \\
\hline & Asante & 1 & 1.3 & 0.0 & 0.0 & 0.0 & 0.0 & 0.0 \\
\hline \multirow[t]{12}{*}{ Kiambu } & Unica & 1 & 1.6 & 0.0 & 0.0 & 0.0 & 0.0 & 0.0 \\
\hline & Tigoni & 5 & 7.8 & 0.0 & 0.0 & 0.0 & 0.0 & 0.0 \\
\hline & Thimathuti & 1 & 1.6 & 0.0 & 0.0 & 0.0 & 0.0 & 0.0 \\
\hline & Sherekea & 2 & 3.1 & 0.0 & 0.0 & 0.0 & 0.0 & 0.0 \\
\hline & Shangi & 34 & 53.1 & 3.1 & 1.6 & 1.5 & 0.0 & 0.0 \\
\hline & Nyayo & 2 & 3.1 & 1.5 & 1.5 & 0.0 & 0.0 & 0.0 \\
\hline & Nderamwana & 2 & 3.1 & 1.6 & 1.6 & 0.0 & 0.0 & 0.0 \\
\hline & $\begin{array}{l}\text { Kenya } \\
\text { Karibu }\end{array}$ & 6 & 9.4 & 0.0 & 0.0 & 0.0 & 0.0 & 0.0 \\
\hline & Kalucy & 2 & 2.4 & 0.0 & 0.0 & 0.0 & 0.0 & 0.0 \\
\hline & Dutch & 4 & 6.3 & 0.0 & 0.0 & 0.0 & 0.0 & 0.0 \\
\hline & Robyjn & & & & & & & \\
\hline & Desiree & 5 & 7.8 & 1.6 & 1.6 & 0.0 & 0.0 & 0.0 \\
\hline \multirow{5}{*}{ Meru } & $\begin{array}{l}\text { Unica } \\
\text { Sherekea }\end{array}$ & $\begin{array}{l}2 \\
8\end{array}$ & 2.5 & $\begin{array}{l}0.0 \\
0.0\end{array}$ & $\begin{array}{l}0.0 \\
0.0\end{array}$ & $\begin{array}{l}0.0 \\
0.0\end{array}$ & $\begin{array}{l}0.0 \\
0.0\end{array}$ & $\begin{array}{l}0.0 \\
0.0\end{array}$ \\
\hline & Shangi & 9 & 11.3 & 0.0 & 0.0 & 0.0 & 0.0 & 0.0 \\
\hline & Kombere & 54 & 67.5 & 18.8 & 17.5 & 2.5 & 0.0 & 6.3 \\
\hline & Desiree & 1 & 1.3 & 0.0 & 0.0 & 0.0 & 0.0 & 0.0 \\
\hline & Asante & 6 & 7.5 & 0.0 & 0.0 & 0.0 & 0.0 & 0.0 \\
\hline \multirow{7}{*}{ Nakuru } & Unica & 1 & 1.5 & 0.0 & 0.0 & 0.0 & 0.0 & 0.0 \\
\hline & Tigoni & 5 & 7.7 & 0.0 & 0.0 & 0.0 & 0.0 & 0.0 \\
\hline & Sherekea & 4 & 6.2 & 0.0 & 0.0 & 0.0 & 0.0 & 0.0 \\
\hline & Shangi & 50 & 76.9 & 0.0 & 0.0 & 0.0 & 0.0 & 0.0 \\
\hline & Kenya & 4 & 6.2 & 0.0 & 0.0 & 0.0 & 0.0 & 0.0 \\
\hline & Karibu & & & & & & & \\
\hline & Desiree & 1 & 1.5 & 0.0 & 0.0 & 0.0 & 0.0 & 0.0 \\
\hline \multirow[t]{4}{*}{ Nyandarua } & Unica & 1 & 1.5 & 0.0 & 0.0 & 0.0 & 0.0 & 0.0 \\
\hline & Tigoni & 1 & 1.5 & 0.0 & 0.0 & 0.0 & 0.0 & 0.0 \\
\hline & Shangi & 62 & 95.4 & 1.5 & 1.5 & 0.0 & 0.0 & 0.0 \\
\hline & Nyayo & 1 & 1.5 & 1.5 & 1.5 & 0.0 & 0.0 & 0.0 \\
\hline
\end{tabular}

PVY was not detected both in ELISA and in RT-PCR in cultivars Unica, Sherekea, Tigoni, Desiree and Asante in all the samples analysed in the two counties and over the three seasons. This is in line with the results obtained for the five different counties in the first long rains season of 2016. Over the three seasons and across the two counties, it was the most prevalent strain in all cultivars. 
$\mathrm{PVY}^{\mathrm{N}-\mathrm{Wi}}$ prevalence was highest in Meru County with $17.5 \%, 16.3 \%$ and $20.0 \%$ during the first, second and third seasons respectively. Similarly, PVY ${ }^{\mathrm{N}-\mathrm{Wi}^{\mathrm{i}}}$ was the most prevalent in Nyandarua during the first (3.1\%) and the second seasons $(1.5 \%)$ but the strain disappeared in the third season and instead PVYNTN was detected $(3.1 \%)$ though the PVY prevalence in this County was lower.

Table 5: Prevalence of the total potato virus $Y$ (PVY) and PVY strains infections in the different cultivars grown in Meru and Nyandarua counties over three consecutive seasons (long rains 2016, short rains 2016 and long rains 2017) where, $N=$ Total number of samples tested per cultivar; $\% N=$ Percentage of each cultivars tested out of all the samples tested in each county; \%PVY = Proportion of samples detected with PVY out of all the samples analysed from each county; Prev*= Prevalence of each PVY strain per county and \%Wi, \%NTN, \%YN, \%YO = Proportion of PVYN-Wi; PVYNTN; PVYN and PVYO infections respectively

\begin{tabular}{|c|c|c|c|c|c|c|c|c|c|}
\hline County & Season & Cultivar & $\mathrm{N}$ & $\% \mathrm{~N}$ & $\%$ PVY & $\% W i$ & $\%$ NTN & $\% Y N$ & $\% \mathrm{O}$ \\
\hline \multirow[t]{5}{*}{ Nyandarua } & \multirow[t]{5}{*}{1} & Shangi & 62 & 95.4 & 1.5 & 1.5 & 0.0 & 0.0 & 0.0 \\
\hline & & Nyayo & 1 & 1.5 & 1.5 & 1.5 & 0.0 & 0.0 & 0.0 \\
\hline & & Tigoni & 1 & 1.5 & 0.0 & 0.0 & 0.0 & 0.0 & 0.0 \\
\hline & & Unica & 1 & 1.5 & 0.0 & 0.0 & 0.0 & 0.0 & 0.0 \\
\hline & & Prev* & & & 3.1 & 3.1 & 0.0 & 0.0 & 0.0 \\
\hline \multirow[t]{5}{*}{ Nyandarua } & \multirow[t]{5}{*}{2} & Shangi & 62 & 95.4 & 0.0 & 0.0 & 0.0 & 0.0 & 0.0 \\
\hline & & Nyayo & 1 & 1.5 & 1.5 & 1.5 & 0.0 & 0.0 & 0.0 \\
\hline & & Tigoni & 1 & 1.5 & 0.0 & 0.0 & 0.0 & 0.0 & 0.0 \\
\hline & & Unica & 1 & 1.5 & 0.0 & 0.0 & 0.0 & 0.0 & 0.0 \\
\hline & & Prev* & & & 1.5 & 1.5 & 0.0 & 0.0 & 0.0 \\
\hline \multirow{5}{*}{ Nyandarua } & \multirow[t]{5}{*}{3} & Shangi & 62 & 95.4 & 3.1 & 0.0 & 3.1 & 0.0 & 0.0 \\
\hline & & Nyayo & 1 & 1.5 & 1.5 & 0.0 & 0.0 & 0.0 & 0.0 \\
\hline & & Tigoni & 1 & 1.5 & 0.0 & 0.0 & 0.0 & 0.0 & 0.0 \\
\hline & & Unica & 1 & 1.5 & 0.0 & 0.0 & 0.0 & 0.0 & 0.0 \\
\hline & & Prev* & & & 4.6 & 0.0 & 3.1 & 0.0 & 0.0 \\
\hline \multirow[t]{7}{*}{ Meru } & \multirow[t]{7}{*}{1} & Unica & 2 & 2.5 & 0.0 & 0.0 & 0.0 & 0.0 & 0.0 \\
\hline & & Sherekea & 10 & 12.5 & 0.0 & 0.0 & 0.0 & 0.0 & 0.0 \\
\hline & & Shangi & 10 & 12.5 & 0.0 & 0.0 & 0.0 & 0.0 & 0.0 \\
\hline & & Kombere & 51 & 63.8 & 17.5 & 17.5 & 2.5 & 0.0 & 6.3 \\
\hline & & Desiree & 1 & 1.3 & 0.0 & 0.0 & 0.0 & 0.0 & 0.0 \\
\hline & & Asante & 6 & 7.5 & 0.0 & 0.0 & 0.0 & 0.0 & 0.0 \\
\hline & & Prev* & & & 18.8 & 17.5 & 2.5 & 0.0 & 6.3 \\
\hline \multirow[t]{7}{*}{ Meru } & \multirow[t]{7}{*}{2} & Unica & 2 & 2.5 & 0.0 & 0.0 & 0.0 & 0.0 & 0.0 \\
\hline & & Sherekea & 10 & 12.5 & 0.0 & 0.0 & 0.0 & 0.0 & 0.0 \\
\hline & & Shangi & 10 & 12.5 & 0.0 & 0.0 & 0.0 & 0.0 & 0.0 \\
\hline & & Kombere & 52 & 65.0 & 16.3 & 16.3 & 0.0 & 0.0 & 0.0 \\
\hline & & Desiree & 1 & 1.3 & 0.0 & 0.0 & 0.0 & 0.0 & 0.0 \\
\hline & & Asante & 5 & 6.3 & 0.0 & 0.0 & 0.0 & 0.0 & 0.0 \\
\hline & & Prev* & & & 16.3 & 16.3 & 0.0 & 0.0 & 0.0 \\
\hline \multirow[t]{7}{*}{ Meru } & \multirow[t]{7}{*}{3} & Unica & 2 & 2.5 & 0.0 & 0.0 & 0.0 & 0.0 & 0.0 \\
\hline & & Sherekea & 7 & 8.8 & 0.0 & 0.0 & 0.0 & 0.0 & 0.0 \\
\hline & & Shangi & 9 & 11.3 & 0.0 & 0.0 & 0.0 & 0.0 & 0.0 \\
\hline & & Kombere & 57 & 71.3 & 20.0 & 20.0 & 2.5 & 1.3 & 12.5 \\
\hline & & Desiree & 1 & 1.3 & 0.0 & 0.0 & 0.0 & 0.0 & 0.0 \\
\hline & & Asante & 4 & 5.0 & 0.0 & 0.0 & 0.0 & 0.0 & 0.0 \\
\hline & & Prev* & & & 20.0 & 20.0 & 2.5 & 1.3 & 12.5 \\
\hline
\end{tabular}




\subsection{Discussions and conclusions}

\subsubsection{The overall PVY prevalence}

A survey was conducted in five major potato growing counties in Kenya and the randomly collected 354 potato leaf samples were tested in DAS-ELISA to identify PVY infected samples which were then tested in RT-PCR to detect and differentiate the four PVY strain $\left(P V Y^{N-W i}, P V Y^{N T N}, P V Y^{O}\right.$ and $\left.P V Y^{N}\right)$. Follow up surveys were conducted for two more seasons in two of the five counties to confirm the results during the first season. The overall PVY prevalence observed on the 354 samples was very low (8.2\%). This was not expected considering the high prevalence that had been reported for PVY in past surveys done in Kenya (Gildemacher et al. 2009; Muthomi et al. 2011; Nyamwamu et al. 2014). In a survey conducted in 2006 in Nakuru, Kirinyaga, Nyeri, Laikipia, Nakuru, Meru, Muranga and Nyandarua counties, a high prevalence of $77.6 \%$ was reported from an ELISA test of tuber sprouts of 1000 randomly selected potato seed tubers informally sold in local markets (Gildemacher et al. 2009). A few years later in 2009, a prevalence of $70.0 \%$ was reported in potato leaf samples from Meru, Nyeri, Nakuru, Narok and Nyandarua counties (Muthomi et al. 2011). A more recent survey conducted in 2011 (Nyamwamu et al. 2014) reported 27.0\% PVY prevalence, clearly lower as compared to the two previous surveys. When the results of this study were compared with those of previous reports, there seemed to have been a decreasing trend of PVY prevalence over the past 10 years.

Cultivars grown by farmers are among the major factors determining prevalence and geographical distribution of the different PVY strains (Dupuis et al. 2018). In Kenya, there is evidence that Kenyan farmers have been changing cultivars over time. For instance, cultivars Nyayo and Desiree were the major cultivars grown in the 1980's and early 1990's (Crissman et al. 1993) but are now among the least grown cultivars as reported in this study. In a survey conducted in 2008 , the major cultivars grown by farmers were Tigoni (20\%), Nyayo (19\%), Thimathuti (9\%), Dutch Robyjn (7\%) and Asante (6\%) while Shangi was among the least popular cultivars with only 5\% (MoA/GTZ/PSDA 2009). Based on this study, Shangi is now the most popularly grown cultivar (60.9\%) and considering the low prevalence $(0.6 \%)$ of PVY in this cultivar, it is possible that the popularity of this cultivar has contributed to the decreasing PVY prevalence in Kenya over the past 10 years. Shangi is a farmer variety whose source is not known but it was evaluated and 
officially registered as a variety in the year 2015 by KALRO (NPCK 2017). The fact that this cultivar has gained popularity without supply of certified seed tubers for over 10 years is an indication of its ability to withstand degeneration resulting not only from PVY but also other locally important viruses like potato leaf roll virus (PLRV), potato virus X (PVX), potato virus A (PVA), potato virus S (PVS) and potato virus $M(P V M)$. A survey conducted for the presence of these six viruses (see Chapter 3), cultivar Shangi, together with Sherekea, Kenya Karibu and Asante were among the cultivars with lowest virus titres of each of the six viruses which can be an indication of tolerance to multiple infection of the viruses under field conditions and ability to withstand virus degeneration.

\subsubsection{Deducing resistance of PVY strains in cultivars from prevalence surveys}

The Kenyan potato growing conditions exposes potato cultivars to different sources of virus inoculum and hence make it a suitable system for screening virus resistance in cultivars under farming conditions. This is supported by the fact that the majority of the Kenyan farmers obtain seed tubers for planting from either local markets, neighbours and from their previous harvests (Gildemacher et al. 2009; Onditi 2020 submitted for publication). Such sources of seed tubers are often infected with viruses and act as sources of inoculum for virus transmission within and between potato farms (Boiteau et al 1988; Ragsdale et al 2001; Chandla et al. 2001). In Kenya, this occurs because farmers lack sufficient quantities of certified seed tubers and only $5 \%$ of the tubers planted in Kenya are from certified stock (KEPHIS 2016; NPCK 2017). Potato viruses persist in the farms because after initial infection of a mother plant, a virus (i.e. PVY) is normally passed to the daughter tubers leading to a subsequent increase in virus prevalence, virus concentration in the plant and severity of the symptoms over seasons. As a result, farmers incur yield losses due to reduced numbers and size of tubers and sometimes death of the plants with the continuous practice of replanting virus infected seed tubers especially in susceptible cultivars (Jayashige et al., 1989; Beukema and van der Zaag, 1990). The virus spread is further accelerated by the fact that farmers do not have sufficient knowledge of the concept of virus infections and on how to monitor and control the virus vectors as is discussed in Chapter 2 of this thesis (Onditi 2020 submitted for publication). This was also confirmed by surveys that indicated high incidences of some of the 
aphids in the major potato growing Counties in Kenya (Machangi et al. 2003; Olubayo et al. 2010; Were et al. 2013) and subsequent high virus prevalence in the County (Gildemacher et al. 2009; Muthomi et al. 2009; Were et al. 2013).

When a potato plant gets exposed to high virus pressure from different sources of virus inoculum under natural growing conditions for several seasons without becoming infected or showing only very low infection levels of the virus, it can be regarded as a form of tolerance/resistance to that virus under such conditions (Davies et al. 1975). This study identified cultivars which were not found with any of the four PVY strains in all the five counties and over different growing seasons; cultivars Tigoni, Unica, Thimathuti, Sherekea and Asante. These cultivars however were grown only by a very limited number of farmers $(0.3-4 \%$, see Table 3$)$. Cultivar Shangi grown by a majority of the farmers $(60.5 \%)$ and with a very low PVY prevalence of $0.6 \%$ and with very low virus titres, can be used to minimize virus prevalence in the field considering that it is already well adopted among farmers.

The PVY resistance as deduced from PVY prevalence can routinely be used in PVY resistance screening if the results obtained are validated in controlled PVY sap inoculation experiments followed by field exposure trials (Davies et al. 1975; Solomon-Blackburn and Barker 2001; see also Chapter 5 of this thesis). Under field conditions, PVY resistance genes protect the plants by triggering local or systemic necrosis of virus infected tissues to eliminate initial infection or to limit cell to cell movement of the virus within the plant and to tubers, sometimes resulting in no or less infected daughter tubers as compared to the mother tubers (Bertschinger et al. 2017). In the field, a cultivar can also be unattractive to the vectors making it impossible to be infected under natural conditions (Flanders et al. 1992). When such plants are tested in ELISA very low prevalence of the virus or very low virus titres are detected just like in the case of Shangi and other cultivars which were not detected with PVY in this study.

\subsubsection{Relevance of this prevalence survey in setting up PVY control in Kenya}

To effectively manage the PVY problem in Kenya, there is need for development/introduction, promotion and adoption of PVY resistant cultivars with multiple traits that fit the Kenyan farming system and the whole potato value chain. Setting up a PVY resistance breeding program requires knowledge of the 
current infection rates of the most prevalent PVY strains. This study shows that these rates may differ from one county to another and from one cropping seasons to another. Even though PVY is known to occur in Kenya (Gildemacher et al. 2009; Muthomi et al. 2009; Were et al. 2013; Nyamwamu et al. 2014), this study provides the very first prevalence information about the different PVY strains that occur in Kenya. PVYN-Wi was the most prevalent and most widely distributed PVY strain in the cultivars grown in Kenya. To ensure easy adoption of the virus resistant cultivars by the Kenyan farmers, it would be advisable to conduct evaluations to confirm if the traits in the cultivars identified with PVY resistance in this study meet the demands of Kenyan farmers and consumers. Past surveys indicate that Kenyan farmers prefer cultivars that produce high yields and large size tubers and also having early maturity, short dormancy, late blight tolerance, bacterial wilt tolerance and good cooking and processing qualities (Crissman et al. 1993; Kaguongo et al. 2008; Onditi et al. 2020 submitted for publication, see also Chapter 2 of this thesis). Breeding for PVY resistance should therefore focus on screening and identification of cultivars with resistance to this strain from among the Kenyan potato germplasm (Chapter 5).

\subsection{Acknowledgements}

We thank the Kenya Agricultural and Livestock Research Organization (KALRO), Kenya and Wageningen University and Research (WUR), The Netherlands for supporting and hosting this study. Special thanks to Dr. Florence Munguti and the staff at Kenya Plant Health Inspectorate Service for hosting Laboratory diagnosis of plant samples. We finally thank the Kenyan farmers for allowing us into their farms to conduct this study. 


\title{
Chapter 5
}

\section{Screening for PVYN-Wi resistance in Kenyan potato cultivars}

\author{
John Onditi ${ }^{1} \mathbf{2}$, Moses Nyongesa ${ }^{1}$ and René van der Vlugt ${ }^{2}$ \\ ${ }^{1}$ Kenya Agricultural and Livestock Research Organization, Horticultural Research \\ Institute, KALRO Tigoni, P.O. Box 338 Limuru 00217 Kenya; \\ ${ }^{2}$ Laboratory of Virology, Wageningen University and Research, Droevendaalsesteeg 1 \\ 6708PB Wageningen, The Netherlands.
}

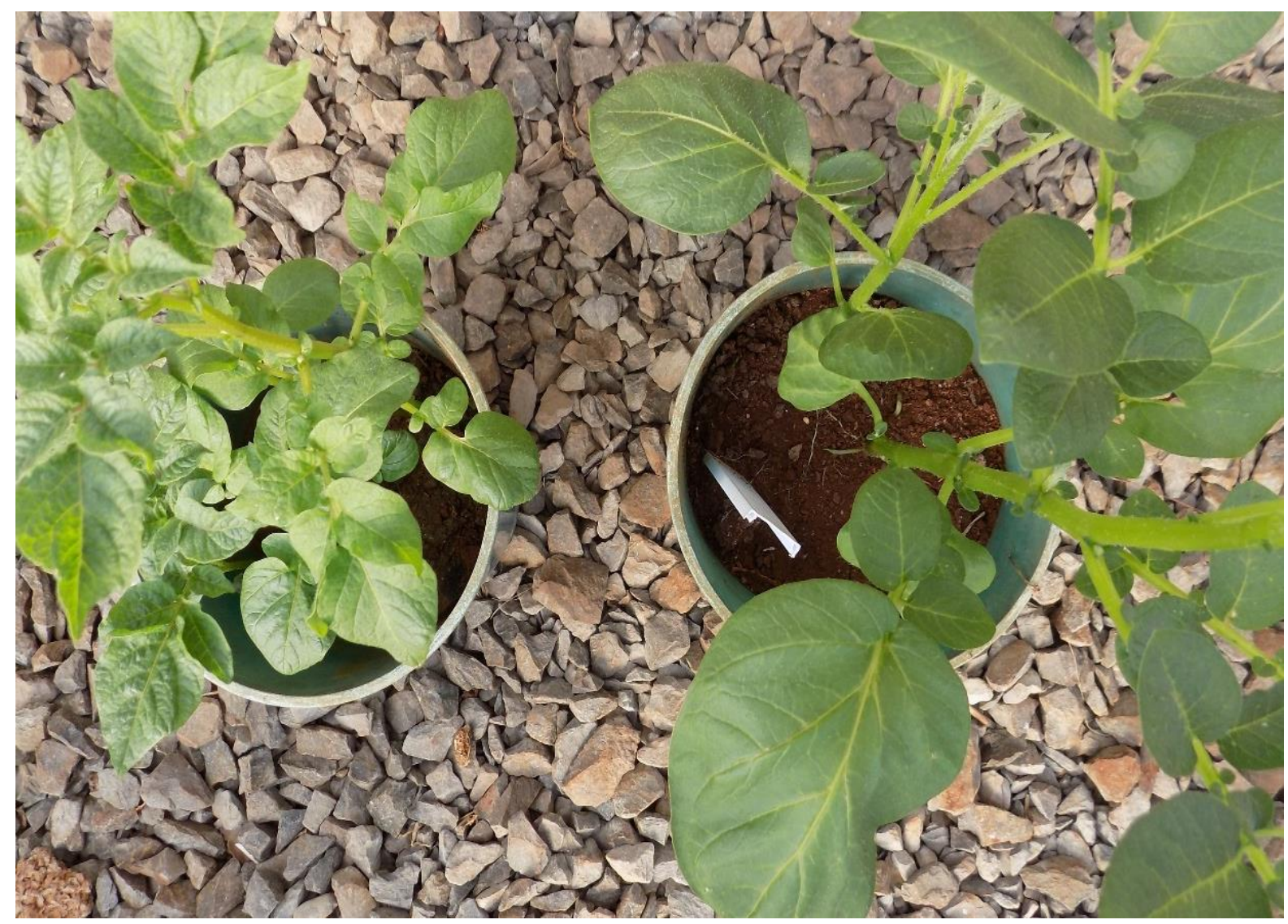

This chapter has been submitted for publication in Potato Research 


\section{Abstract}

Potato virus Y (PVY) causes serious yield losses in potato (Solanum tuberosum L.) crops. Over the past decades, two traditionally known strains of this virus (PVYO and $P V Y^{N}$ ), have largely been replaced by two new strains (PVY ${ }^{\mathrm{N}-\text { Wi (Wilga) and PVY }}{ }^{\mathrm{NTN}}$ ) which are now considered the most widely distributed and rapidly spreading PVY strains all over the world. The new PVY strains have broken some of the known PVY resistance genes in commercial cultivars which implies a need for new resistant cultivars. PVY ${ }^{\mathrm{N}-\mathrm{Wi}}$ was recently found to be the most prevalent strain in Kenya. To identify effective sources of resistance in the available potato germplasm in Kenya, we screened potato genotypes using a Kenyan isolate of the PVYN-Wi strain and quantified the associated yield losses. Three cultivars; Kenya Karibu, Sherekea and Unica and two early generation clones CIP312284.737 and CIP313028.42 were identified as resistant because they were all found to be free of PVY infections over three seasons of both greenhouse and field screening experiments. In susceptible cultivars Dutch Robyjn, Nyayo and in Kenya Mpya, PVY ${ }^{N-W i}$ infection caused yield losses of $21.6 \%, 39.0 \% 53.1 \%$ respectively after three seasons. This study demonstrated the necessity to screen for PVY resistance based on the current most prevalent PVY strains and to make an informed decision on the usefulness of current levels of resistance in potato cultivars.

\subsection{Introduction}

Potato (Solanum tuberosum L.) is the world's fourth most important food after wheat, rice and maize. The crop is grown in over 100 countries in all continents in the world (Birch et al. 2012). In Kenya, potato is the second most important food crop after maize because of its potential to provide food and nutrition security (MoALF 2016). Potato virus Y (PVY) is the most important virus of the potato crop and the fifth most important plant virus (German et al. 2001; Scholthof et al. 2011). The virus, which is the type member of the genus Potyvirus and family Potyviridae (Adams et al. 2012) may cause yield losses of up to $80 \%$ in susceptible cultivars (Kopp et al. 2015). PVY is transmitted mainly from one cropping season to another through infected mother tubers to daughter tubers and by different species of aphids in a non-persistent manner (Quenouille et al. 2013). The virus can also be transmitted through mechanical contamination with infected plant tissues (Quenouille et al. 2013). Over the past three decades, the virus has been 
difficult to control mainly because of the rapid rate at which the virus has been undergoing genetic changes by recombination between the genomes of the two traditionally known strains $P V Y^{N}$ and $P V Y^{O}$ leading to the emergence of new strains (Kehoe et al. 2016). As a result, $P V Y^{N}$ and $P V Y^{O}$ have now been replaced by over 10 new PVY strains. Of these PVY ${ }^{N T N}$ (PVY-N Tuber Necrosis) and PVY ${ }^{N-W i}$ (PVY-N Wilga) are of most concern because they are the most widespread and cause yield losses in potato crop around the world (Crosslin et al. 2006; Lorenzen et al. 2006; Singh et al. 2008; Karasev and Gray 2013; Green et al. 2017). An effective, economical, long-term and environmentally friendly option which has been successfully used to solve PVY problems is the use of resistant cultivars. PVY host resistance is either classified as extreme resistance (ER) or hypersensitive resistance (HR) (Solomon-Blackburn and Barker 2001). ER is effective against all the known strains of PVY (Quenouille et al. 2013). When a potato plant with ER is infected with PVY, the virus can replicate within the infected cell, but the cell gets killed quickly, effectively nearly eliminating cell-to-cell spread of the virus and thus its systemic spread throughout the plant. This ER results in very tiny necrotic spots or lesions which are often too small to be seen by eye. When such plants are tested using sensitive techniques, the virus is usually not detected in the plant though in some rare circumstances, extremely low amounts of the virus can be detected (Solomon-Blackburn and Barker 2001). Genotypes with ER genes (Rychc, Rysto and Ryadg) for PVY resistance have been backcrossed from wild relatives of potato (Solanum chacoense, S. hougasii, S. stoloniferum ssp andigena respectively) and are available in many commercial cultivars around the world (Cockerham 1943; Munoz et al. 1975 and Sato et al. 2006; Valkonen et al. 2017). HR genes on the other hand elicit hypersensitive reactions in potato cultivars upon infection with PVY. The virus can infect the plant but there is limited movement of the virus within the plant tissues. The plant also tries to kill its own cells (apoptosis) in an attempt to stop systemic spread of the virus, sometimes resulting in visible necrotic spots on the leaves. The genes for HR (Nytbr and Nctbr) were sourced from $S$. sparsipilum and $S$. tuberosum respectively and have also been incorporated into commercial cultivars from the 1970s onwards (Jones 1990; Kerlan 1999). Unlike ER, the HR genes have however been broken by some PVY strains like $P V Y^{Z}, P V Y^{E}, P V Y^{N}, P Y^{N T N}$ and $P V Y^{N-W i}$ but have so far remained effective against $P V Y^{\circ}$ and $P V Y^{C}$ (Jones 1990; Kerlan 1999). Considering the rapid spread of the new recombinant strains and the nature of available sources of PVY 
resistance, cultivars previously developed and screened against PVY may have lost their resistance and need to be re-screened using the new PVY strains to get effective sources of PVY resistance in potato cultivars.

In Kenya, PVY has been reported with high prevalence in farmer's fields (Gildemacher et al. 2009; Muthomi et al. 2011; Were et al. 2013; Nyamwamu et al. 2014) and could be one of the mains reasons for the low average tuber yields of 8.7 T/Ha (FAOSTAT 2017), compared to over $35 \mathrm{~T} / \mathrm{Ha}$ which can be realized under experimental field potato growing conditions (Lung'aho et al. 2006; Onditi et al. 2012; NPCK 2017). The most widespread and destructive new recombinant PVY strains, (PVYN-Wi and PVYNTN) have been reported in the country (Were et al. 2013) with PVYN-Wi found as the most prevalent PVY strain in a recent survey (Chapter 4 of this thesis). There is however lack of information on whether there is $\mathrm{PVY}^{\mathrm{N}-\mathrm{Wi}}$ resistance in the available potato germplasm collection in Kenya and whether the resistances available are effective in managing yield losses in major local cultivars. The alternative option of PVY control using certified seed tubers in Kenya has not been successful because the quantity of certified potato seed available (5\%) is very low (NPCK 2017). This has forced farmers to replant their own saved seed tubers, a practice that may be contributing to further spread of the virus in the farmer's fields. In this situation, PVY resistant cultivars can help in limiting spread of viruses through seed tubers over seasons in the cultivars grown by farmers. This study therefore, (a) compares pathogenicity of PVYN-Wi against $\mathrm{PVY}^{\mathrm{O}}$, (b) identifies effective sources of $\mathrm{PVY}^{\mathrm{N}-\mathrm{Wi}^{\mathrm{i}}}$ resistance within the Kenyan potato germplasm and (c) assesses the extent of yields losses caused by PVY ${ }^{\mathrm{N}-\mathrm{Wi}}$ in the major potato cultivars.

\subsection{Materials and methods}

\subsubsection{Potato genotypes and PVY strains for $P V Y$ resistance screening}

Potato genotypes used in this study included 12 potato cultivars (No. 1-12 in Table 1), obtained from the Kenya Agricultural and Livestock Research Organization (KALRO), Tigoni and 17 potato clones obtained from the International Potato Centre (CIP), Sub-Saharan Africa (SSA), Nairobi, Kenya. The 12 cultivars were selected because they are among the major potato cultivars grown in Kenya (NPCK 2017) and are also the main cultivars multiplied and distributed by the KALRO seed potato programme. 
Table 1: Potato clones/cultivars used in the potato virus $Y$ (PVY) resistance screening experiments with their parental background, owner, year of official release in Kenya and previously described level of PVY resistance in different potato variety catalogues (CIP 2019; NPCK 2017) where $S=$ susceptible, $M R=$ moderate resistance, $H R=$ hypersensitive resistance, $R=$ resistant and Unknown = without any information on PVY resistance

\begin{tabular}{|c|c|c|c|c|c|}
\hline No. & Genotype & Parentage & Owner & Year of release & Resistance \\
\hline 1 & Kenya Mpya & CIP 387170.16 x CIP 387170.9 & KALRO & 2010 & Unknown \\
\hline 2 & Dutch Robyjn & Rode Star x Preferent & KALRO & 1945 & S \\
\hline 3 & Sherekea & CIP387231.7 x CIP387170.9 & KALRO & 2010 & $\mathrm{HR}$ \\
\hline 4 & Kenya Karibu & CIP 676064 x CIP 800946 & KALRO & 2005 & Unknown \\
\hline 5 & Asante & CIP378493.15 x BK PRECOZ & KALRO & 1998 & Unknown \\
\hline 6 & Tigoni & CIP378493.15 x BK PRECOZ & KALRO & 1998 & Susceptible \\
\hline 7 & Kenya Baraka & SDL.3680 e (18) xSDL. 3070 d (4) & KALRO & 1973 & MR \\
\hline 8 & Kenya Mavuno & CIP $381378.18 \times$ CIP 720084 & KALRO & 2002 & Unknown \\
\hline 9 & Unica & CIP387521.3 X APHRODITE & KALRO & 2017 & $\mathrm{R}$ \\
\hline 10 & Kerr's pink & Fortyfold x Smith's Early & KALRO & 1925 & S \\
\hline 11 & Nyanyo & Unknown & Unknown & Unknown & Unknown \\
\hline 12 & Shangi & Unknown & KALRO & 2015 & Unknown \\
\hline 13 & CIP312086.768 & CIP396311.1 x CIP398203.244 & CIP & Not released & Unknown \\
\hline 14 & CIP314923.69 & Tigoni x CIP398190.615 & CIP & Not released & Unknown \\
\hline 15 & CIP313010.19 & Desiree x CIP398190.735 & CIP & Not released & Unknown \\
\hline 16 & CIP313002.4 & Kenya Mpya x CIP388615.22UN & CIP & Not released & Unknown \\
\hline 17 & CIP313001.279 & Kenya Mpya x Shangi & CIP & Not released & Unknown \\
\hline 18 & CIP313039.199 & Tigoni x CIP397073.7 & CIP & Not released & Unknown \\
\hline 19 & CIP313009.84 & Asante x CIP397073.7 & CIP & Not released & Unknown \\
\hline 20 & CIP312084.731 & CIP392820.1 x CIP398208.219 & CIP & Not released & Unknown \\
\hline 21 & CIP313009.43 & Asante x CIP397073.7 & CIP & Not released & Unknown \\
\hline 22 & CIP314921.104 & Tigoni x CIP399002.52 & CIP & Not released & Unknown \\
\hline 23 & CIP313009.46 & Asante x CIP397073.7 & CIP & Not released & Unknown \\
\hline 24 & CIP314930.72 & Tacna x Meru Mugaruro & CIP & Not released & Unknown \\
\hline 25 & CIP314398.114 & Nyayo x B1C5024.53 & CIP & Not released & Unknown \\
\hline 26 & CIP313028.42 & Nyayo x CIP398201.510 & CIP & Not released & Unknown \\
\hline 27 & CIP312284.737 & LD-57.67 x CIP398208.219 & CIP & Not released & Unknown \\
\hline 28 & CIP313011.28 & Desiree x CIP398298.51 & CIP & Not released & Unknown \\
\hline
\end{tabular}


The CIP clones (No. 13-28 in Table 1), were crosses between some of the major Kenyan cultivars and CIP parental lines with PVY resistance. The clones are at the early generation selection stage of breeding and have not previously been described with respect to their levels of PVY resistance.

All the above genotypes were obtained as in-vitro plantlets from the potato tissue culture laboratory at KALRO Tigoni and were free of the six major potato viruses; potato virus $Y(P V Y)$, potato leaf roll virus (PLRV), potato virus $X(P V X)$, potato virus $M$ (PVM), potato virus $A$ (PVA) and potato virus S (PVS) as tested by double antibody sandwich enzyme linked immune-sorbent assay (DAS-ELISA). PVY strains for screening resistance were identified based on a survey of the PVY strains that occur in the five major potato growing areas in Kenya and where PVY ${ }^{\mathrm{N}-\mathrm{Wi}}$ was the most prevalent PVY strain (Chapter 4 of this thesis). PVYO, also identified from the above survey was included in this study mainly to compare its ability to cause diseases in potato cultivars in relation to PVY ${ }^{\mathrm{N}-\mathrm{Wi}}$. The selected PVY strains were inoculated and maintained in tobacco plants (Nicotiana tabacum, cultivar White Burley) for use in the subsequent PVY resistance screening experiments.

\subsubsection{Screen-house inoculations of PVY in resistance}

In all screen-house experiments (described below), in-vitro potato plantlets were raised in steam sterilized ( $121^{\circ} \mathrm{C}$ for 15 minutes) soil in pots in an aphid proof screen house at KALRO, Tigoni, Kenya. The pots were $3 / 4$ filled with the soil mixed with $10 \mathrm{~g}$ of Di-Ammonium Phosphate (DAP-18-46-0) fertilizer. The plants were inoculated two weeks (4 - 6 leaf stage) after transplanting at a time when the plants had established. Tobacco leaves infected with the PVY strains (as described below in each experiment) were macerated in an ELISA extraction buffer (prepared as described in the ELISA procedure below) in the ratio of $1 \mathrm{~g}$ of leaf tissue to 2 $\mathrm{ml}$ of the buffer. A small amount of Carborundum powder (300 mesh) was sprinkled on the leaves and $100 \mu$ l of PVY inoculum was applied to the leaves of the plant and pressed gently on the leaf to spread the PVY inoculum. Water was applied to wash excess Carborundum from the leaves 5 minutes after inoculation. Sufficient moisture was maintained by daily irrigation throughout the cultivation period. 


\subsubsection{Serological detection of PVY in resistance screening}

All ELISA assays were done using the DAS-ELISA kit, antibodies and instructions as obtained from CIP, Lima, Peru. Wells of the ELISA plates (Thermo Scientific, Denmark) were loaded with $100 \mu$ l of coating solution $(35 \mu l$ of PVY coating antiserum (PVY IgG) in $10 \mathrm{ml}$ of the coating buffer $\left(0.2 \mathrm{~g} \mathrm{Na}_{2} \mathrm{CO}_{3}, 0.44 \mathrm{~g} \mathrm{NaHCO}_{3}\right.$, $0.03 \mathrm{~g} \mathrm{NaN}_{2}$ in $120 \mathrm{ml}$ of distilled water, $\left.\mathrm{pH} 9.6\right)$ and incubated overnight at $4^{\circ} \mathrm{C}$. Washing of the plates were done using a buffer consisting of $8.0 \mathrm{~g} \mathrm{NaCl}, 0.2 \mathrm{~g}$ $\mathrm{KH}_{2} \mathrm{PO}_{4}, 0.2 \mathrm{~g} \mathrm{KCL}, 1.13 \mathrm{~g} \mathrm{NaH}_{2} \mathrm{PO}_{4}, 0.29 \mathrm{~g} \mathrm{NaN}_{2}$ and $0.05 \%$ of Tween 20 in 1 litre of distilled water, $\mathrm{pH} 7.4$ (PBS-T), with a 3 minute soakings between the washes (procedure for all subsequent washings). One gram of leaf material was macerated in $2 \mathrm{ml}$ of ELISA extraction buffer $(4.0 \mathrm{~g}$ PVP-40,000 and $2.0 \mathrm{~g}$ of egg ovalbumine in $200 \mathrm{ml}$ of PBS-T) and then $100 \mu$ of each sample were loaded into the wells in duplicates and incubated overnight at $4^{\circ} \mathrm{C}$. Three positive controls consisting of potato leaf samples previously found infected with PVY in an ELISA test and 6 negative controls consisting those found without PVY in the same test were

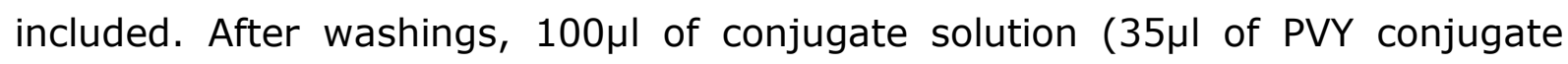
antiserum (PVY IgG-AP) in $10 \mathrm{ml}$ of ELISA extraction buffer) was added to each well and incubated overnight tat $4^{\circ} \mathrm{C}$. Plates were washed and colour development was initiated by incubating the plates with $100 \mu \mathrm{l}$ per well of $15 \mathrm{mg}$ paranitrophenylphosphate (pNPP) in $20 \mathrm{ml}$ substrate buffer ( $97 \mathrm{ml}$ diethanolamine in $1000 \mathrm{ml}$ distilled water, $\mathrm{pH}$ 9.8) at room temperature and incubating for 60 minutes. Absorbance values of the samples were then taken at a wavelength 405 nm using an ELISA reader (Biotek ELX800, Vermont, USA). Positive samples were calculated as those with absorbance values equal or greater than the mean of the negative controls plus three times the standard deviation of the healthy controls. ELISA absorbance values were used to compare OD values in inoculated plants.

\subsubsection{Design of PVY resistance screening experiments}

5.2.4.1 Experiment 1: Comparing levels of cultivar resistance to $P V Y^{N-W i}$ in relation to $P V Y^{O}$

Seven potato cultivars (Asante, Dutch Robyjn, Kenya Mpya, Sherekea, Kenya Karibu, Tigoni and Shangi from among the Kenyan cultivars in Table 1) were arranged in a completely randomized design (CRD) in split plots with six plants per plot in three replications. The main plots were the cultivars while the sub-plots were the two treatments which involved inoculating all plants of each cultivar per 
plot with $\mathrm{PVY}^{\mathrm{O}}$ and another similar set of cultivars with $\mathrm{PVY}^{\mathrm{N}-\mathrm{Wi}}$. Positive and negative controls of inoculated and non-inoculated tobacco indicator plants, cultivar White Burley were included. The plants were maintained in the screenhouse and at 28 days after inoculation (DAI), leaf samples were collected from the third leaf from the top from each of the six plants per plot and tested in ELISA in two composites. Data were collected on the type of symptoms observed and on the severity of symptoms, scored in a scale where, $0=$ no symptom, $1=$ very mild, $2=$ moderately mild, $3=$ moderate, $4=$ severe and $5=$ very severe.

\subsubsection{Experiment 2: Screening for PVY ${ }^{N-W i}$ resistance in a screen-house over} three seasons

This experiment was conducted over three seasons of replanting tubers harvested from the previous season. The same experimental arrangement, management, data collection and ELISA tests were followed in all seasons. The experiment was arranged in a CRD design in split plots where the 12 Kenyan potato cultivars (No.112 in Table 1) were the main plots and the two sub-plots were PVY ${ }^{\mathrm{N}-\mathrm{Wi}^{\mathrm{i}}}$ inoculated plants of each cultivar and another set that were not inoculated. Each plot (treatment) consisted of six plants in three replications. Leaf samples from each of the six plants per plot were tested in ELISA in two composites at 28 DAI. At this time, type of symptoms observed on sampled plants were recorded. Severity of symptoms were scored in a scale where, $0=$ no symptom, $1=$ very mild, $2=$ moderately mild, $3=$ moderate, $4=$ severe and $5=$ very severe. The plants were harvested at full maturity and data were collected on number and weight (Kgs) of tubers per plant. Harvested tubers of each treatment of every cultivar were pooled together and randomly mixed. After sprouting, the tubers were planted for the second season experiment and similarly, tubers harvested from the second season were mixed randomly and were used to plant the third season experiment.

\subsubsection{Experiment 3: Screening for PVYN-Wi resistance in the field over three} seasons

In-vitro plantlets of the 12 local potato cultivars were all (30 plants per cultivar) inoculated with PVY ${ }^{\mathrm{N}-\mathrm{Wi}}$ strain. The inoculated plants were maintained in the screenhouse and at harvest, at least 120 tubers were randomly picked from each lot of 12 cultivars, sprouted and used to plant the first season field experiment at KALRO Tigoni. Tubers harvested from each cultivar were thoroughly mixed and 120 tubers were selected randomly, sprouted and used to plant the second seasons trial and 
similarly tubers of the second season trial were used to plant a third season trial. Over the three seasons, the same experimental arrangement, management, data collection and ELISA tests were followed. The first season trial was conducted during long rains (April-July) 2017, the second season during short rains (September -November) 2017 and third season during long rains 2018.

The trials were planted in Randomized Complete Block Design (RCBD) in three replications with 40 plants per plot at a spacing of $0.77 \mathrm{~m} \times 0.3 \mathrm{~m}$ and each plot measured $3 \mathrm{~m} \times 3 \mathrm{~m}\left(9 \mathrm{~m}^{2}\right)$ with $1.0 \mathrm{~m}$ distance between the plots. The tubers were planted with 100 grammes per plant of Di-Ammonium Phosphate (DAP-1846-0) fertilizer (Lung'aho et al. 2007). The crop was sprayed with insecticides to control virus vectors (aphids) and minimize virus transmission during the cropping period using locally recommended doses of insecticide, Marshal 250 EC (50 ml / 20 litres of Carbosulfan 20\%) at 2-week intervals (or at every appearance of aphids). Late blight (Phytophthora infestants) infection in the crop was controlled using fungicides (Dithane M45, wettable powder $80 \%$ mancozeb; $2.0 \mathrm{~g} / \mathrm{l}$ at emergence and Ridomil gold, wettable powder 64\% mancozeb; 4\% metalaxil; 2.5 $\mathrm{g} / \mathrm{I}$ ) at every appearance of the first symptom. Weeding was done at emergence and was followed by earthing up just before flowering (Lung'aho et al. 2007). At 45 days after planting, eight plants from the middle rows of each plot were sampled (third leaf from the top) and tested in ELISA in two composites of four plants each. Type of symptoms observed in the sampled plants were recorded. Severity of symptoms were scored in a scale where, $0=$ no symptom, $1=$ very mild, $2=$ moderately mild, $3=$ moderate, $4=$ severe and $5=$ very severe. Harvesting was done at full maturity of the plants and data were collected on number and weight (Kgs) of tubers per plant.

5.2.4.4 Experiment 4: Screening for PVYN-Wi resistance in early generation potato clones

Early generation potato clones (No.13-28 in Table 1 ) were arranged in CRD in three replications consisting of 6 plants per plot. All the plants were inoculated with PVYN-Wi strain and maintained in the screen-house for one season. In addition to the clones, cultivar Sherekea was used as a PVY ${ }^{\mathrm{N}-\mathrm{Wi}}$ resistant control and similarly Dutch Robyn and Kenya Mpya as susceptible controls. After inoculations, the plants were maintained in the screen-house until 28 days DAI when leaf samples were collected from each of the six plants per plot (third leaf from the 
top). ELISA tests were conducted on all the six plants in two composites. Data were collected on the type of symptoms observed and on the severity of symptoms, scored in a scale where, $0=$ no symptom, $1=$ very mild, $2=$ moderately mild, $3=$ moderate, $4=$ severe and $5=$ very severe.

\subsubsection{Data analysis}

All data collected on ELISA OD values and the number and weight of tubers from the experiments were subjected to analysis of variance (ANOVA) using General statistics (GENSTAT) software to generate means. The differences between the means were compared using least significant difference at LSD 0.05 (Steel and Torrie, 1980).

\subsection{Results}

\subsubsection{Comparing levels of cultivar resistance to $P V Y^{N-W i}$ in relation to PVYo}

Seven potato cultivars were inoculated in a screen-house sap inoculation experiment with $\mathrm{PVY}^{\mathrm{N}-\mathrm{Wi}}$ and compared with a similar set of cultivars inoculated with $\mathrm{PVY}^{\circ}$ and compared in its ELISA OD values and type and severity of symptoms as summarised in Table 2. Cultivars Kenya Karibu and Sherekea were found not infected with both $\mathrm{PVY}^{\circ}$ and $\mathrm{PVY}^{\mathrm{N}-\mathrm{Wi}}$ at $28 \mathrm{DAI}$. These two cultivars were also not observed with symptoms both in $\mathrm{PVY}^{\mathrm{O}}$ and $\mathrm{PVY} \mathrm{N}^{\mathrm{N}-\mathrm{Wi}}$ inoculated plants. Cultivar Shangi was infected with PVYN-Wi but not PVYO based on the ELISA test. The cultivar did not show symptoms in both cases where it was inoculated with any of the two PVY strains. Similarly, Asante was also infected with PVYN-Wi and not PVYO but only half of the samples tested positive. The rest of the cultivars, Tigoni, Dutch Robyjn and Kenya Mpya were all found be infected by each of the two PVY strains. Among these three cultivars, the ELISA OD values were lowest in cultivar Tigoni followed by Dutch Robyjn and was highest in Kenya Mpya for each of the two PVY strains. PVYN-Wi inoculated plants of cultivars Dutch Robyjn and Kenya Mpya showed significantly $(P \leq 0.05)$ higher ELISA OD values compared to those inoculated with $P V Y^{\circ}$. There were also higher OD values in $\mathrm{PVY}^{\mathrm{N}-\mathrm{Wi}_{\mathrm{i}}}$ inoculated plants as compared to those inoculated with $\mathrm{PVY}^{\mathrm{O}}$ in cultivars Shangi, Asante and Tigoni but the differences were not significant $(P \leq 0.05)$ and the virus titres were very low. No plants inoculated with $\mathrm{PVY}^{\circ}$ were observed with symptoms but those inoculated with PVYN-Wi were found with mosaic and leaf wrinkle symptoms, particularly for 
cultivars Kenya Mpya and Dutch Robyjn (ranked as $4=$ severe) as compared to those inoculated with $\mathrm{PVY}^{\circ}$ (ranked as $2=$ moderately mild).

Table 2: Reactions of seven Kenyan potato cultivars to mechanical inoculation of PVY ${ }^{N-W i}$ in comparison to $\mathrm{PVY}^{\mathrm{O}}$ where $n s=$ no significant difference and $*=$ significant difference $(P \leq 0.05)$. Severity of symptoms, $0=$ no symptom, $1=$ very mild, $2=$ moderately mild, $3=$ moderate, $4=$ severe and $5=$ very severe,$+=P V Y$ detected and $-=P V Y$ not detected and $+/-=P V Y$ was not detected in all samples tested, $P C=$ positive control, $N C=$ negative control, Healthy $=$ no visible symptoms, $M=$ mosaic, $W r=$ wrinkle and $V n=$ veinal necrosis

\begin{tabular}{|c|c|c|c|c|c|c|c|c|}
\hline \multirow[t]{2}{*}{ Cultivar } & \multicolumn{2}{|c|}{ ELISA OD values } & \multicolumn{2}{|c|}{ Infection } & \multicolumn{2}{|c|}{$\begin{array}{c}\text { Symptom } \\
\text { score }\end{array}$} & \multicolumn{2}{|c|}{ Symptoms } \\
\hline & $\begin{array}{l}\mathrm{PVY} \\
\mathrm{N}-\mathrm{Wi}\end{array}$ & $\begin{array}{c}\text { PVY } \\
\text { O }\end{array}$ & $\begin{array}{l}\text { PVY } \\
\text { N-Wi }\end{array}$ & $\begin{array}{c}\text { PVY } \\
\text { O }\end{array}$ & $\begin{array}{l}\mathrm{PVY} \\
\mathrm{N}-\mathrm{Wi}\end{array}$ & $\begin{array}{c}\text { PVY } \\
\text { O }\end{array}$ & $\begin{array}{l}\mathrm{PVY} \\
\mathrm{N}-\mathrm{Wi}\end{array}$ & $\begin{array}{c}\text { PVY } \\
0\end{array}$ \\
\hline Kenya Karibu & $0.052 \mathrm{~ns}$ & 0.051 & - & - & 0 & 0 & Healthy & Healthy \\
\hline Sherekea & $0.056 n s$ & 0.052 & - & - & 0 & 0 & Healthy & Healthy \\
\hline Shangi & $0.104 \mathrm{~ns}$ & 0.080 & + & - & 0 & 0 & Healthy & Healthy \\
\hline Asante & $0.114 \mathrm{~ns}$ & 0.091 & + & $+/-$ & 0 & 0 & Healthy & Healthy \\
\hline Tigoni & $0.122 \mathrm{~ns}$ & 0.096 & + & + & 0 & 0 & Healthy & Healthy \\
\hline Dutch Robyjn & $1.871^{*}$ & 0.719 & + & + & 4 & 2 & $\mathrm{M}$ and $\mathrm{Wr}$ & Healthy \\
\hline Kenya Mpya & $2.038 *$ & 0.716 & + & + & 4 & 2 & $\mathrm{M}$ and $\mathrm{Wr}$ & Healthy \\
\hline NC-Tobacco & $0.049 \mathrm{~ns}$ & 0.051 & - & - & 0 & 0 & Healthy & Healthy \\
\hline PC-Tobacco & $2.537 *$ & 0.734 & + & + & 4 & 2 & $\mathrm{M}, \mathrm{Vn}$ and $\mathrm{Wr}$ & M \\
\hline
\end{tabular}

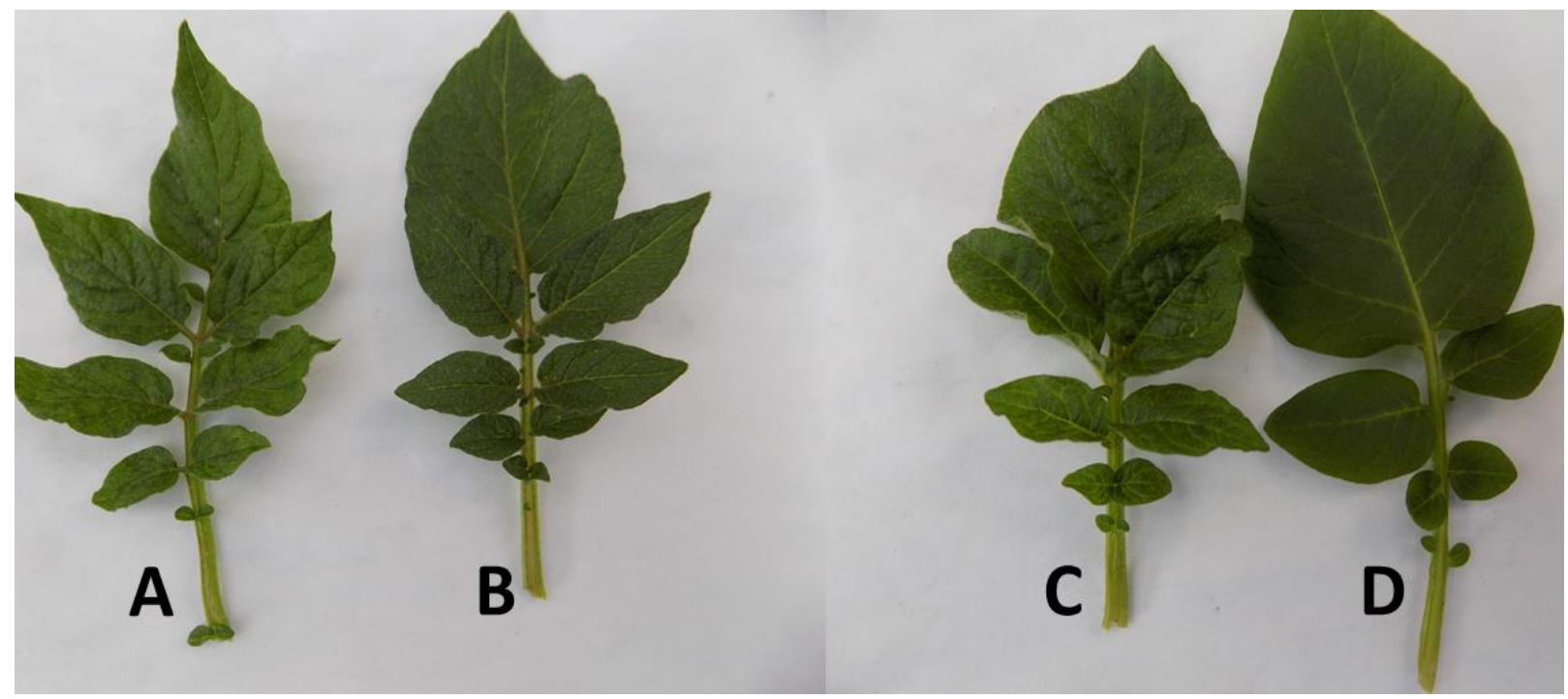

Fig. 1: Leaf symptoms of two PVY susceptible potato cultivars upon inoculation with $P V Y^{N-W i}, A=$ Cultivar Dutch Robyjn with moderate mosaic and wrinkle symptoms resulting from inoculation of the plants with PVYN-Wi strain, $B=$ Dutch Robyjn not inoculated (healthy control), $C=$ Cultivar Kenya Mpya with moderate mosaic and wrinkle symptoms resulting from inoculation of the plants with $P V Y^{N-W i}$ strain and $D=$ Kenya Mpya not inoculated (healthy control) 


\subsubsection{Screening for $P V Y^{N-W i}$ resistance in a screen-house over three seasons}

Twelve Kenyan potato cultivars were evaluated in a screen-house experiment over three consecutive seasons of replanting tubers. Differences in weight (Kgs) of tubers, number of tubers per plant, ELISA OD values and severity of symptoms between PVY ${ }^{\mathrm{N}-W \mathrm{i}}$ infected plants and non-infected plants were compared (Table 3 ). Over the three seasons PVY ${ }^{\mathrm{N}-\mathrm{Wi}}$ was not detected in the three cultivars Sherekea, Unica and Kenya Karibu. The cultivars were not found with virus symptoms. There was no significant difference $(P \leq 0.05)$ in number and weight of tubers between $\mathrm{PVY}^{\mathrm{N}-\mathrm{Wi}}$ inoculated plants and non-inoculated plants of these cultivars.

Shangi was infected with PVY ${ }^{\mathrm{N}-\mathrm{Wi}}$ after inoculation though over the seasons but ELISA OD values were low to a level that PVY was not detected in some samples. There was also no significant $(P \leq 0.05)$ decrease in the weight and number of tubers of PVYN-Wi inoculated plants of this cultivar. Virus symptoms were not observed in this cultivar over the three seasons.

PVYN-Wi infection in cultivars Kenya Mavuno, Kenya Baraka, Asante, Tigoni and Kerr's Pink were symptomless. Among these cultivars, PVYN-Wi infection caused yield losses in cultivar Asante $(18.5 \%$ and $23.8 \%$ by the end of second and the third season respectively) and also a reduction in the number of tubers per plant from 4.9 to 4.1 in comparison with healthy controls. In Kenya Baraka, there was a yield loss of $11.7 \%$ but only by the end of the second season.

There was a significant $(P \leq 0.05)$ increase in the ELISA OD values coupled with a corresponding decrease in weight and number of tubers over the three seasons in cultivars Dutch Robyjn and Kenya Mpya. Characteristic PVY ${ }^{\mathrm{N}-\mathrm{Wi}}$ symptoms observed in these two cultivars under the screen-house conditions were basically mosaic and wrinkle on the leaves. Severity of the symptoms increased from very mild during the first season to moderate (Fig. 1) in the second season to very severe during the third season. PVY ${ }^{\mathrm{N}-\mathrm{Wi}}$ infection contributed to a yield loss of $21.2 \%, 33.3 \%$ and $57.1 \%$ in Dutch Robyjn and $16.5 \%, 53.6 \%$ and $78.0 \%$ in Kenya Mpya by the end of the first, second and third season respectively when compared to non-inoculated plants. Even though Nyayo was infected and had increasing ELISA OD values and symptoms severity over seasons, there was no significant yield loss in this cultivar over the seasons. None of the tubers harvested for the 12 cultivars showed 
symptom of tuber necrotic ring spot diseases (PTNRD) over the three consecutive seasons.

\subsubsection{Screening for $P V Y^{N-W i}$ resistance in the field over three seasons}

Twelve potato cultivars (initially planted using tubers harvested from in-vitro potato plants inoculated with $\mathrm{PVY}^{\mathrm{N}-\mathrm{Wi}}$ ) were re-planted in a standard field trial for three consecutive seasons. The results of the ELISA tests, types of symptoms and severity of symptom at 45 days after planting and number and weight of tubes harvested are summarised in Table 4. PVY was not detected in four cultivars (Unica, Sherekea, Kenya Karibu and Kenya Mavuno). There were no significant ( $P$ $\leq 0.05)$ reductions in their number of tubers per plant and yield of tubers $(\mathrm{T} / \mathrm{Ha})$ over the three seasons. No PVY symptoms were observed in any of the plants in the plots with these cultivars. Two of these cultivars, Sherekea (37.3T/Ha) and Unica (35.1 T/Ha) were found with significant $(P \leq 0.05)$ higher yields than the rest of the cultivars by the end of the third season.

PVYN-Wi infection did not cause yield losses over the three seasons in cultivars Tigoni, Shangi and Kenya Baraka. In these cultivars, PVY infection was found with very low titres and the plants showed no PVY symptoms. Symptomless PVY infections were also observed in cultivar Asante which showed increasing ELISA OD values and corresponding significant $(P \leq 0.05)$ yield loss of $13.9 \%$ by the end of the third season.

PVY symptoms were found only in three cultivars, Nyayo, Kenya Mpya and Dutch Robyjn. The characteristic PVY symptoms in Dutch Robyjn and Kenya Mpya were mosaic during the first and the second seasons and mosaic, crinkled leaves, stunted growth and leaf necrosis spreading to the stems in the third season (Fig. 2). Leaf mosaic was the only PVY symptom observed in cultivar Nyayo (Fig.2). The increase in symptom severity over the seasons was coupled to an increase in ELISA $O D$ values and a corresponding reduction in the number and weight of tubers per plant. Percentage yield loss was calculated from the difference in the weight of tubers per plant between the first and the third seasons. There were significant ( $P$ $\leq 0.05$ ) yield losses of $21.6 \%$ in Dutch Robyjn, $39.0 \%$ in Nyayo and $53.1 \%$ in Kenya Mpya. As a result, the yields were lowest in Nyayo, Kenya Mpya, Dutch Robyjn with $14.4 \mathrm{~T} / \mathrm{Ha}, 18.4 \mathrm{~T} / \mathrm{Ha}$ and $21.8 \mathrm{~T} / \mathrm{Ha}$ respectively by the end of the third season. 
Table 3: Screening for potato virus $Y\left(P V Y^{N-W i}\right)$ resistance in 12 Kenyan potato cultivars in the screen-house over 3 seasons where ns $=$ no significant difference and $*=$ significant difference $(P \leq 0.05)$ from previous season, $\neq=$ Significant difference $(P \leq 0.05)$ between the $P V Y^{N-W i}$ infected plants $($ Wi) and their respective healthy controls (HC). Severity of symptoms, $0=$ no symptom, $1=$ very mild, $2=$ moderately mild, $3=$ moderate, $4=$ severe and $5=$ very severe,$+=$ PVY detected and $-=$ PVY not detected and $+/-=$ PVY was not detected in all samples tested, healthy $=$ no visible symptoms, $M=$ mosaic,$W r=$ wrinkle, $\#$ tubers $/$ plant $=$ mean number of tubers per plant and $\%$ loss $=$ Percentage yield loss between the PVYN-Wi inoculated plants and their respective healthy controls by the end of every season

\begin{tabular}{|c|c|c|c|c|c|c|c|c|c|c|c|c|}
\hline \multirow[t]{2}{*}{ Cultivar } & \multirow[t]{2}{*}{ Season } & \multicolumn{2}{|c|}{ Weight/plant (Kg) } & \multicolumn{2}{|c|}{ \# tubers/plant } & \multirow[t]{2}{*}{$\%$ loss } & \multicolumn{2}{|c|}{ ELISA OD values } & \multirow[t]{2}{*}{ Infection } & \multicolumn{2}{|c|}{ Severity score } & \multirow[t]{2}{*}{ Symptoms } \\
\hline & & $\mathrm{HC}$ & $\mathrm{Wi}$ & $\mathrm{HC}$ & $\mathrm{Wi}$ & & $\mathrm{HC}$ & $\mathrm{Wi}$ & & $\mathrm{HC}$ & Wi & \\
\hline \multirow[t]{3}{*}{ Sherekea } & 1 & 0.78 & 0.82 & 13.6 & 12.7 & -5.1 & 0.045 & 0.046 & - & 0 & 0 & Healthy \\
\hline & 2 & 0.84 & 0.79 & 13.8 & 13.0 & 6.0 & 0.046 & 0.046 & - & 0 & 0 & Healthy \\
\hline & 3 & 0.80 & 0.83 & 13.4 & 13.6 & -3.7 & 0.045 & 0.046 & - & 0 & 0 & Healthy \\
\hline \multirow[t]{3}{*}{ Unica } & 1 & 0.80 & 0.82 & 6.1 & 6.1 & -2.5 & 0.048 & 0.045 & - & 0 & 0 & Healthy \\
\hline & 2 & 0.82 & 0.77 & 6.2 & 6.3 & 6.1 & 0.045 & 0.050 & - & 0 & 0 & Healthy \\
\hline & 3 & 0.81 & 0.80 & 5.9 & 6.4 & 1.2 & 0.046 & 0.046 & - & 0 & 0 & Healthy \\
\hline \multirow[t]{3}{*}{ Kenya Karibu } & 1 & 0.88 & 0.83 & 7.9 & 7.9 & 5.7 & 0.051 & 0.049 & - & 0 & 0 & Healthy \\
\hline & 2 & 0.82 & 0.83 & 8.1 & 8.1 & -1.2 & 0.046 & 0.051 & - & 0 & 0 & Healthy \\
\hline & 3 & 0.84 & 0.85 & 7.8 & 8.1 & -1.2 & 0.047 & 0.046 & - & 0 & 0 & Healthy \\
\hline \multirow[t]{3}{*}{ Shangi } & 1 & 0.79 & 0.78 & 7.7 & 7.3 & 1.3 & 0.046 & 0.078 & $+/-$ & 0 & 0 & Healthy \\
\hline & 2 & 0.80 & 0.82 & 7.5 & 7.8 & -2.5 & 0.047 & 0.075 & $+/-$ & 0 & 0 & Healthy \\
\hline & 3 & 0.80 & 0.78 & 7.9 & 7.9 & 2.5 & 0.046 & 0.083 & $+/-$ & 0 & 0 & Healthy \\
\hline \multirow[t]{3}{*}{ Kenya Mavuno } & 1 & 0.70 & 0.71 & 6.2 & 6.5 & -1.4 & 0.049 & 0.085 & - & 0 & 0 & Healthy \\
\hline & 2 & 0.78 & 0.75 & 6.4 & 6.4 & 3.8 & 0.048 & $0.107 \neq$ & + & 0 & 0 & Healthy \\
\hline & 3 & 0.76 & 0.79 & 6.7 & 6.1 & -3.9 & 0.047 & $0.295 * \ddagger$ & + & 0 & 0 & Healthy \\
\hline \multirow[t]{3}{*}{ Kenya Baraka } & 1 & 0.57 & 0.58 & 6.4 & 6.6 & -1.8 & 0.045 & $0.113 \neq$ & + & 0 & 0 & Healthy \\
\hline & 2 & 0.60 & $0.53 \neq$ & 6.4 & 6.6 & 11.7 & 0.046 & $0.275^{*} \ddagger$ & + & 0 & 0 & Healthy \\
\hline & 3 & 0.57 & $0.52 *$ & 6.2 & 6.2 & 8.8 & 0.052 & $0.307 * \neq$ & + & 0 & 0 & Healthy \\
\hline \multirow[t]{3}{*}{ Asante } & 1 & 0.63 & 0.63 & 6.2 & 5.5 & 0.0 & 0.044 & $0.676 \neq$ & + & 0 & 0 & Healthy \\
\hline & 2 & 0.65 & 0.53 & 6.2 & $4.9 \neq$ & 18.5 & 0.047 & $0.915^{*} \neq$ & + & 0 & 0 & Healthy \\
\hline & 3 & 0.63 & $0.48^{*} \neq$ & 6.3 & $4.1 * \neq$ & 23.8 & 0.051 & $1.351 * \neq$ & + & 0 & 0 & Healthy \\
\hline \multirow[t]{3}{*}{ Tigoni } & 1 & 0.56 & 0.59 & 6.7 & 7.1 & -5.4 & 0.046 & $0.155 \neq$ & + & 0 & 0 & Healthy \\
\hline & 2 & 0.53 & 0.53 & 6.9 & 6.9 & 0.0 & 0.046 & 0.110 & + & 0 & 0 & Healthy \\
\hline & 3 & 0.55 & 0.56 & 6.7 & 6.9 & -1.8 & 0.046 & 0.108 & + & 0 & 0 & Healthy \\
\hline \multirow{3}{*}{ K. Pink } & 1 & 0.35 & 0.39 & 2.4 & 2.6 & -11.4 & 0.051 & 0.375 ₹ & + & 0 & 0 & Healthy \\
\hline & 2 & 0.36 & 0.36 & 2.2 & 2.2 & 0.0 & 0.047 & $1.297 * \neq$ & + & 0 & 0 & Healthy \\
\hline & 3 & 0.33 & 0.33 & 2.3 & 2.4 & 0.0 & 0.048 & $1.716 * \neq$ & + & 0 & 0 & Healthy \\
\hline \multirow{3}{*}{ Nyanyo } & 1 & 0.48 & 0.51 & 9.9 & 9.9 & -6.3 & 0.045 & $1.073 \neq$ & + & 0 & 0 & M \\
\hline & 2 & 0.47 & 0.45 & 10.1 & 9.5 & 4.3 & 0.047 & $1.262 \neq$ & + & 0 & 2 & M \\
\hline & 3 & 0.46 & 0.45 & 10.7 & 9.9 & 2.2 & 0.047 & $1.264 * \neq$ & + & 0 & 3 & M \\
\hline \multirow{3}{*}{ Dutch Robyjn } & 1 & 0.52 & $0.41 \neq$ & 4.9 & 5.1 & 21.2 & 0.046 & $1.497 \neq$ & + & 0 & 1 & $\mathrm{M}$ and $\mathrm{Wr}$ \\
\hline & 2 & 0.51 & $0.34 * \neq$ & 4.3 & $3.8^{*}$ & 33.3 & 0.044 & $2.436 * \ddagger$ & + & 0 & 3 & $\mathrm{M}$ and $\mathrm{Wr}$ \\
\hline & 3 & 0.49 & $0.21 * \neq$ & 4.4 & $1.9 * \neq$ & 57.1 & 0.046 & $3.186 * \neq$ & + & 0 & 5 & $\mathrm{M}$ and $\mathrm{Wr}$ \\
\hline \multirow[t]{3}{*}{ Kenya Mpya } & 1 & 0.85 & 0.71 & 5.6 & 3.9 & 16.5 & 0.045 & $1.450 \neq$ & + & 0 & 1 & $\mathrm{M}$ and $\mathrm{Wr}$ \\
\hline & 2 & 0.83 & $0.39 * \neq$ & 5.3 & $2.2^{*} \neq$ & 53.0 & 0.050 & $2.350 * \ddagger$ & + & 0 & 3 & $\mathrm{M}$ and $\mathrm{Wr}$ \\
\hline & 3 & 0.82 & $0.18^{*} \neq$ & 5.0 & $0.8^{*} \neq$ & 78.0 & 0.049 & $3.566 * \neq$ & + & 0 & 5 & $\mathrm{M}$ and $\mathrm{Wr}$ \\
\hline LSD (0.05) & & $\mathrm{ns}$ & 0.05 & $\mathrm{~ns}$ & 0.8 & & $\mathrm{~ns}$ & 0.102 & & & & \\
\hline
\end{tabular}


Table 4: Yield loss and potato virus $Y\left(P V Y^{N-W i}\right)$ infections in 12 cultivars planted in the field over three consecutive seasons after inoculation with the virus where $\mathrm{Cr}=$ crinkle, $M=$ mosaic, $\mathrm{St}=$ stunted, healthy $=$ no visible symptoms and Nec $=$ necrotic symptoms, severity of symptoms score, $0=$ no symptom, $1=$ very mild, $2=$ moderately mild, $3=$ moderate, $4=$ severe and $5=$ very severe, $+=$ PVY detected and $-=$ PVY not detected and $*=$ Significant difference $(P \leq 0.05)$ with the previous season

\begin{tabular}{|c|c|c|c|c|c|c|c|c|}
\hline Cultivar & Season & $\begin{array}{l}\text { ELISA OD } \\
\text { value }\end{array}$ & Infection & $\begin{array}{c}\text { No.of } \\
\text { tubers/plant }\end{array}$ & Yield $(\mathrm{T} / \mathrm{Ha})$ & $\%$ yield loss & Severity Symptom score & Symptoms \\
\hline \multirow{3}{*}{ Sherekea } & 1 & 0.046 & - & 14.5 & 36.8 & & 0 & Healthy \\
\hline & 2 & 0.045 & - & 13.0 & 36.7 & & 0 & Healthy \\
\hline & 3 & 0.045 & - & 13.7 & 37.3 & -1.4 & 0 & Healthy \\
\hline \multirow[t]{3}{*}{ Kenya Karibu } & 1 & 0.050 & - & 7.5 & 26 & & 0 & Healthy \\
\hline & 2 & 0.047 & - & 8.8 & 27.5 & & 0 & Healthy \\
\hline & 3 & 0.048 & - & 8.2 & 25.9 & 0.4 & 0 & Healthy \\
\hline \multirow{3}{*}{ Tigoni } & 1 & 0.148 & + & 9.2 & 29.1 & & 0 & Healthy \\
\hline & 2 & 0.146 & + & 9.1 & 31.4 & & 0 & Healthy \\
\hline & 3 & 0.141 & + & 9.5 & 28.7 & 1.4 & 0 & Healthy \\
\hline \multirow[t]{3}{*}{ Unica } & 1 & 0.047 & - & 7.1 & 35.8 & & 0 & Healthy \\
\hline & 2 & 0.048 & - & 6.8 & 33.9 & & 0 & Healthy \\
\hline & 3 & 0.047 & - & 7.7 & 35.1 & 2.0 & 0 & Healthy \\
\hline \multirow[t]{3}{*}{ Shangi } & 1 & 0.121 & + & 8.9 & 35.6 & & 0 & Healthy \\
\hline & 2 & 0.113 & + & 9.3 & 34.2 & & 0 & Healthy \\
\hline & 3 & 0.141 & + & 8.4 & 34.7 & 2.5 & 0 & Healthy \\
\hline \multirow[t]{3}{*}{ Kenya Mavuno } & 1 & 0.049 & - & 6.5 & 21.8 & & 0 & Healthy \\
\hline & 2 & 0.047 & - & 6.5 & 21.2 & & 0 & Healthy \\
\hline & 3 & 0.044 & - & 6.6 & 20.8 & 4.6 & 0 & Healthy \\
\hline \multirow[t]{3}{*}{ Kerr's pink } & 1 & 0.110 & + & 3.7 & 17.4 & & 0 & Healthy \\
\hline & 2 & 0.224 & + & 3.3 & 17.5 & & 0 & Healthy \\
\hline & 3 & 0.207 & + & 3.0 & 15.6 & 10.3 & 0 & Healthy \\
\hline \multirow{3}{*}{ Kenya Baraka } & 1 & 0.147 & + & 4.9 & 19.4 & & 0 & Healthy \\
\hline & 2 & 0.163 & + & 4.3 & 18.0 & & 0 & Healthy \\
\hline & 3 & 0.190 & + & 4.4 & 17.0 & 12.4 & 0 & Healthy \\
\hline \multirow[t]{3}{*}{ Asante } & 1 & 0.133 & + & 5.5 & 30.3 & & 0 & Healthy \\
\hline & 2 & $0.296 *$ & + & 6.5 & $25.7 *$ & & 0 & Healthy \\
\hline & 3 & $0.387 *$ & + & 7.3 & $26.1 *$ & 13.9 & 0 & Healthy \\
\hline \multirow{3}{*}{ Dutch Robyjn } & 1 & 0.118 & + & 7.3 & 27.8 & & 0 & mosaic \\
\hline & 2 & $0.588^{*}$ & + & 5.6 & 23.6 & & 1 & mosaic \\
\hline & 3 & $1.487 *$ & + & 6.3 & $21.8^{*}$ & 21.6 & 2 & $\mathrm{Cr}, \mathrm{St}, \mathrm{M}, \mathrm{Nec}$ \\
\hline \multirow{3}{*}{ Nyanyo } & 1 & 0.163 & + & 10.6 & 23.6 & & 1 & $M$ \\
\hline & 2 & $1.108 *$ & + & 9.6 & $17.1^{*}$ & & 2 & $M$ \\
\hline & 3 & $2.017 *$ & + & $7.3 *$ & $14.4 *$ & 39.0 & 3 & $M$ \\
\hline \multirow[t]{3}{*}{ Kenya Mpya } & 1 & 0.408 & + & 4.6 & 39.2 & & 1 & mosaic \\
\hline & 2 & $1.032 *$ & + & 4.5 & $27.6 *$ & & 2 & mosaic \\
\hline & 3 & $1.507 *$ & + & $3.1 *$ & $18.4 *$ & 53.1 & 3 & $\mathrm{Cr}, \mathrm{St}, \mathrm{M}, \mathrm{Nec}$ \\
\hline
\end{tabular}




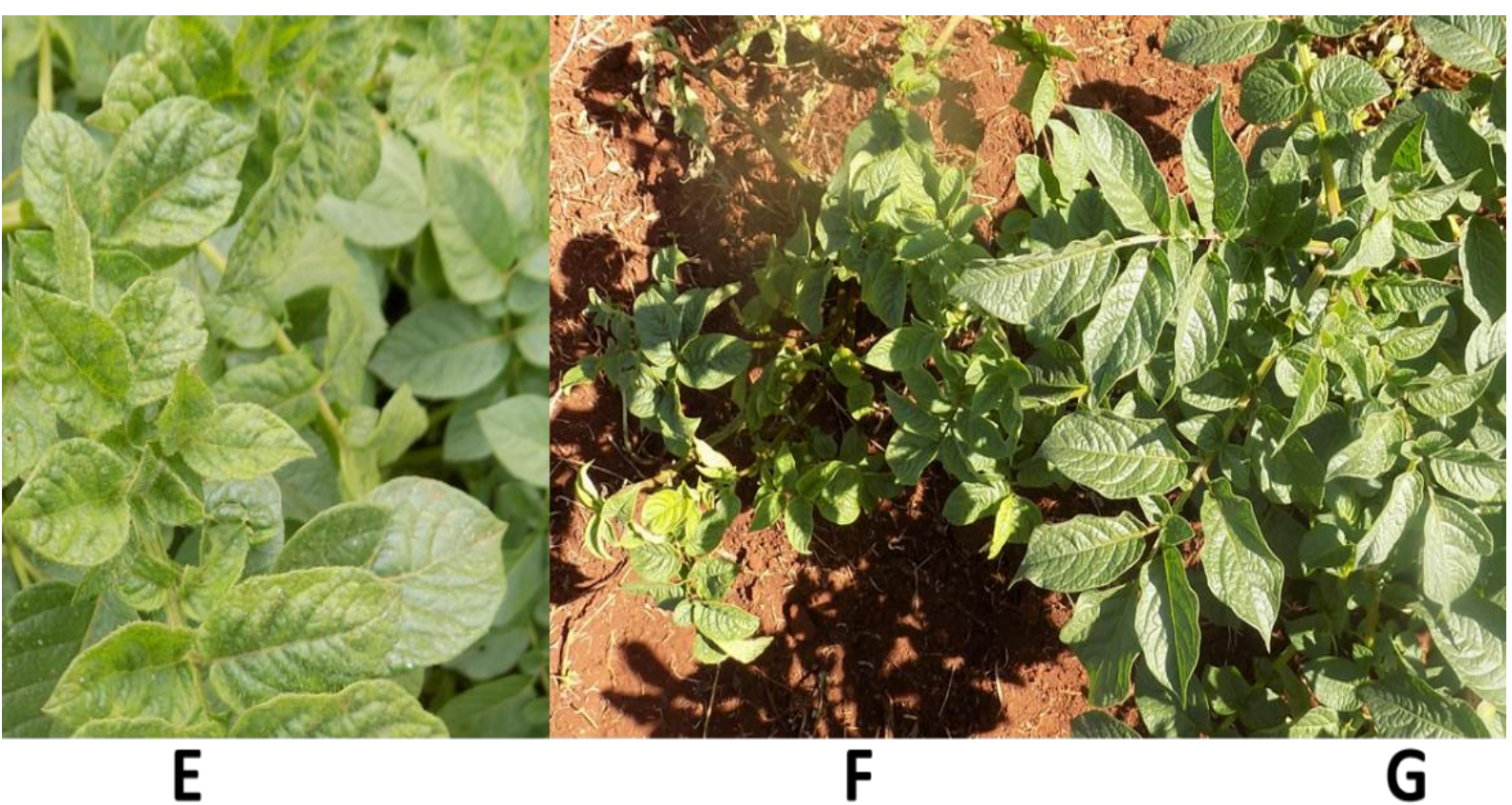

Fig 2: Characteristic field symptoms of potato virus $Y\left(P V Y^{N-W i}\right)$ in cultivars Dutch Robyjn and Nyayo, $E=$ Nyayo infected with PVYN-Wi and showing mosaic symptoms, $F=P V Y^{N-W i}$ infected Dutch Robyjn in the field with stunted growth, mosaic, crinkled leaves with leaf veinal and stem necrosis observed during the third season of evaluation and $G=$ Dutch Robyjn without PVYN-Wi infection in the field

\subsubsection{Screening for $P V Y^{N-W i}$ resistance in early generation potato clones}

Seventeen early generation potato clones obtained from the breeding program of CIP were subjected to sap inoculation with PVYN-Wi. ELISA test results (conducted for one season) on leaf samples and symptoms observed at 28 DAI were used to identify genotypes with resistance to this PVY strain (Table 5). Two clones (CIP312284.737 and CIP313028.42) were found to be resistant to PVYN-Wi because they were found free of PVY in ELISA and they also did not show any symptoms. PVYN-Wi infected plants of CIP313011.28, CIP313009.46, CIP314398.114, CIP314930.72 and CIP314923.69 were symptomless while the rest of the clones produced mild mosaic symptoms upon infection with $\mathrm{PVY}^{\mathrm{N}-\mathrm{Wi}}$. 
Table 5: Screening for potato virus $Y\left(P V Y^{N-W i}\right)$ resistance in early generation CIP potato clones where $M=$ mosaic, severity of symptoms score, $0=$ no symptom, $1=$ very mild, $2=$ moderately mild, $3=$ moderate, $4=$ severe and $5=$ very severe,$+=P V Y$ detected and $-=$ PVY not detected

\begin{tabular}{lllll}
\hline Cultivar/clone & $\begin{array}{l}\text { ELISA OD } \\
\text { values }\end{array}$ & Infection & $\begin{array}{l}\text { Symptom } \\
\text { score }\end{array}$ & Symptoms \\
\hline CIP312284.737 & 0.046 & - & 0 & Healthy \\
Sherekea & 0.046 & - & 0 & Healthy \\
CIP313028.42 & 0.047 & - & 0 & Healthy \\
Kenya Mpya-NC & 0.047 & - & 0 & Healthy \\
Sherekea-NC & 0.048 & - & 0 & Healthy \\
Dutch Robyjn-NC & 0.049 & - & 0 & Healthy \\
CIP313011.28 & 0.117 & + & 0 & Healthy \\
CIP313009.46 & 0.136 & + & 0 & Healthy \\
CIP314398.114 & 0.224 & + & 0 & Healthy \\
CIP314930.72 & 0.254 & + & 0 & Healthy \\
CIP314923.69 & 0.518 & + & 0 & Healthy \\
CIP312086.768 & 0.564 & + & 1 & Mosaic \\
CIP314921.104 & 0.647 & + & 1 & Mosaic \\
CIP313001.279 & 0.657 & + & 1 & Mosaic \\
CIP313010.19 & 0.668 & + & 1 & Mosaic \\
CIP313002.4 & 0.672 & + & 1 & Mosaic \\
CIP313039.199 & 0.788 & + & 2 & Mosaic \\
CIP313009.84 & 0.801 & + & 2 & Mosaic \\
CIP312084.731 & 0.897 & + & 2 & Mosaic \\
CIP313009.43 & 0.933 & + & 2 & Mosaic \\
Dutch Robyjn & 1.046 & + & 2 & Mosaic \\
Kenya Mpya & 1.075 & + & 2 & Mosaic \\
\hline LSD (0.05) & 0.208 & & & \\
\hline
\end{tabular}

\subsection{Discussions and conclusions}

There is evidence that PVY has been a problem in the Kenyan potato production system as early as the 1940's (Bock and Robertson, 1976). More recent surveys indicate that PVY is still a problem with high prevalences of $77.6 \%$ (Gildemacher et al. 2009), $70.0 \%$ (Muthomi et al. 2009) and 27.0\% (Nyamwamu et al. 2014) in the major potato growing areas. In a recent survey for PVY strains in Kenya, PVY ${ }^{\mathrm{N}}$ ${ }^{\text {Wi }}$ was found to be the most prevalent PVY strain in cultivars grown in the major potato growing counties (see Chapter 4 of this thesis). In different countries and continents in the world, there are reports of variations in the prevalence rates of the different PVY strains which have also been changing over time with $\mathrm{PVY}^{\mathrm{N}-\mathrm{Wi}}$ and PVYNTN being being most widespread. These changes and differences in PVY strain populations need to be incorporated in setting local breeding objectives by giving greater priority to the most prevalent PVY strains and to the strains causing greater yield losses. The resistance screening in this study was therefore mainly based on 
this survey by utilizing $\mathrm{PVY}^{\mathrm{N}-\mathrm{Wi}}$ to screen for PVY resistance in Kenyan potato cultivars.

The first experiment set out to compare $P V Y^{N-W i}$ and $P V Y^{O}$ in their ability to infect and cause disease in local cultivars. PVYN-Wi demonstrated greater pathogenicity in the Kenyan potato cultivars than PVYO. In susceptible cultivars, Dutch Robyjn and Kenya Mpya, inoculation of PVYN-Wi caused significant higher ELISA OD values as compared to $\mathrm{PVY}^{\circ}$. This relative higher ability of $\mathrm{PVY} \mathrm{N}^{\mathrm{N}} \mathrm{Wi}$ to cause diseases in Kenyan potato cultivars could be among the factors supporting its spread within the Kenyan potato cultivars. In a recent survey conducted in the major potato growing areas in Kenya, PVYN-Wi occurred more commonly and was more distributed in different regions than $\mathrm{PVY}^{\mathrm{O}}$ (Chapter 4 of this thesis). There is therefore a need to identify cultivars with resistance to $\mathrm{PVY}^{\mathrm{N}-\mathrm{Wi}}$ strain.

In this study, PVYN-Wi infection occurred symptomless in some of the most commonly grown cultivars. Previous studies indicate that such symptomless infections is one of the factors that has contributed to the rapid spread of PVY ${ }^{\mathrm{N}-\mathrm{Wi}_{\mathrm{i}}}$ in different potato growing regions all over the world by invisibly acting as a source of PVY inoculum for spread of the virus (Karasev and Gray 2013; MacKenzie et al. 2018). Symptomless PVY ${ }^{N-W i}$ infections were found in cultivars Shangi, Tigoni, Kerr's Pink, Kenya Baraka and Asante both in the screen-house and in the field screening of cultivars over seasons after inoculation with the PVY strain. These are among the major cultivars grown by the Kenyan farmers. Shangi in particular is grown by the majority (60.5\%) of farmers (Chapters 2, 3, 4 of this thesis). Symptomless virus infections can be managed by conducting regular virus surveys to know the regions and cultivars infected with the virus and by replacing susceptible cultivars with resistant ones. In susceptible cultivars, with clear symptoms like Dutch Robyn, Kenya Mpya and Nyayo, PVY can be controlled alternatively by rogueing out symptomatic plants to avoid further spread of the virus or by positive selection i.e selecting healthy looking plants as planting materials for the subsequent seasons to reduce virus prevalence and subsequently improve potato tubers yields (Gildemacher et al. 2011; Schulte-Geldermann et al. 2012; Priegnitz et al. 2019). In a recent survey, Kenyan farmers were found with limited knowledge in the concept of viruses and virus control and they engage in practices that promote potato virus transmission (Chapter 2 of this thesis). Most important among these was the practice of replanting virus infected tubers over seasons. This practice contributes to the spread of the viruses from the mother 
tuber to the daughter tuber from one generation to another (Chandla et al. 2001). Yield losses observed in susceptible cultivars Dutch Robyn (21.6\%), Nyayo (39.0\%) and Kenya Mpya (53.1\%) were found in cultivars where there was spread of the PVY strain from one season to another through seed tubers (significant increase in ELISA OD values and in symptom severity over seasons).

This study intended to contribute to virus control by identifying locally grow cultivars with PVY resistance and which can be recommended to farmers to minimize virus spread. The following criteria were used to identify resistant cultivars:

1. Cultivars that do not get PVY infection (as tested in ELISA) after sap inoculation with the virus (Solomon-Blackburn and Barker 2001).

2. Cultivars that do not pass PVY infection from one season to another through tubers (Beemster 1976; Dupuis et al. 2017).

3. Cultivars that do not experience any significant yield loss after inoculations when evaluated both in the screen-house and in the field over seasons (Solomon-Blackburn and Barker 2001; Rahman et al. 2010).

Among the 12 cultivars evaluated, the three cultivars Kenya Karibu, Sherekea and Unica were found resistant to $\mathrm{PVY}^{\mathrm{N}-\mathrm{Wi}}$ because they met all the above criteria. Kenya Mavuno was found resistant in the screen-house but not in the field. Since the 12 Kenyan potato cultivars were inoculated with $\mathrm{PVY}^{\mathrm{N}-\mathrm{Wi}^{\mathrm{i}}}$ and were evaluated as secondarily infected tubers planted over the three seasons, the results obtained in this study are an indication that it was not possible for $\mathrm{PVY}^{\mathrm{N}-\mathrm{Wi}}$ to be transmitted through tubers in these cultivars. Considering the Kenyan potato cultivation situation where over 95\% replant their own non-certified seed tubers and do not have access to certified seed tubers (NPCK 2017), such cultivars can help to control the spread of the virus through seed tubers and can be useful in minimizing virus prevalence in the farmer's fields and subsequent yield losses currently being experienced by the Kenyan farmers. The high yields of $37.3 \mathrm{~T} / \mathrm{Ha}$ and $35 \mathrm{~T} / \mathrm{Ha}$ in Unica and Sherekea respectively are a further indication that these cultivars can be used to improve the low average tubers yields currently reported to be only 8.7 T/Ha among the Kenyan farmer's fields.

The second category of cultivars (Tigoni, Shangi, Kerr's Pink and Kenya Baraka), did not experience any significant yield loss over three seasons and though they were PVY infected, there was no significant increase in severity of virus infections over seasons in both screen-house and in the field. These cultivars too can be 
useful in minimizing virus prevalence, particularly Shangi which is already being grown by the majority $(60.5 \%)$ of the Kenyan farmers (see Chapter 2 of this thesis) and was found with very low (1.4\%) virus prevalence in field surveys conducted in five major potato growing counties in Kenya (Chapter 4 of this thesis). These cultivars identified with PVY resistance should however be evaluated further to confirm if they also carry other important traits like resistance to late blight and bacterial wilt (Ralstonia solanacearum), large size tubers, good cooking and culinary qualities, market demand (including tuber skin colour), good storability, short dormancy and early maturity to ensure they fit the needs of the whole Kenyan potato value chain in order to be widely adopted (Crissman 1993; Kaguongo et al. 2008; Chapter 2 of this thesis).

Future breeding efforts in Kenya should focus on introducing and screening new PVY resistant genotypes with effective resistance genes tested using Kenyan PVY isolates. The identified PVY resistant cultivars can therefore be crossed with local cultivars to introduce the PVY resistance trait. In this study, we made efforts towards this by screening 17 early generation potato genotypes, two of which we identified as PVY resistant. The clones were generated from crosses made between local Kenyan cultivars and PVY resistant CIP clones with the aim to give a breeding population with both PVY resistance and locally important traits. Unfortunately, it is not known which PVY strain was used in the evaluation of virus resistance. The clones should be further evaluated for other locally important traits and released to benefit the farmers. Further research however would be advisable to genotype the cultivars and identify the specific resistance genes in these cultivars and to relate their mechanism of host resistance with the data obtained in this study.

\subsection{Acknowledgements}

We sincerely thank all those who directly or indirectly assisted in the process of this study both from Wageningen University and Research (WUR) the Netherlands and at the Kenya Agricultural and Livestock Research organization (KALRO), Kenya. I thank KALRO for the financial, physical and logistical support during this study. Sincere thanks to my student, Kevin Waweru at KALRO Tigoni for helping me in managing the experiments. 


\section{Chapter 6}

\section{General discussions}

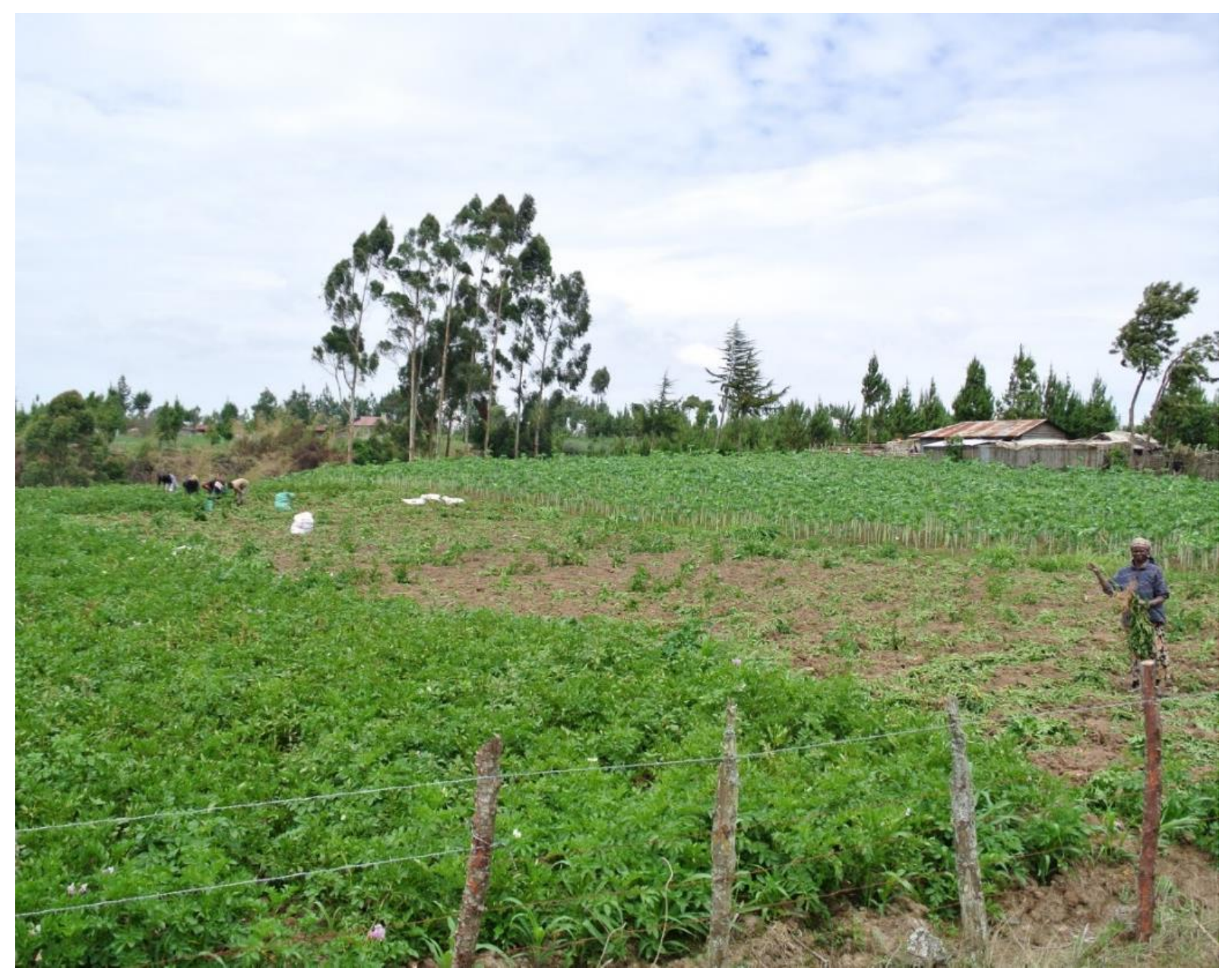




\subsection{Introduction}

The potato crop makes a significant contribution to food security in Kenya as the second most widely grown food crop after maize. Livelihoods of more than 800,000 farmers and about 3.3 million people who are employed both directly and indirectly in the potato sector depend on this crop (MoALF 2016). There are currently low average potato yields (8.7 T/Ha) (FAOSTAT 2017) attributed to the high incidence of pests and diseases, mainly viruses and lack of adequate quantities of certified seed tubers (Were et al. 2003; Gildemacher et al. 2009; Muthomi et al. 2009; Schulte-Geldermann et al. 2012; Were et al. 2013).

Potato viruses play a major role in reducing crop quality and productivity over generations of using same seed stock (Boiteau et al. 1988; Jayashige et al. 1989; Beukema and van der Zaag 1990). In Kenya, the main strategy to minimize virus prevalence have been to improve the quantity of certified seed tubers planted by farmers (Janssen et al. 2013; MoALF 2016). Despite the efforts, only 5\% of farmers have access to certified seed tubers forcing the rest of the farmers to replant their own saved seed tubers (NPCK 2017). In many cases, these are virus infected which contributes to further spread the viruses in their farms. To put up an effective virus control strategy, there is therefore need for careful assessment of the current farming situation in order to make a more well-informed decision on the practical and appropriate virus control method.

This thesis addresses the potato virus problem in Kenya and possible solutions by investigating the 'epidemiology and control of potato virus $Y$ in Kenya'. The thesis puts a major emphasis on the control of PVY because it is considered the most important virus of potato crops which causes major yield losses in all the regions of the world where potato is grown (Scholthof et al. 2011). In Kenya, PVY is one of viruses that occur with high prevalence in the major potato growing regions (Gildemacher et al. 2009; Muthomi et al. 2009; Nyamwamu et al. 2014). This thesis explores options of virus control in a situation where farmers may not be having the capacity to control potato viruses in their farms and quality of seed tubers planted are poor.

The following objectives were therefore investigated:

1. To identify gaps in farmer's perceptions and practices in relation to potato virus control and to propose appropriate virus control. 
2. To describe prevalence, distribution and relative importance of the six major viruses and suggest cultivars, regions and viruses that should be given priorities in potato virus control.

3. To determine the present status of prevalence of the PVY strains in cultivars grown in different potato growing regions in Kenya and to deduce levels of virus resistance from the prevalence of PVY strains.

4. Identify cultivars with resistance to the most prevalent PVY strain within the Kenyan potato germplasm and quantify yield losses attributed to the PVY strain in susceptible cultivars.

\subsection{Key findings in view of the research objectives}

\section{Objective (1) To identify gaps in farmer's perceptions and practices in} relation to potato virus control and to propose appropriate virus control measures.

This objective is addressed in Chapter 2, through farmer household interviews conducted in two of the major potato growing counties. Results obtained reflected that farmers did not have sufficient knowledge of virus diseases and the ways these viruses are spread to enable them to effectively control the viruses. Majority of the farmers $(81.8 \%)$ were not able to identify the virus symptoms and the aphids (virus vectors) (63.9\%) and also did not know (94.5\%) that aphids can act as vectors for virus transmission. Lack of sources of technical information about the potato viruses and their control was the main reason for the lack of knowledge. With high virus prevalence in major potato growing regions as presented in Chapter 3 and also in the past prevalence surveys (Nderitu and Mueke 1986; Were et al. 2003; Machangi et al. 2003; Muthomi et al. 2009; Gildemacher et al. 2009; Olubayo et al. 2010; Were et al. 2013; Nyamwamu et al. 2014), it was clear that improving capacity of farmers in virus control was among the factors that should be put into consideration to effectively manage the viruses. With improved potato cultivation practices in field experiments using local cultivars, it has been possible to obtain an average yield of over 35 T/Ha (Lung'aho et al. 2006; Onditi et al. 2012), which is high compared to the current low (8.7 T/Ha) average yields (FAOSTAT 2017). This result is an indication of the necessity to address the major constraints of potato production including the viruses to improve potato yields. The interviews (Chapter 2) showed that farmers had little knowledge about some of 
the basic potato production principles. They therefore need to be advised to do the following:

1. Avoid maintaining volunteer potatoes because they can act a source virus inoculum for transmission to their main potato crop (Wright and Bishop 1981; Koekpe-Hill et al. 2010). This is important considering that over a half of the farmers $(57.7 \%)$ deliberately maintained volunteer potatoes because for them it provides food early in the season before the main crop.

2. Farmers in the same region should synchronise their potato planting and avoid overlapping potato cultivation periods all through the year. Such a strategy will limit potato virus transmission from farm to farm and from one cropping season to another with the help of aphids (Difonzo et al. 1994).

3. Avoid maintaining crop plants or weeds of the same botanical family (Solanaceae) as potato in or around the same farm with potato. These can act as alternative hosts for potato viruses from where the viruses can get transmitted to the farmer's potato crop (Duffus 1971; Thresh 1982). Farmers can also implement a crop rotation program where Solanaceous crops are not followed by potato crop.

4. Understand that potato viruses can be transmitted through seed tubers from one cropping generation to another resulting in reduced crop quality (ThomasSharma et al. 2016). From this, farmers can seek alternative ways of maintaining/improving seed potato health and quality (Hide and Lapwood 1992; Priegnitz et al. 2019).

5. Plant resistant cultivars which do not show visible virus symptoms in the field (Cooper and Jones 1983; Valkonen 1994). In addition to virus resistance, it would however be good to note that Kenyan farmers have specific attributes that they consider important in cultivars which will also need to be put into consideration.

6. Monitor for pest and diseases in their potato farms and apply pesticides correctly and safely to control virus vectors (Ragsdale et al. 2001; Rahman et al. 2013; Islam et al. 2017).

7. In addition, avoid practices that would lead to mechanical injury and exposure of potato crop to plant sap with potential source of virus infection (Woodford 1992), though this was already well understood by most farmers. 
In Chapter 2, the potato virus problem in Kenya is approached by assessing the relative impact of each of the methods of virus control by a team of scientists in relation to the current levels of farmer knowledge and practices. Among the different methods of virus control, the use of resistant cultivars was least understood by farmers and was proposed to be relatively more applicable under the Kenyan potato cultivation conditions. This is because virus resistant cultivars have the ability to withstand degeneration resulting from virus infections when exposed to different sources of virus infection in the field over several generations without requiring little other input (Jayashige et al. 1989; Beukema and van der Zaag, 1990; Chandla et al. 2001). Considering the limited knowledge of virus control among the farmers, such cultivars can be used to reduce virus prevalence if adopted by farmers. Virus resistant cultivars will lower the cost of replacing degenerated seed tubers with certified seed tubers and also the cost of monitoring and controlling virus vectors using pesticides. Control of potato viruses in Kenya should therefore give major focus on identification on the regions with high virus prevalence and then identify and introduce of virus resistant cultivars to lower virus prevalence in the potato growing regions in Kenya.

\section{Objective (2) To describe prevalence, distribution and relative importance of the six major viruses and suggest cultivars, regions and viruses that should be given priorities in potato virus control}

This objective is addressed in Chapter 3 where the virus problem in Kenya is described based on actual prevalence surveys of the six major viruses in cultivars grown in five major potato growing counties in Kenya. The 354 potato leaf samples from the survey were tested in DAS-ELISA to detect six major potato viruses PVY, PLRV, PVX, PVM, PVS and PVA and quantify the extent of virus infection based on the ELISA OD values. There was generally a high virus prevalence of the six potato viruses just like in the previous reports (Were et al. 2003; Muthomi et al. 2009; Gildemacher et al. 2009; Were et al. 2013; Nyamwamu et al. 2014). The viruses were found to occur in 22 different combinations of multiple infections of the six viruses. These mixed infections contribute to the virus problem considering the possible synergistic effects of multiple virus infections known to be accelerating reduction of crop quality and yield losses. 
Interestingly, potato viruses were found to occur only in specific localities within each of the five counties and only on specific cultivars. This finding negates the idea of blanket recommendations to all the farmers in all the potato growing regions in the country because of the wide variations between regions and subregions in the occurrence of each of the six viruses and the potato cultivars grown in these regions. Cultivars with multiple virus resistances have the ability to withstand crop and seed quality degeneration arising from exposure to different sources of virus infection under field potato growing conditions (Cockerham 1943; Davies et al. 1975; Solomon-Blackburn and Barker 2001; Thomas-Sharma et al. 2016). This ability of some cultivars to have low virus infection in the field could be an indication of some form of resistance to natural sources of virus infection. In Chapter 3, this knowledge was used to identify cultivars with low virus prevalence and also low ELISA OD values consistently across the different seasons and counties for the six different viruses. In absence of known sources of potato virus resistance in Kenya, such potato cultivars can offer practical and relatively quick to implement solutions towards lowering virus prevalence if adopted by farmers. Data on how virus prevalence and deduction of the levels of virus resistance in potato cultivars with the focus on the different PVY strains in Kenya is provided in Chapter 4.

Objective (3) To determine the present status of prevalence of the PVY strains in cultivars grown in different potato growing regions in Kenya and deduce PVY resistance from the prevalence of PVY strains.

In Chapter 4 and 5, there was a shift in the research focus from all the six viruses to give room for a major focus on PVY, which is the most important virus of potato crops worldwide. Over the past few decades, there has been genetic recombination between two of the original PVY strains ( $P Y^{O}$ and $P V Y^{N}$ ) giving rise to new recombinant strains, with the two most important ones being PVY ${ }^{\mathrm{N}-\mathrm{Wi}^{\mathrm{i}}}$ and PVYNTN (Kehoe et al. 2016). These two recombinant strains have quickly spread and are now the most prevalent worldwide and have broken some of the known resistance genes in commercial cultivars creating the need to develop/introduce new resistant cultivars (Jones 1990; Kerlan 1999). In Kenya, occurrence of the different PVY strains and levels of cultivar resistance to these strains is not known. To address this problem, (Chapter 4) a survey of 354 potato leaf samples collected from various cultivars in five major potato growing counties was therefore conducted. 
The samples were subjected to DAS-ELISA to identify samples infected with PVY, which were then further tested in RT-PCR to differentiate the PVY strains (Lorenzen et al. 2006). Contrary to previous findings that reported high PVY prevalence of 77.6\%, 70.0\% and 27.0\% (Gildemacher et al. 2009; Muthomi et al. 2009; Nyamwamu et al. 2014), occurrence of PVY among all the samples analysed in this study were relatively low (8.2\%). The type of cultivars grown by the farmers and levels of cultivar resistance to the different PVY strains could be among the major reasons for the changes in prevalence (Dupuis et al. 2018). The most popularly grown $(60.5 \%)$ cultivar, Shangi was found with very low PVY prevalence $(1.4 \%)$, with only 3 out of 214 samples infected with PVY. In addition, seven cultivars Sherekea, Asante, Kalucy, Kenya Karibu, Tigoni, Unica and Thimathuti were found not infected with any of the PVY strains across the five counties and over two more seasons of a follow up survey in two of the five counties. The low virus prevalence under high virus pressure in farmer's fields in Kenya could be indication of some levels of resistance to PVY in these cultivars. Selected cultivars were further subjected to mechanical sap inoculation with the virus under both screen-house and field conditions to confirm the virus resistance observed in the surveys (Chapter 5).

The virus strains were found only on specific (susceptible) cultivars across the different counties and over seasons. This is an indication that overall PVY prevalence can be reduced if farmers in specific counties can replace the susceptible cultivars they presently grow with more resistant ones. PVY ${ }^{\mathrm{N}-\mathrm{Wi}_{\mathrm{i}}}$ was found to be the most prevalent PVY strain in Kenya. This now forms a basis for setting objectives for PVY resistance breeding in Kenya with a major focus on the PVYN-Wi strain. To provide immediate solution to the farmers, it is important to first focus on screening for resistance to $\mathrm{PVY}^{\mathrm{N}-\mathrm{Wi}}$ within the cultivars already grown by farmers. This is because some of these cultivars already have other important traits Kenyan farmers prefer like large size tubers, late blight tolerance, early maturity, short dormancy and good cooking and processing qualities (Crissman et al. 1993; Lung'aho et al. 2006; Onditi et al. 2012; NPCK 2017). This would ensure easy adoption if in addition to these traits they are found with effective sources of PVY resistance. The cultivars can be promoted to further lower PVY prevalence awaiting future long-term solutions to the virus. 


\section{Objective (4) Identify sources of resistance to the most prevalent PVY strain within the Kenyan potato germplasm and their extent of yields losses.}

This objective is addressed in Chapter 5. The actual levels of PVY resistance in locally grown cultivars and their respective yield losses were determined. In these experiments, PVYN-Wi was found with more severe symptoms and produced higher virus titres based on ELISA OD values in susceptible cultivars as compared to PVYO after sap inoculation in the screen-house. This could be an indication of higher pathogenicity of the PVYN-Wi strain in these cultivars. Twelve potato cultivars were inoculated with the PVY ${ }^{\mathrm{N}-\mathrm{Wi}}$ strain and the tubers harvested were then replanted for three consecutive seasons both in the screen-house and in standard randomized and replicated field trials. From ELISA tests on leaf samples, cultivars Sherekea, Unica and Kenya Karibu were identified as PVY ${ }^{\mathrm{N}-\mathrm{Wi}}$ resistant cultivars because they could not get infected with PVY over the three seasons both in the screen-house and also in the field experiments. This is consistent with resistances deduced from the PVY prevalence surveys in Chapter 4, where no virus infection was detected on these same cultivars grown in five different counties and also over multiple consecutive seasons. Cultivars Sherekea and Unica were initially developed at CIP, Lima, Peru and then later officially released in Kenya after adaptation trials (Lung'aho et al. 2006; Onditi et al. 2012). A description of the cultivars in the CIP variety catalogue indicate that Sherekea has hypersensitive resistance and Unica extreme resistance (CIP 2019) though the specific PVY strains used in previous screening for resistance is not known. Kenya Karibu was bred locally and was only described with respect to PVY for the first time in this study. Cultivar Shangi which was grown by a majority of farmers (60.5\%) and depicted by low PVY prevalence were similarly found with the lowest ELISA OD values in Chapter 5 under controlled screening experiments. Shangi was discovered by Kenyan farmers (from an unknown source) and later evaluated and registered officially in 2015 by KALRO (NPCK 2017). In view of the results obtained in Chapter 4 which were further supported in Chapter 5, it would be advisable to utilize these cultivars to suppress PVY prevalence in potato growing regions in Kenya. To sustain the future of PVY resistance breeding in Kenya, it is important to introduce and screen cultivars from other regions and also identify more genotypes with PVY resistance within the local potato breeding population. In Chapter 5, seventeen potato clones obtained from 
CIP and undergoing early generation selection were also screened for $\mathrm{PVY}^{\mathrm{N}-\mathrm{Wi}}$ resistance and two genotypes were found to be resistant to PVY ${ }^{\mathrm{N}-\mathrm{Wi}}$. These early generation clones were a result of bi-parental crosses between popular local cultivars and the CIP PVY resistant clones. The crosses were made in 2013 by a CIP breeder based in Nairobi, Kenya to give PVY resistant clones with locally important traits. This was the first time these clones were described with respect to their PVY resistance. The identified clones can be further evaluated for important traits that fits within the farmer and consumer needs within the Kenyan potato value chain and for future release, multiplication and distribution to the farmers.

\subsection{Implications of the finding to PVY epidemiology and control in Kenya}

The findings of this study points to certain implications and practical measures towards an improved potato production situation in Kenya. Firstly, farmers being the most important people in decision making at the farm level (Midega et al. 2016; Mendesil et al. 2016) should to be engaged prior to decision making in potato virus control and also during implementation of the recommend virus control strategies. In this study, their contribution was necessary in identifying the potato growing counties with specific virus problems which need to be given higher priority in virus control. The limited capacity of farmers to recognize the concept of virus diseases and thus to control them could be one of the major reasons for the high virus prevalence in the farmer's fields. Setting up a strategy for better virus control by the agricultural extension officers and collaborators should therefore begin by training farmers to improve their capacity to apply the recommended practical and most appropriate virus control method based of their farming situations. Unlike other common diseases of potato in Kenya like late blight (Phytophthora infestans) and bacterial wilt (Ralstonia solanacearum) which are easy to spot by the farmers, viruses are often hard to recognize. Virus symptoms are often confused with other biotic and abiotic stresses during the growth of the plant such as varietal response to drought stress, chemical injury or nutrient deficiency (Salazar 1996). Virus symptoms are in particular important in implementation of positive seed selection or negative selection which entirely relies on the farmer's ability to identify the virus symptoms on potato cultivars (Gildemacher et al. 2009; Schulte-Geldermann et al. 2012; Onduru et al. 2019; Priegnitz el al. 2019). During positive selection, farmers select healthy looking 
plants from among the virus infected (symptomatic) plants and use the selected tubers as planting materials for the subsequent seasons to improve general crop health. This is an economically feasible and relatively simple practice that can easily be adopted by farmers to successively increase yield increase over seasons if farmers can be trained on the basic concepts of the practice (Priegnitz et al. 2019).

Secondly, the study has revealed a gap in breeding for virus resistance. Over the past few decades, the national potato breeding program at KALRO has been focusing on selection, evaluation, release and distribution of cultivars with higher levels of resistance to late blight, good storability, higher yields and good processing quality in the existing cultivars (Lung'aho et al. 2006; Onditi et al. 2012) while paying very little attention to other important traits needed by farmers like virus resistance, short dormancy and early maturity as shown in Chapter 2. For this reason, this current research intended to set a benchmark in demonstrating the importance of virus resistance breeding by conducting PVY screening experiments to show that yield losses observed in susceptive cultivars can be reduced by using virus resistant cultivars. This study has confirmed that PVY ${ }^{N-W i}$ was the most prevalent strain in Kenyan cultivars and in the different potato growing regions. Substantial yield losses caused by this virus strain were demonstrated by both screen-house and field experiments. As host resistance is likely to become a major component in the overall virus control strategy, the breeding objectives of the national potato program need to be re-oriented to ensure virus potato varieties are available for recommendation and adoption by farmers in Kenya.

Thirdly, screening for virus resistance is an essential tool whose continual use should form part of the virus control 'tool-box'. This study has demonstrated how farmer's field prevalence surveys is a representation of how the virus resistance works in real life situations. This method of virus resistance screening is cheaper and can respond faster to farmer needs in comparison to conventional breeding programmes which normally takes $10-15$ years to provide resistant cultivars (Bradshaw and Mackay 1994; Landeo and Gastelo 2004). For this method of virus resistance screening to work best, the sample collection should be random and sample sizes should be large enough to be statistically representative of the different potato growing regions. In addition, there should be accompanying 
evidence that there is high prevalence of the viruses and also high vector population on the potato crops and also evidence that farmers lack the capacity to control the viruses (Onditi et al. 2020 submitted for publication) and have the practice of replanting their own saved seed tubers over seasons.

Based on the results obtained from this study and also reviewing other methods of virus control applicable under similar potato growing situations (Gildemacher et al. 2009; Olubayo et al. 2010; Gildemacher et al. 2011; Schulte-Geldermann et al. 2012; Thomas-Sharma et al. 2016; Onduru 2018; Onduru 2019; Priegnitz et al. 2019), the use of resistant varieties together with the use of positive seed selection can work together to improve potato seed quality and subsequently lower viruses prevalence in farmers field and subsequently increase potato tuber yields.

\subsection{Potato virus control in Kenya beyond the scope of this thesis}

There are other essential interventions which are required to revitalize potato production in Kenya but which are beyond the scope of the present study. Some are enumerated here to provide a basis for future work on this subject. Firstly, apart from the use of resistant cultivars in virus control as emphasized in this study, potato viruses in Kenya can also be controlled by exploring other methods which work towards improving seed tuber health both at the farm level and in the formal seed production and supply scheme. As scarcity of certified seed potato in Kenya is likely to persist into the foreseeable future, farmers have the alternative of improving the quality of their seed tubers by use of positive seed selection. This innovation has been practiced with farmer groups and has been found to improve potato tubers yields in Kenya (Gildemacher et al. 2011; Schulte-Geldermann et al. 2012; Onduru et al. 2019). Other factors that hinder success of positive selection like existence of potato viruses like PVM, PVS and PVA which in many cases do not show symptoms but may be causing major yield losses should however be investigated. Training of farmers and farmer groups should go hand in hand with upscaling the use of positive selection to ensure that farmers are conversant with basic skills for selecting healthy looking plants. Farmers can also plant border crops around their potato farms to reduce vector populations and subsequent virus transmission to their crops (Muindi et al. 2009). It is essential to develop and implement appropriate protocols and guidelines for production and use of seed 
potato via positive seed selection to address concerns about seed quality and the risk of spread of tuber borne diseases.

Secondly, to improve availability of certified seed potato, the current infrastructure for production of disease free early generation seed materials should be expanded. High altitude regions with low vector populations for field multiplications of certified seed potatoes should be explored. In addition, there should be up-scaling of some of the new methods of rapid mini-tuber production like aeroponics, hydroponics (Mbiyu et al. 2012) and potato apical stem cutting technique (Carli 1991) which have been found to increase the rate of seed production. Appropriate incentives need to be implemented to attract more private investors into potato seed production businesses. Importation of certified seed tubers from established potato seed and breeding companies in Europe has already been piloted over the past several years now and has provided lessons on the regulatory and phytosanitary challenges that still need to be overcome to assure increased availability of certified seed tubers to farmers (KEPHIS 2016; NPCK 2017). Methods of monitoring and minimizing vector populations need to be developed/adopted locally to reduce virus transmission within the farmer's field and also in the seed production sites.

Finally, strengthening the potato breeding program in Kenya is key to success of virus control. This will ensure the continuous release and distribution of new improved potato cultivars that will respond to the changing needs of farmers and consumers within the Kenyan potato value chain. There is need to utilize genomic tools to identify the markers for PVY resistance in potato genotypes and also to further correlate genomic data with the phenotypic $d$ ata obtained in this study to improve the efficiency of breeding and release of new improved cultivars. A model needs to be developed to involve major actors in improving the extension service to unlock the bottleneck that has in the past hindered farmers from getting access to the knowledge of potato viruses and their control. There will be a need for collaboration between the major stakeholders in potato industry to jointly address the major crosscutting issues in the sector more effectively. Researchers need to collaborate with the local agricultural extension officers from the Ministry of Agriculture Livestock and Fisheries (MoALF) in the respective counties, communitybased organizations and farmer groups to ensure that new technologies for potato virus control are disseminated to the farmers like through farmer field school, field 
days, open days and mass media. This collaboration can also help in identifying constraints within the farmer's fields which can be addressed by scientists. International collaboration with well-established breeding programs can also help in acquisition of new virus resistant potato germplasm which can be used to sustain the future of potato breeding in the country. To ensure virus resistance breeding is relevant to the Kenyan farmers, potato breeding objectives should focus on combining virus resistance with late blight resistance, bacterial wilt resistance, high tuber yield, cooking and processing quality, good storability, short dormancy and other locally important traits.

\subsection{General conclusions and recommendations}

1. Potato virus control should be designed based on the level of farmer knowledge and practices which are specific to every farming situation.

2. Among the different methods of virus control available to the farmers in Kenya, the use of virus resistant cultivars has potential for lowering virus prevalence in farmer's fields and is applicable to the Kenyan potato growing situation.

3. Virus prevalence surveys provide useful information about resistance levels to the viruses in potato cultivars which can immediately be used to advice farmers on cultivars to grow.

4. Virus resistant cultivars have the ability to minimize virus transmission through seed tubers over seasons of re-using virus infected seed tubers and subsequently minimize yield losses attributed to virus infections.

5. Prevalence of PVY strains varies from region to region and PVY resistance breeding should be based on the current most prevalent PVY strain in a particular region. 


\section{References}

Abraham A (2019) Emerged plant virus disease in Ethiopian agriculture: Causes and control options. Ethiopian J Agric Sci 29: 39- 55.

Adam RI, Sindi K, Badstue L (2015) Farmer knowledge, perceptions and management of diseases affecting sweet potatoes in the Lake Victoria Zone region, Tanzania. Crop Prot. 72: 97-107.

Adams MJ, Zerbini FM, French R, Rabenstein F, Stenger DC, Valkonen JPT (2012) Family Potyviridae. In: King A, Adams M, Carstens E, Lefkowitz E. (Eds.), 10691089. In virus taxonomy. Ninth report of the international committee on taxonomy of viruses. Elsevier, Oxford.

Almekinders CJM, Walsh S, Jacobsen KS et al (2019) Why interventions in the seed systems of roots, tubers and bananas crops do not reach their full potential. Food Sec. $11: 23-27$.

Beemster ABR, de Bokx JA (1987) Viruses, viroids, mycoplasmas and diseases with a virus-like aetiology. Survey of properties and symptoms pp 233-245. In: Viruses of potatoes and seed-potato production Second Edition Edited by JA. de Bokx and J.RH. van der Want. PUDOC, Wageningen, Netherlands.

Bertschinger L, Bühler L, Dupuis B, Duffy B, Gessler C, Forbes GA, Keller ER, Scheidegger UC, Struik PC (2017) Incomplete infection of secondarily infected potato plants, an environment dependent underestimated mechanism in plant virology. Front Plant Sci 3: 8-74.

Beukema HP and van der Zaag DE (1990) Introduction to potato production. PUDOC. Wageningen, Netherlands.

Birch P R. J., G Bryan \& B Fenton, E M. Gilroy, I Hein, J T. Jones, A Prashar, Mark A. Taylor, L Torrance and I K. Toth (2012) Crops that feed the world 8: Potato: are the trends of increased global production sustainable? Food Sec 4: 477-508.

Bock R K and Robertson D G (1976) Notes on East African plant viruses 9: Potato virus Y. E. Afr Agric For J 41: 340-343.

Boiteau G, Singh RP, Parry RH, Pelletier Y (1988) The spread of PVY in New Brunswick potato fields: timing and vectors. Am Potato J 65: 639-649. 
Bradshaw JE and Mackay GR (1994) Breeding strategies for clonally propagated potatoes. In: Potato Genetics (Edited by Bradshaw, J.E and Mackay G.R).CAB International. pp 467-498.

Brandolini A, Caligari PDS, Mendoza HA (1992) Combining resistance to potato leaf roll virus (PLRV) with immunity to potato viruses $X$ and $Y$ (PVX and PVY). Euphytica 61: $37-42$.

Carli C, Njoroge PK, Makwa CM (1991) Seed potato (solanum spp.) production using apical cuttings and tubercles in Kenya. Acta Hortic 380: 513-513.

Celebi-Toprak F, Slack SA, Jahn MM (2002) A new gene, Nytbr, for hypersensitivity to Potato virus $Y$ from Solanum tuberosum Maps to chromosome IV. Theor Appl Genet 104: 669-674.

Chandla VK, Shiv K, Sighn MN, Verma KD, Paul Khurana SM (2001) Role of aphids in degeneration of seed stocks in the higher hills. Ind Pot Ass 28:117-118.

Chiunga E (2013) Viruses occurring in potatoes (Solanum tuberosum) in Mbeya region, Tanzania. Master's thesis, Department of Agricultural Sciences, University of Helsinki, Finland.

Chomczynski P, Sacchi N (1987) Single Step Method of RNA Isolation by Acid Guanidinium Thiocyanate-Phenol-Chloroform Extraction. Anal Biochem 162:156159.

CIP (2019) Catalogue of advanced clones. International Potato Centre, Lima, Peru. https://research.cip.cgiar.org/cipcatlg_ac/. Accessed December 2019.

Clark MF, Adams AW (1977) Characteristics of the microplate method of enzymelinked immunosorbent assay (ELISA) for detection of plant viruses. J Gen Virol 34: 475- 483.

Cockerham G (1943). Potato breeding for virus resistance. Ann of Appl Bio 30: 105-108.

Cockerham G (1970) Genetical studies on resistance to potato viruses $\mathrm{X}$ and $\mathrm{Y}$. Heredity 25: 309-348.

Colvin J, Nagaraju N, Moreno-Leguizamon C, Govindappa RM, Reddy TBM, Padmaja SA, Joshi N, Hanson PM, Seal SE, Muniyappa V (2012) Socioeconomic 
and scientific impact created by whitefly-transmitted, plant-virus disease resistant tomato varieties in southern India. J Integr Agric 11: 337-345.

Cooper JI, Jones AT (1983) Responses of plants to viruses, proposals for the use of terms. Phytopathol 73:127-128.

Crissman CC, Crissman LM, Carli C (1993) Seed potato systems in Kenya: a case study. International Potato Centre, Lima, Peru.

Crosslin JM, Hamm PB, Hane DC, Jaeger J, Brown CR, Shiel PJ, Berger PH, Thornton RE (2006) The occurrence of PVYO, PVYN, and PVYN:O strains of Potato virus $Y$ in certified potato seed lot trials in Washington and Oregon. Plant Dis 90:1102-1105.

Crosslin JM, Hamm PB, Shiel PJ, Hane DC, Brown CR, Berger PH (2005) Serological and molecular detection of tobacco veinal necrosis isolates of Potato virus Y (PVYN) from potatoes grown in the Western United States. Am J Potato Res 82:263-269.

Davidson TMW, Butzonitch IP (1978) The grouping of some strains of potato virus $Y$ in relation to resistant cultivars. Page 161 in: Proc. Seventh Triennial Conf. Eur. Assoc. Potato Res. EAPR, Warsaw, Poland.

Davies HT, McEwen HL, Dixon NC (1975) Field testing potatoes for resistance to leaf roll and virus Y. Am Potato J 52: 151-155.

de Bokx JA Huttinga H (1981) Potato Virus Y. Descriptions of Plant Viruses, No. 242. Commonw. Mycol. Inst. /Assoc. Appl. Biol, Kew, England.

de Bokx JA, van der Want JPH (1987) Viruses of Potatoes and Seed Production, 259 pp. Wageningen, The Netherlands: PUDOC.

De Olde EM, Oudshoorn FW, Sorensen CAG, Bokkers EAM, De Boer IJM (2016) Assessing sustainability at farm-level: Lessons learned from a comparison of tools in practice. Ecological Indicators 66: 391-404.

DiFonzo CD, Ragsdale DW, Radcliffe EB (1994) Potato leaf roll virus spread in differentially resistant potato cultivars under varying aphid densities. Am Potato J 72:119-132.

Dolby CA, Jones RAC (1987) Occurrence of the Andean strain of Potato virus $S$ in imported potato material and its effects on potato cultivars. Plant Pathol 36:381388. 
Dougherty WG, Carrington JC (1988) Expression and function of potyviral gene products. Ann Rev Phytopathol 26: 123-143.

Duffus JE (1971) Role of weeds in the incidence of virus diseases. Ann Rev Phytopathol 9: 313-340

Dupuis B, Bragard C, Schumpp O (2018) Resistance of potato cultivars as a determinant factor of Potato virus Y (PVY) epidemiology. Potato Res 62: 123.

Ellis P, Stace-Smith R, Bowler G, Mackenzie DJ (1996) Production of monoclonal antibodies for detection and identification of strains of Potato virus Y. Canadian J Plant Pathol 18:64-70.

Fageria M, Nie X, Gallagher A, Singh M (2015) Mechanical transmission of Potato Virus $Y(P V Y)$ through seed cutting and plant wounding. Am Potato J 92: 143-147.

FAOSTAT (2017) FAOSTAT. Commodities by country, Kenya, potatoes, 2017. http://www.fao.org/faostat/en/\#rankings/commodities_by_country. Accessed in August 2019.

Flanders KL, Hawkes JG, Radcliffe EB, Lauer FI (1992) Insect resistance in potatoes, sources, evolutionary relationships, morphological and chemical defences, and ecogeographical associations. Euphytica 61: 83-111.

Florin MJ, van de Ven GWJ, van Ittersum MK (2014). What drives sustainable biofuels? A review of indicator assessments of biofuel production systems involving smallholder farmers. Env Sci and Pol 37: 142-157.

Florin MJ, van Ittersum MK, van de Ven GWJ (2012) Selecting the sharpest tools to explore the food-feed-fuel debate: Sustainability assessment of family farmers producing food, feed and fuel in Brazil. Ecological Indicators 20: 108-120.

Frost KE, Groves RL, Charkowski AO (2013) Integrated control of potato pathogens through seed potato certification and provision of clean seed potatoes. Plant Dis 97: $1268-1280$.

García-Arenal F, Fraile A, Malpica JM (2001) Variability and genetic structure of plant virus populations. An Rev Phytopathol 39: 157-186.

German TL (2001) Potato virus Y. In Compendium of potato diseases, ed. WR Stevenson, R Loria, GD Franc, and DP Weingartner, 2nd ed., pp. 69-71. The American Phytopathological Society Press, Minnesota. 
Gildemacher P, Demo P, Barker I, Kaguongo W, Woldegiorgis G, Wagoire W, Wakahiu M, Leeuwis C, Struik PC (2009) A description of seed potato systems in Kenya, Uganda and Ethiopia. Am J Potato Res 86: 373-382.

Gildemacher P, Schulte-Geldermann E, Borus D, Demo P, Kinyae P, Mundia P, Struik PC (2011) Seed potato quality improvement through positive selection by smallholder farmers in Kenya. Potato Res 54: 253-266.

Gray S, De Boer S, Lorenzen J, Karasev A, Whitworth J, Nolte P, Singh R, Boucher A, Xu H (2010) Potato virus Y: an evolving concern for potato crops in the United States and Canada. Plant Dis 94: 1384-1397.

Green KJ, Brown CJ, Gray SM, Karasev AV (2017) Phylogenetic study of recombinant strains of Potato virus Y. Virology 507: 40-52.

Hanne DC, Hamm PB (1999) Effects of seedborne Potato virus $Y$ infection in two potato cultivars expressing mild disease symptoms. Plant Dis 83: 43-45.

Hide GA, Lapwood DH (1992) Disease aspects of Potato production. In: The potato crop. The scientific basis of potato improvement. Second Edition (By Paul Harris).

Hummon AB, Lim SR, Fil P, Panton MJ, Ried T (2007) Isolation and solubilization of proteins after TRIzol $\circledast$ extraction of RNA and DNA from patient material following prolonged storage. Biotechniques 42: 467-472.

Islam WJ, Zhang M, Adnan A, Noman M, Zaynab M, Wu Z (2017) Plant virus ecology: A glimpse of recent accomplishments. Appl Ecol Env Res 15: 691-705.

Janssens SRM, Wiersema SG, Goos H and Wiersema W (2013) The value chain for seed and ware potatoes in Kenya; Opportunities for development. LEI Memorandum pp13-80, Wageningen.

Jayashige U, Chuquilllanqui C, Salazar LF (1989) Modified expression of virus resistance in potato in mixed virus infections. Am Potato J 66: 137-144.

Jones AC, Woodford JAT, Main SC, Pallett D, Barker H (1996) The role of volunteer potatoes in the spread of potato virus $\mathrm{Y}^{\mathrm{N}}$ in ware crops of $\mathrm{cV}$. Record. Ann Appl Biol 129: 471-498.

Jones RAC (1990) Strain group specific and virus specific hypersensitive reactions to infection with Potyviruses in potato cultivars. Ann Appl Biol 117: 93-105. 
Jones RAC, Stuart JV (2018) Strain-specific hypersensitive and extreme resistance phenotypes elicited by potato virus $\mathrm{Y}$ among 39 potato cultivars released in three world regions over a 117-year period. Plant Dis 102:185-196.

Kaguongo WP, Gildemacher P, Demo P, Wagoire W, Kinyae P, Andrade J, Forbes G, Fuglie K, Thiele G (2008) Farmer practices and adoption of improved potato varieties in Kenya and Uganda. International Potato Centre (CIP), Lima, Peru.

Karasev AV, Gray SM (2013) Continuous and emerging challenges of Potato virus $\mathrm{Y}$ in potato. Ann Rev Phytopathol 51: 571-586.

Kehoe MA, Jones RAC (2016) Improving Potato virus Y strain nomenclature: Lessons from comparing isolates obtained over a 73-year period. Plant Pathology 65: 322-333.

KEPHIS (2016) Seed potato production and certification guidelines. KEPHIS, Nairobi, Kenya.

Kerlan C, Moury B (2008) Potato virus Y. Pages 287-296 in: Encyclopedia of Virology, 3rd ed., vol. 4. B. W. J. Mahy and M. H. V. Van Regenmortel, eds. Elsevier, Oxford.

Kerlan C, Tribodet M, Glais L, Guillet M (1999) Variability of Potato virus Y in potato crops in France. J Phytopathol 147: 643-51.

Khurana SMP, Pandey SK, Bhale U, Patel RL, Lakra BS (1998) Degeneration of potato varieties in northern and central India. Indian J Viro. 14: 111-119.

Kim J, Kwon M (2019) Population dynamics of aphid species in Korean seed potato cultivation area over four decades. Entomological Res 49: 179-184.

Koepke-Hill R, Armel G, Wilson H, Hines T, Vargas J (2010) Herbicide combinations for control of volunteer potato. Weed Tech 24: 91-94.

Kopp A, Kondrák M, Bánfalvi Z (2015) Review article: Molecular mechanisms of resistance to potato virus $X$ and $Y$ in potato. Acta Phytopathologica et Entomologica Hungarica 50: 151-160.

Landeo JA, Gastelo M (2004) Selection procedures to develop potato varieties. Specialized Technology Document, International Potato Centre, Lima, Peru. 
Loebenstein G, Berger P, Brunt AA, Lawson RG (2001) Virus and virus-like diseases of potatoes and production of seed- potatoes. Kluwer Academic Publishers, Dordrecht, The Netherlands.

Lorenzen JH, Piche LM, Gudmestad NC, Meacham T, Shiel P (2006) A multiplex PCR assay to characterize Potato virus $Y$ isolates and identify strain mixtures. Plant Dis 90: 935-940.

Lung'aho C, Lemaga B, Nyongesa M, Gildermacher P, Kinyae P, Demo P, Kabira J (2007) Commercial seed potato production in eastern and central Africa. Kenya Agricultural Research Institute, Nairobi, Kenya.

Lung'aho C, Nderitu SKN, Kabira JN, El-Bedewy R, Olanya OM, Walingo A (2006) Yield performance and release of four late blight tolerant potato varieties in kenya. J of Agronomy 5: 57-61.

Machangi JM (2003) Occurrence of viruses and aphid vectors in small-scale potato seed production systems and their effect on yield in Kenya, Msc thesis University of Nairobi, Kenya.

MacKenzie TDB, Lavoie J, Nie X, Singh M (2018) Differential spread of Potato virus Y (PVY) strains $\mathrm{O}, \mathrm{N}: \mathrm{O}$ and NTN in the field: Implications for the rise of recombinant PVY strains in New Brunswick, Canada. Am J Potato Res 95: 301-310.

Maduka OG, Akpan S, Maleghemi (2017) Using Android and Open Data Kit Technology in Data Management for Research in Resource-Limited Settings in the Niger Delta Region of Nigeria: Cross-Sectional Household Survey. JMIR Mhealth Uhealth 5: 171 .

Marinus W, Ronner E, Ven GWJ, Kanampiu F, Adjei-Nsiah S, Giller KE (2018) The devil is in the detail! : Sustainability assessment of African smallholder farming. In: Bell S, Mors S, and Routledge. Routledge Handbook of Sustainability Indicators $427-450$.

Mbiyu MW, Muthoni J, Kabira J, Elmar G, Muchira C, Pwaipwai P, Ngaruiya J, Otieno S, Onditi J (2012) Use of aeroponics technique for potato (Solanum tuberosum) minitubers production in Kenya. J of Hort and For 4: 172-177.

Mendesil E, Shumeta Z, Anderson P, Ramert B (2015) Smallholder farmer knowledge, perceptions and management of pea weevil in North and NorthWestern Ethiopia. Crop Protection 81: 30-37. 
Mendez-Lozano J, Torres-Pacheco I, Fauquet CM, Rivera-Bustamante RF (2003) Interactions between geminiviruses in a naturally occurring mixture: pepper huasteco virus and pepper golden mosaic virus. Phytopathol 93: 270-277.

Midega CAO, Murage AW, Pittchar JO, Khan ZR (2016) Managing storage pests of maize: Farmer knowledge, perceptions and practices in western Kenya. Crop Protection 90: 142-149.

MOA/GTZ-PSDA (2009) National Potato Taskforce Report 2009. Final Report. Ministry of Agriculture (MoA) and Germany Technical Cooperation (GTZ)-private Sector Development Agency (PSDA), Nairobi, Kenya.

MoALF (2016) The National Potato Strategy 2016-2020. Ministry of Agriculture Livestock and Fisheries Nairobi, Kenya.

Moury B (2010) A new lineage sheds light on the evolutionary history of Potato virus Y. Mol. Plant Pathol 11: 161-168.

Muindi EM, Muthomi JW, Nderitu JH, Olubayo FM, Kabira JN, Chemining'wa GN, Kiretai SM, Aura JA (2009) Use of cereal border crops in management of aphidtransmitted viral diseases during seed potato (Solanum tuberosum) production. Afr J Hort Sci 2: 69-78

Munoz RJ, Plaisted RL, Thurston HD (1975) Resistance to Potato virus Y in Solanum tuberosum ssp. andigena. Am Potato J 52: 107-115.

Muthomi JW, Kinyungu TN, Nderitu JH, Olubayo FM (2011) Incidence of aphidtransmitted viruses in farmer-produced seed potato tubers in Kenya. Afr J Hort Sci 5:18-25

Muthomi JW, Nyaga JN, Olubayo FM, Nderitu JH, Kabira JN, Kiretai SM, Aura JA, Wakahiu M (2009) Incidence of aphid transmitted viruses in farmer-based seed potato production in Kenya. Asian J of Plant Sci 8: 166-171.

Nderitu JH, Mueke JM (1986) Aphid infestation on eight potato cultivars (Solanum tuberosum L.) in Kenya. Insect Sci Applic 7: 667 -682.

Nie B, Singh M, Murphy A, Sullivan A, Xie C, Nie X (2012) Response of potato cultivars to five isolates belonging to four strains of Potato virus $Y$. Plant Dis 96:1422-1429. 
Nie X, Singh RP (2002) A new approach for the simultaneous differentiation of biological and geographical strains of Potato virus $\mathrm{Y}$ by uniplex and multiplex RTPCR. J Virol Methods 104: 41-54.

Nolte P, Whitworth JL, Thornton MK, McIntosh CS (2004) Effect of seedborne Potato virus $Y$ on performance of Russet Burbank, Russet Norkotah, and Shepody potato. Plant Dis 88: 248-252.

NPCK (2017) Potato variety catalogue. National Potato Council of Kenya, Nairobi, Kenya. Available online:http://npck.org/Catalogues/.pdf. Accessed in November 2019.

Nyamwamu P, Mukoye B, Osogo A, Omuse C, Ajanga S, Were HK (2014) Distribution and biological characterization of potato virus $Y$ in Kenya. J of AgriFood and Appl Sci 2: 258-264.

ODK (2018) Open Data Kit. Available: http://opendatakit.org/. Accessed: July 2018.

Okonya JS, W Ocimati, Nduwayezu A, Kantungeko D, Niko N, Blomme G, Legg JP, Kroschel J (2019) Farmer Reported Pest and Disease Impacts on Root, Tuber, and Banana Crops and Livelihoods in Rwanda and Burundi. Sustainability 11:1592.

Olubayo F, Kibaru J, Nderitu J, Njeru R, Kasina M (2010) Management of aphids and their vectored diseases on seed potatoes in Kenya using synthetic insecticides, mineral oil and plant extract. J Innov Dev Strategy 4: 1-5.

Onditi J, Njoroge K, Shibairo S (2013) Improving potato tuber yields using genotypes with multiple virus resistance in Kenya Agric Biol J N Am 4: 406-441.

Onditi JO, Nderitu SWK, Landeo JA, Abong' GO, Sikinyi EO and Kabira JN (2012) Release of three improved varieties for the expanded potato market in Kenya. Agric Biol J N Am 3: 192-197

Onduru O. G, Kalpana S, E Atieno, R D Narla, D W Miano and E SchulteGeldermann (2018) Effectiveness of positive selection in managing seed-borne potato viruses. J Agric Sci 10: 211-233.

Onduru OG, Narla RD, Otieno HMO, Schulte-Geldermann E (2019) Response of selected potato genotypes to natural virus infection in the field. Asian $\mathrm{J}$ of Res in Crop Sci 3: 1-13. 
Priegnitz U, Lommen W JM, van der Vlugt RAA, Struik PC (2019) Impact of positive selection on incidence of different viruses during multiple generations of potato seed tubers in Uganda. Potato Res 62: 1-30.

QGIS (2019) QGIS, A Free and Open Source Geographic Information System. https://qgis.org/en/site/. Accessed January 2019.

Quenouille J, Vassilakos N, Moury B (2013) Potato virus Y: A major crop pathogen that has provided major insights into the evolution of viral pathogenicity. Mol Plant Pathol 14: 439-452.

Ragsdale DW, Radcliffe EB, DiFonzo CD (2001) Epidemiology and field control of PVY and PLRV. In: Loebenstein, G., P.H. Berger, A.A. Brunt, and R.H. Lawson (eds), Virus and Virus-like Diseases of Potatoes and Production of Seed-potatoes pp. 237-270. Kluwer Academic Publishers, Dordrecht.

Rahman AS, Mehboob W, Khan NA (2013) Reaction of gram (Cicer Arietinum L.) Varieties against gram blight disease (Didymella rabiei (Kovatsch.) Arx) and its management through foliar fungicides in rain-fed areas of Pakistan Pak J Phytopathol 25: 07-14.

Rahman MS, Akanda AM, Mian IH, Bhuian MKA, Karim MR (2010) Growth and yield performance of different generations of seed potato as affected by PVY and PLRV. Bangladesh J Agric Res 35: 37- 42.

Riechmann JL, Lain S, Garcia JA (1992) Highlights and prospects of potyvirus molecular biology. J Gen Virol 73: 1-16.

Rose DG, Hubbard AL (1986) Production of monoclonal antibodies for the detection of Potato virus Y. Ann. Appl Biol 109: 317-21.

Salazar LF (1996) Potato viruses and their control. International Potato Centre, Lima, Peru.

Sato M, Nishikawa K, Komura K, and Hosaka K (2006) Potato virus Y resistance gene, Rychc, mapped to the distal end of potato chromosome 9. Euphytica 149: 367-372.

Scholthof KG, Adkins S, Czosnek H, Palukaitis P, Jaquot E, Hohn T, Hohn B, Saunders K, Candresse T, Ahlquist P, Hemenway C, Foster G (2011) Top 10 plant viruses in molecular plant pathology. Mol Plant Pathol 12: 938-954. 
Schubert J, Fomitcheva V, Sztangret-Wiśniewska J (2007) Differentiation of Potato virus $Y$ strains using improved sets of diagnostic PCR-primers. J Virol Methods 140: 66-74.

Schulte-Geldermann E, Gildemacher PR, Struik PC (2012) Improving Seed Health and Seed Performance by Positive Selection in Three Kenyan Potato Varieties. Am J Potato Res 89: 424- 429.

Scott GJ, Labarta R, Suarez V (2013) Booms, Busts, and Emerging Markets for Potatoes in East and Central Africa 1961-2010. Potato Res 56: 205-236.

Semagn AK, De Jong W, Perry K, Halseth D, Mengistu F (2017) Participatory Variety Selection: A tool to understand farmer's potato variety selection criteria. Open Agriculture. 2: 453-463.

Singh AS, Masuku MB (2014) Sampling techniques \& determination of sample size in applied statistics research: an overview. Int J of Econ Comm and Manag 2: 23. Singh RP, Valkonen JPT, Gray SM, Boonham N, Jones RAC, Kerlan C, Schubert J (2008) Discussion paper: the naming of Potato virus $Y$ strains infecting potato. Arch Virol 153: 1-13.

Smith EA, DiTommaso A, Fuchs M, Shelton AM, Nault BA (2012) Abundance of weed hosts as potential sources of onion and potato viruses in Western New York. Crop Protection 37: 91-96.

Smith KM (1931) Composite nature of certain potato viruses of the mosaic group. Nature 127:702.

Soliman T, Mourits MCM,. Oude Lansink AGJM, van der Werf W (2012) Quantitative economic impact assessment of an invasive plant disease under uncertainty. A case study for potato spindle tuber viroid (PSTVd) invasion into the European Union. Crop Protection 40: 28-35.

Solomon-Blackburn RM, Barker H (2001) A review of host major-gene resistance to potato viruses $\mathrm{X}, \mathrm{Y}, \mathrm{A}$ and $\mathrm{V}$ in potato, genes, genetics and mapped locations. Heredity 86: 8-16.

Steel RGD, Torrie JH (1980) Principles and procedures of statistics. A biometrical approach. $2^{\text {nd }}$ edition. McGraw and Hill Inc. 
Struik PC, Wiersema SG (1999) Seed Potato Technology. Wageningen: Wageningen Pers, 1999. 383 pp. Plant Cell, Tissue and Organ Culture 65: 173174.

Struik PC, Kuyper TW, Brussaard L, and Leeuwis C (2014) Deconstructing and unpacking scientific controversies in intensification and sustainability: Why the tensions in concepts and values? Current Opinion in Env Sust 8: 80-88.

Syller J (1996) Potato leaf-roll virus (PLRV): its transmission. Integrated Pest Management Reviews 1: 217-227.

Syller J, Kaliciak A (2009) New hosts of Potato virus Y (PVY) among common wild plants in Europe. Euro J of Plant Path 124: 707-713.

Szajko K, Chrzanowska M, Witek K, Strzelczyk-Żyta D, Zagórska H et al (2008) The novel gene $N y-1$ on potato chromosome IX confers hypersensitive resistance to Potato virus $Y$ and is an alternative to $R y$ genes in potato breeding for PVY resistance. Theor Appl Genet 116: 297-303.

Taliansky M, Mayo MA, Barker H (2003) Potato leafroll virus: A classic pathogen shows some new tricks. Mol Plant Pathol 4: 81-89.

Tesfaye T, T Feyissa and A Abraham (2011) Survey and serological detection of sweet potato (Ipomoea batatas (L.) Lam.) viruses in Ethiopia J Appl Bio Sci 41: 2746 - 2756.

Thomas-Sharma S, Abdurahman A, Ali S, Andrade-Piedra JL, Bao S, Charkowski AO (2016) Seed tuber degeneration in potato: the need for a new research and development paradigm to mitigate the problem in developing countries. Plant Pathol. 65: 3-16.

Thresh JM (1982) Cropping practices and virus spread. Ann Rev Phytopathol 20: 193-218.

Valkonen JPT, Jones RAC, Slack SA, Watanabe KN (1994) Resistance specificities to virus in potato, standardization of nomenclature. Plant Breeding 115: 433-438. Wang B, Maa Y, Zhang Z, Wu Z, Wu Y, Wang Q, Li M (2011) Potato viruses in China. Crop Protection 30: 1117-1123.

Waqar I (2017) Management of plant virus diseases; farmer's knowledge and our suggestions. Hosts and Viruses $4: 28-33$. 
Were HK, Narla RD, Nderitu JH, Weidemann H-L (2003) The status of potato leafroll virus in Kenya. J Plant Pathol 85 (3): 153-156.

Were HK, Kabira JN, Kinyua ZM, Olubayo FM, Karinga JK, Aura J, Lees AK, Cowan $\mathrm{GH}$, Torrance $L$ (2013) Occurrence and distribution of potato pests and diseases in Kenya. Potato Res 123: 12-25.

Whitfield AE, Falk BW, Rotenberg D (2015) Insect vector-mediated transmission of plant viruses. Virology 48: 278-289.

Whitworth J, Davidson RD (2008) Quality seed: Seed improvement, cultivar and seed lot election and certification. pp 31-41 in: Potato Health Management. D. A. Johnson, ed. American phytopathological Society, St. Paul, MN.

Woodford JAT (1992) Virus transmission by aphids in potato crops. Netherlands J Plant Pathol 98: 47-54.

Wright and Bishop (1981) Volunteer potatoes as a source of potato leaf roll virus and potato virus X. Am. J. Potato Res. 58: 603-609.

Yadav N, Khurana SMP (2015) Plant virus detection and diagnosis: Progress and challenges. Frontier Discoveries and Innovations in Interdisciplinary Microbiology 27: 97-132. 


\section{Summary}

Potato (Solanum tuberosum L.) is the second most important food crop after maize and it has the potential of improving food and nutritional security in Kenya. The crop is mainly grown in the highlands of Kenya at altitudes ranging between 1500 to 3000 metres above sea level. In these regions, potato is the main staple food for small scale farmers who grow it for their own consumption while surplus is sold to generate household income. Production of this crop is faced by a number of constraints, one of the main ones being the lack of sufficient quantities of certified seed tubers for planting. This implies that the majority of farmers plant their own saved tubers from the harvest of previous seasons or ware tubers from neighbours and local markets. This practice is known to contribute to the spread of seed borne diseases and most importantly viruses. Previous virus prevalence surveys indicated high incidences of viruses and virus vectors in the major potato growing regions. Potato viruses are particularly a problem because once a plant is infected, the disease is spread through seed tubers from the mother plant to daughter tubers. The viruses can also be spread by aphids (vectors) which have been reported to occur with high incidence in the major potato growing regions in Kenya. This results in successive reductions in yield and crop quality over seasons of replanting virus infected tubers. Presently, Kenyan farmers experience very low potato yields $(8.7 \mathrm{~T} / \mathrm{Ha})$ partly attributed to the high virus prevalences. Controlling potato viruses are among the things that can be done to improve potato yields in the farmer's fields.

The main aim for conducting this study was to give recommendations for potato virus control based on the current potato production situation in Kenya. For a quick response to the food security situation in the country, this study was focused on virus control options which can easily be adopted and immediately be available for use by farmers to lower virus prevalence while waiting for long term solutions for virus control. Chapter 1 therefore gives the background of the potato growing situation in Kenya, the existing intuitional infrastructure in the potato sector and the past efforts in potato viruses control in Kenya. This includes a description of the potato virus problem in Kenya including previous potato virus prevalence surveys and efforts by local scientist to propose various of managing the viruses and major challenges hindering virus control. 
Six major potato viruses; potato virus Y (PVY), potato leafroll virus (PLRV), potato virus $X(P V X)$, potato virus $A$ (PVA), potato virus $S$ (PVS) and potato virus $M$ (PVM) were found to occur in the potato growing areas in Kenya. PVY was previously identified as one of the most important viruses in Kenya and also all over the world in all regions where potatoes are grown and was highlighted for a more detailed study among the viruses. It was clear that previous approaches towards virus control in Kenya had not been successful. There were unanswered questions about the general potato virus epidemiology and control from a farmer's perspective.

In Chapter 2, a farmer household survey was described that involved 147 respondents in two major potato growing regions in Kenya. Lack of sufficient technical information among the farmer on potato virus symptoms $(81.8 \%)$, vectors $(63.9 \%)$, modes of virus transmission (94.5\%) were found to be among the hindrances to the efforts towards virus control. The practices that farmers engaged in which could be promoting virus spread included; maintaining volunteer potatoes as an early season crop in their farms (79.8\%), planting own saved seeds tubers $(77.4 \%)$, maintaining plant species of the same botanical family as potato that can act as sources of virus transmission to their farms (19.7\%), growing potatoes all months of the year in one region which allows for virus transmission all through the year and either not applying pesticides at all to control (aphids) vectors (55.1\%) or incorrect application of pesticides. To set up a strategy for virus control, six different aspects of potato virus control were compared: (a) aphid (vector) virus transmission, (b) virus transmission through seed tubers, (c) mechanical or contact virus transmission to the potato crop, (d) sources of virus inoculum around the potato crop, (e) lack of use of host resistance by the farmers and (f) lack of effective use of pesticides by farmers. These were analysed in a spider diagram in terms of the scores assigned to them as per the present levels of farmer knowledge and also based on experts opinion on their potential impact on overall potato virus epidemiology and control. Use of virus resistant cultivars was found with the lowest score meaning it required the most urgent attention compared to other aspects of virus control and was expected to have greater impact in lowering virus prevalence in farmer's fields.

This is followed by an investigation on the actual prevalence (Chapter 3 ) of the six viruses (PVY, PLRV, PVX, PVM, PVA, and PVS) to determine the specific regions with the virus problem for easy targeting during implementation of viruses control and to identify virus resistant cultivars which normally occur with low virus 
prevalence especially under high virus pressure in the farmer's fields. Among 354 potato leaf samples tested in DAS-ELISA, the viruses were detected in $72.9 \%$ of the samples collected from farms in five major potato growing counties. PVX was the most prevalent virus (54.8\%) followed by PVS (47.5\%), PVM (13.0\%), PVY (8.2\%), PLRV (6.8\%) and PVA (2.5\%) but multiple infections occurred in $55.9 \%$ of the samples. Virus distribution maps were used to locate viruses occurring only in particular geographic regions indicating that any effective approach in virus control should be region specific. Among the 13 cultivars grown, four cultivars, Sherekea, Shangi, Kenya Karibu and Asante were identified with the lowest average ELISA absorbance (OD) values of the six viruses which was used as an indication of field resistance to the viruses. To further study how virus prevalence surveys can be used in screening for virus resistance, the next chapter (Chapter 4) used the same approach to screen for resistance in the cultivars but focused on PVY and particularly on the different PVY strains.

PVY is an important virus of potato crop worldwide and causes major yield losses. The virus occurs as different strains which can be distinguished biologically, serologically and on specific differences in their genome nucleotide sequences. Over the years, there has been an evolutionary shift resulting from genome recombination of two of the traditionally known strains ( $P V Y^{\circ}$ and $P V Y^{N}$ ) to new recombinant strains, predominantly PVYNTN and PVYN-Wilga leading to changes in prevalence of particular PVY strains in different regions in the world. Such new PVY strains have broken some of the known sources of resistance in cultivars creating the need to re-screen existing cultivars using the present most prevalent strains. This study (Chapter 4) intended to identify PVY resistant cultivars from among the major commercial potato cultivars in Kenya. Among the 354 potato leaf samples taken from 13 different cultivars in the five major potato growing counties $\mathrm{PVY}^{\mathrm{N}-\mathrm{Wi}_{\mathrm{i}}}$ was the most prevalent PVY strain (7.3\%) followed by PVYO $(2.3 \%)$ and PVYNTN $(1.4 \%)$ while PVY ${ }^{N}$ was not detected. The PVYN-Wi strain occurred across the three seasons and across the counties but only on specific cultivars. Three cultivars were identified as PVY resistant and the most widely grown cultivar Shangi $(60.2 \%)$, had only a low PVY prevalence of $0.6 \%$. In Chapter 5 , the cultivars identified as (partially) resistant to PVY from prevalence surveys were screened under controlled sap inoculation experiments both in the screen-house and in the field. Three cultivars; Kenya Karibu, Sherekea and Unica were confirmed as resistant because they were all found to be free of PVY infections over three seasons of both 
greenhouse and field screening experiments as well as from the previous surveys. In susceptible cultivars Dutch Robyjn, Nyayo and in Kenya Mpya, PVYN-Wi infection caused yield losses of $21.6 \%, 39.0 \% 53.1 \%$ respectively after three seasons.

Based on the findings from this thesis, this study discusses and recommends (Chapter 6) deployment of potato virus control methods which are innovatively based on the existing level of farmer knowledge and practices. Among the different methods of virus control available to the farmers in Kenya, the use of virus resistant cultivars is one of the methods with potential for lowering the virus prevalence in farmer's fields and is applicable to the Kenyan potato growing situation. This study demonstrates that virus prevalence surveys can provide useful information about resistance levels to the viruses in potato cultivars which can immediately be used to advice farmers. Virus resistant cultivars can therefore be recommended especially in regions identified with high virus prevalence. 


\section{Acknowledgements}

Time actually flies. I can't imagine my PhD journey is coming to an end. I have learnt a lot and yet still more to learn. I have interacted with different people in my PhD life all of whom have contributed to my learning process in many different ways. I therefore take this opportunity to thank all those who contributed either directly or indirectly towards the research work that is written in this thesis.

First and foremost, I would wish to thank Prof. Dr Ir. RAA van der Vlugt. You were a good promoter, mentor, teacher, coach and a friend. With utmost understanding of cultural diversity, you performed exceptionally well as a coach during my thesis writing. Your athletic coaching skills helped me write the whole thesis in the shortest time possible. It was great travelling with you sometimes through rugged roads to my survey sites in the Kenyan highlands and learning from farmers. In addition to thesis and research, your thoughts and inspirations were very valuable especially when we talked about life in general and also about my passion for improving farming systems in Africa. Now it is my turn to take and use the knowledge, skills and experiences for greater societal impact as a scientist in in potato breeding and seed system.

Prof. Dr MM van Oers, you have made a very valuable contributions towards successful completion of my PhD right from the beginning of my studies. As the chair, your workplace was very conducive for my studies. I owe you lots of thanks for all the technical and administrative support which I got whenever I needed. Besides being a good promoter, your encouragements kept my spirit high especially during thesis writing. I really appreciate the speed at which you read through my drafts.

To all the professors, scientists and the administrative staff in the Laboratory of Virology, you were very supportive, encouraging, friendly and a good family away from home. Thanks so much for your contributions to my work in the local meetings and also in the lab. Special thanks to Richard, Jan, Just, Vera, Gorben, Melanie and Katrien of Plant Production Systems (PPS), WUR. I would also wish to thank all the technicians in the lab (Marleen, Dick, Els, Cristina, Gwen and Corrine) for their assistance during my studies. I also thank the staff of Plant Research International, Virology lab all of whom were very supportive with my research work. Special thanks to Petra, Henry and Martin. I thank my students at WUR (Dirk, Robin, Mark and Darleen) for helping with my research work. 
I also thank all students within the Virology lab for the enjoyable moments we had working together. Postdocs (Andre, Magda, Jelke, Haidong, Astrid and Karen) and all my fellow PhD candidates (Gabriella, Corien, Min, Miao, Xiao, Marcelle, Ana Maria, Linda, Simone, Amhed, Kwame, Sharella, Mandy, Sandra, Jerome, Lisa, Tessy and Irene), I salute you all. I enjoyed every moment with you. I will always remember you all. Special thanks to my paranymphs, Simone and Mandy. You did a great job.

I would wish to thank everyone within the greater WUR family for their positive impact to my life when in the Netherlands. All my friends and Kenyans at WUR, I apologise for running out of space to mention all your names and the good things you did. Thanks for the enjoyable times we had together. Lennart and Claudius of the Graduate School for Production Ecology and Resource Conservation (PE\&RC), I will remember you for the great job you did during my PhD.

Part of this PhD work was done in Kenya. I was based at the Kenya Agricultural and Livestock Research Organization (KALRO) with frequent travel to the farmers' fields and to the collaborating institutions. Dr M.W. Nyongesa my co-promoter, thanks for the technical and administrative support while I was doing my research work in Kenya. Despite all the hurdles and challenges, all was not in vain and we can now see the good fruits of perseverance. I also thank KALRO staff, particularly the Geographic Information Systems (GIS) Unit for their guidance in generating maps and the Information Technology (IT) Unit in data collection using Open data Kit (ODK). Mrs F. Munguti and staff of the Kenya Plant Health Inspectorate Service (KEPHIS), Muguga, thanks so much for your assistance during my experiments in your labs and hosting part of my PhD research. I thank the staff of Ministry of Agriculture Livestock and Fisheries (MoALF), my data enumerators, students (Kevin, Gloria and Sheila) and Kenyan farmers for their technical and logistical advice/support during my field surveys.

To the one I love, my wife (Mrs A.K.S Ojuang) thank you for giving me time to read over the past four years. Your encouragements and support kept me going even at my weakest points. My children equally played a crucial role in the success of my PhD. I'm so proud of you all. You are a great motivation and inspiration for my hard work. I had no choice but to set a good example to you and to practice what I teach. You were always there for me. Thanks so much for your prayers and well wishes.

Finally and most importantly, I thank God for his abundant love grace and care for me not only during my PhD but all my life. 


\section{About the author}

John Ojuang Onditi was born on $3^{\text {rd }}$ January 1982 in Kisii, Kenya. After completing primary and secondary education, he joined the University of Nairobi (UON), Kenya where he studied BSc. in Botany/Zoology. He was passionate about development and dissemination of improved potato cultivars in Africa. After completion of his BSc. in 2004, he therefore immediately joined the International Potato Centre (CIP), Sub-Saharan Africa (SSA), Nairobi as a volunteer intern where he

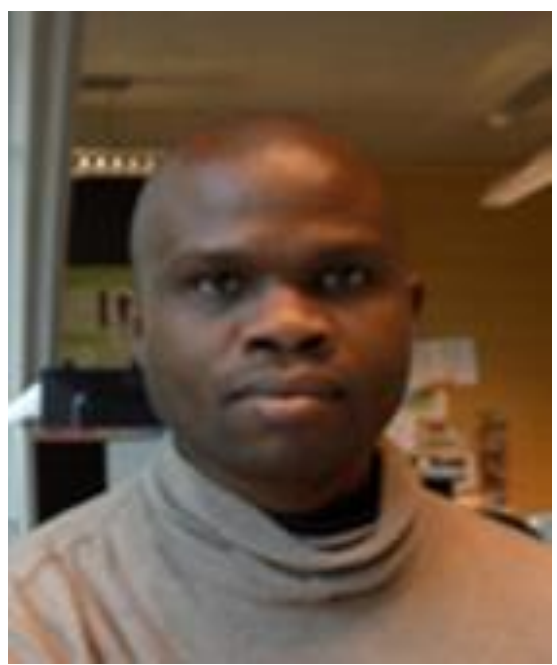
worked in potato tissue culture and production of diseases free mini-tubers of advanced potato clones for regional trials. Between 2006-2008, he was sponsored by CIP to pursue an MSc. in Plant Breeding and Genetics at UON with the thesis titled: Screening for resistance to potato virus $Y$ and potato virus $X$ in potato (Solanum tuberosum. L). Shortly prior to his graduation in 2008, he joined the Kenya Agricultural and Livestock Research Organization (KALRO), National Potato Research Centre, Tigoni in the position of Research Scientist (Potato Breeder). In this position, he led a team of multidisciplinary stakeholders and collaborators in potato variety development, evaluation and release. So far this has resulted to approval and release of seven potato varieties, the most successful being Shangi, currently being grown by over $60 \%$ of Kenyan farmers. To increase the pace of variety development, respond to specialised needs of farmers/consumers and the emerging challenges in potato production systems, he underwent a Professional Plant Breeding Refresher Course (2013-2014) at African Plant Breeding Academy (AfPBA) organized the University of California, Davis. This training was targeted at helping upcoming African plant breeders in incorporating molecular/genomic breeding techniques and related statistical analyses in their breeding programs. In October 2015, he was awarded a sandwich PhD scholarship in the Laboratory of Virology, WUR with the thesis title Epidemiology and control of potato virus $Y$ in Kenya. After finishing his $\mathrm{PhD}$, he looks forward to expanding his collaborative network and using the skills he has acquired to innovatively improve potato breeding and strengthen the potato seed systems. 


\section{List of publications}

\section{Publications}

Onditi J, M Nyongesa and R van der Vlugt (2020) Screening for PVY ${ }^{N-W i}$ resistance in Kenyan potato cultivars (Submitted).

Onditi J, M Nyongesa and R van der Vlugt (2020) Prevalence of potato virus $Y$ (PVY) strains in Kenyan potato cultivars (Submitted).

Onditi J, M Nyongesa and R van der Vlugt (2020) Prevalence, distribution and relative importance of the six major potato viruses in Kenya. (Submitted).

Onditi J, N Ng'ang'a, M Nyongesa and R van der Vlugt (2020) Farmer knowledge in potato virus epidemiology and control in Kenya (Submitted).

Harahagazwe D, B Condori, C Barreda, A Bararyenya, A Byarugaba, D Kude, C Lung'aho, C Martinho, D Mbiri, B Nasona, B Ochieng, J Onditi, J Randrianaivoarivony, C Tankou, A Worku, E Schulte-Geldermann, V Mares, F de Mendiburu, R Quiroz (2018) How big is the potato (Solanum tuberosum L.) yield gap in Sub-Saharan Africa and why? A participatory approach. Open Agric 3: 180189.

Quiroz R, D Harahagazwe, B Condori, C Barreda, F de Mendiburu, A Amele, D Anthony, E Atieno, A Bararyenya, A Byarugaba, P Demo, J Guerrero, B Kowalski, D Anthony Kude, C Lung'aho, V Mares, D Mbiri, G Mulugeta, B Nasona, A Ngugi, J Njeru, B Ochieng, J Onditi, M Parker, JM Randrianaivoarivony, E SchulteGeldermann, CM Tankou, G Woldegiorgis and A Worku (2014) Potato yield gap analysis in SSA through participatory modeling: Optimizing the value of historical breeding trial data. International Potato Centre (CIP), Lima, Peru.

Onditi J, Kiarie N and Shibairo S (2013) Improving potato tuber yields using genotypes with multiple virus resistance in Kenya. Agric Biol J N Am 4 (4): 406412.

Onditi J, Kiarie N, Shibairo S, Lung'aho C, Nyongesa M, Otieno S, Mbiyu M and Oyoo J (2012) Potato virus $Y$ (PVY) and potato virus $X$ (PVX) resistance breeding in Kenya: applicability of conventional approaches. Agric Biol J N Am, 4 (4): 406412.

Onditi J, S Nderitu, J Landeo, G Abong', E Sikinyi and J Kabira (2012) Release of 
three improved varieties for the expanded potato market in Kenya. Agric Biol J N Am 3(5): 192-197.

Onditi J, Kiarie N and Shibairo S (2011) Identification of suitable parents and temperatures for breeding potato virus $\mathrm{Y}$ and Potato virus $\mathrm{X}$ resistant potatoes. Agric Biol J N Am 2(12): 1409-1415.

Onditi J, S Nderitu, J A Landeo, C Lung'aho, M Nyongesa, S Otieno and M Mbiyu (2014) Utilization of late blight resistant potato genotypes for improving potato tuber yields in Kenya. E Afr Agric For J 80(2): 107-112.

Otieno Susan, Jane Muthoni, Miriam Mbiyu, Charles Lung'aho, John Onditi and Judith Oyoo (2013) Application of biotechnological tools in potato breeding: Current situation and future prospects in Kenya. Int J of Biotechnology Res 1(5): 071-080.

Otieno S, J Muthoni, C Lung'aho, M Mbiyu, J Oyoo, J Onditi, M Nyongesa and J Kabira (2013) Micropropagation of different potato cultivars in upscaling seed potato programme in Kenya. E Afr Agric and For J. 79 (3): 171-177.

Nyongesa M , C Lung'aho, T Ngatia , P Pwaipwai , M Mbiyu , S Otieno , J Onditi and L. Wasilwa (2014) A new fungicide formulation to control of potato foliar blight in Kenya. E. Afr. Agric. For. J. 80 (2): 93-98.

Mbiyu M, J Muthoni, J Kabira, C Muchira, P Pwaipwai, J Ngaruiya, J Onditi and S. Otieno (2011) Comparing liquid and solid media on the growth of plantlets from three Kenyan potato cultivars. Am J of Exp Agric (AJEA) 2 (1): 81-89.

Mbiyu M, J Muthoni, J Kabira, G Elmar, C Muchira, P Pwaipwai, J. Ngaruiya, S Otieno and J Onditi (2012) Use of aeroponics technique for potato (Solanum tuberosum) mini-tubers production in Kenya. J of Hort and For 4 (11): 172-177.

\section{Conference posters/presentations}

Onditi J, N Ng'ang'a, M Nyongesa and R van der Vlugt (2019) Farmer knowledge in potato virus epidemiology and control in Kenya. International Plant Virus Epidemiology Symposium. 13-17 May 2019 COEX Mall, Seoul, South Korea.

Onditi J, M Nyongesa and R van der Vlugt (2016) Sample collection methods for potato virus epidemiology surveys in Kenya. 16th Triennial meeting of the virology section of the European Association of Potato Research combined with 8th annual meeting of PVY wide organization May 31st -June 3rd 2016, Ljubljana, Slovenia.

Onditi J, M Nyongesa and Rene van der Vlugt (2016) Sample collection methods 
for potato virus y (PVY) epidemiology surveys in Kenya. 13th International Plant Virus Epidemiology Symposium, from 06-10 June 2016, Avignon, France.

Onditi J, M Nyongesa (2016) Use of virus resistant cultivars in reducing the rate of potato seed degeneration in Kenya. 10th Triennial Conference African Potato Association October 9th -13th 2016, Addis-Ababa, Ethiopia.

Onditi J, M Nyongesa and $R$ van der Vlugt. Occurrence of potato virus $Y$ strains in major potato cultivars grown in Kenya. International Phytosanitary Conference 2016, on 12th to 16th September 2016 at KEPHIS Headquarters, Nairobi, Kenya.

Onditi J, M Nyongesa and R van der Vlugt (2018) Screening potato cultivar resistance to emerging strains of strains of potato virus $Y$ in Kenya. 17th Workshop on Sustainable horticultural production in the tropics 12th - 16th February 2018, Pwani University, Kilifi - Kenya.

Nyongesa M, Lung'aho C, Wasilwa L, Mbiyu M, Onditi J, Otieno S and Kabira J (2013) Changing populations of Phytophthora infestans in Kenya and perspectives for late blight control. In: Book of abstracts, 9th triennial African Potato Association Conference, 30th June to 4th July 2013, Naiveté, Kenya. pp 70.

Ngaruiya J, Muthoni J, Nyongesa M, Lung'aho C, Wanjiku M, Susan O, Onditi J and Kabira J (2013) Production of minitubers using stem cuttings in low and high light intensity greenhouse. In: Book of abstracts, 9th triennial African Potato Association Conference, 30th June to 4th July 2013, Naivasha, Kenya. pp 50.

Otieno S, Lung'aho C, Mbiyu M, Ngaruiya J, Muthoni J, Nyongesa M, Oyoo J, Onditi J and Kabira J (2013) Enhancing potato basic seed production synergistically using stem cutting and hydroponic technology to upscale potato production in Kenya. (Areview). In: Book of abstracts, 9th triennial African Potato Association Conference, 30th June to 4th July 2013, Naivasha, Kenya. pp 18.

Lung'aho C, Mbiyu M, Nyongesa M, Otieno S, Onditi J and Shulte-Geldermann E. (2013). Are dormancy management and physiological age the achilles 'heel of aeroponic minituber production in seed potato value chains in SSA. In: Book of abstracts, 9th triennial African Potato Association Conference, 30th June to 4th July 2013, Naivasha, Kenya. pp 12. 


\section{PE\&RC Training and Education Statement}

With the training and education activities listed below the PhD candidate has complied with the requirements set by the C.T. de Wit Graduate School for Production Ecology and Resource Conservation (PE\&RC) which comprises of a minimum total of 32 ECTS (= 22 weeks of activities)

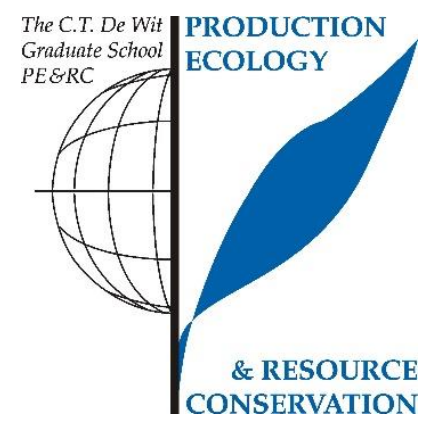

\section{Review of literature (4.5 ECTS)}

Epidemiology and control of potato virus Y (PVY) in Kenya

\section{Writing of project proposal (4.5 ECTS)}

- Epidemiology and control of potato virus Y (PVY) in Kenya

\section{Post-graduate courses (8 ECTS)}

Introduction to R-for statistical analysis; WUR (2016)

Advanced statistics course design of Experiments; WUR (2016)

Summer school on principles of plant disease diagnosis and laboratory equipment operations; MMUST, Kenya (2016)

Introduction to phylogenetics; KEMRI, Kenya (2017)

Farming systems and rural livelihoods: pathway to sustainable development; WUR (2018)

Hands on training on field deployable LAMP assay for Ralstonia diagnosis; KEPHIS, Kenya (2019)

\section{Laboratory training and working visits ( 3 ECTS)}

Molecular detection of PVY strains in Kenya; KEPHIS Kenya (2016)

High throughput genotyping (HTPG) east Africa sampling and data analysis workshop; ICRISAT, Kenya (2019)

\section{Invited review of (unpublished) journal manuscript (1 ECTS)}

- Plant Disease: occurrence of Cycas necrotic stunt virus in Paeonia lactiflora in New Zealand (2019)

\section{Deficiency, refresh, brush-up courses (1.5 ECTS)}

Fundamentals of GIS using free and open software; KALRO, Kenya (2017)

\section{Competence strengthening / skills courses (2.1 ECTS)}

\section{Competence assessment; WUR (2016)}

Information literacy PhD including endnote introduction; WUR (2016)

Writing propositions for your PhD; WUR (2019)

Searching and organising literature for PhD; WUR (2019)

Data management planning; WUR (2016)

Reviewing a scientific paper; WUR (2016) 


\section{PE\&RC Weekend, PE\&RC Day, and other PE\&RC events (2.4 ECTS)}

Microbial power, impact of microbial communities from gut to globe (2015)

PE\&RC Day $(2015,2019)$

PE\&RC First year's weekend (2017)

- PE\&RC Last year's weekend (2019)

\section{Discussion groups / local seminars / other scientific meetings (16.5 ECTS)}

- Plant insect interactions discussion group (2016)

$3^{\text {rd }}$ Wageningen PhD symposium (2016)

$6^{\text {th }}$ Wageningen PhD symposium (2019)

\section{International symposia, workshops and conferences (12.5 ECTS)}

$16^{\text {th }}$ Triennial meeting of the virology section of the European Association of Potato Research combined with 8th annual meeting of PVY wide organization; poster presentation; Ljubljana, Slovenia (2016)

- $13^{\text {th }}$ International Plant Virus Epidemiology Symposium; poster presentation; Avignon, France

International Phytosanitary Conference; oral presentation; Nairobi, Kenya (2016) $10^{\text {th }}$ Triennial Conference African Potato Association; oral and poster presentation; Addis-Ababa, Ethiopia (2016)

- $17^{\text {th }}$ Workshop on sustainable horticultural production in the tropics; oral presentation; Kilifi, Kenya (2018)

\section{Societally relevant exposure (2.4 ECTS)}

KALRO/GIZ Training of Agricultural Officers on good agricultural practice in potato farming: Crop rotation for potato farmers $(2017,2019)$

Farmers TV, on potato research at KALRO Tigoni on potato breeding in Kenya (2018)

- Kenyan TV interview on progress in potato breeding in Kenya (2019)

- Kenya Agricultural and Livestock Research Organization(KALRO), Kenya documentary on potato research in Kenya (2019)

\section{Lecturing / supervision of practicals / tutorials (9 ECTS)}

Ecological aspects of bio-interactions (2016, 2019) 
The research described in this thesis was financially supported by a Wageningen University sandwich PhD fellowship and the Kenya Agricultural and Livestock Research Organization.

Cover design: Anne Morbach http://www.schlaugemacht.net/ Printed by: GVO drukkers \& vormgevers B.V. 


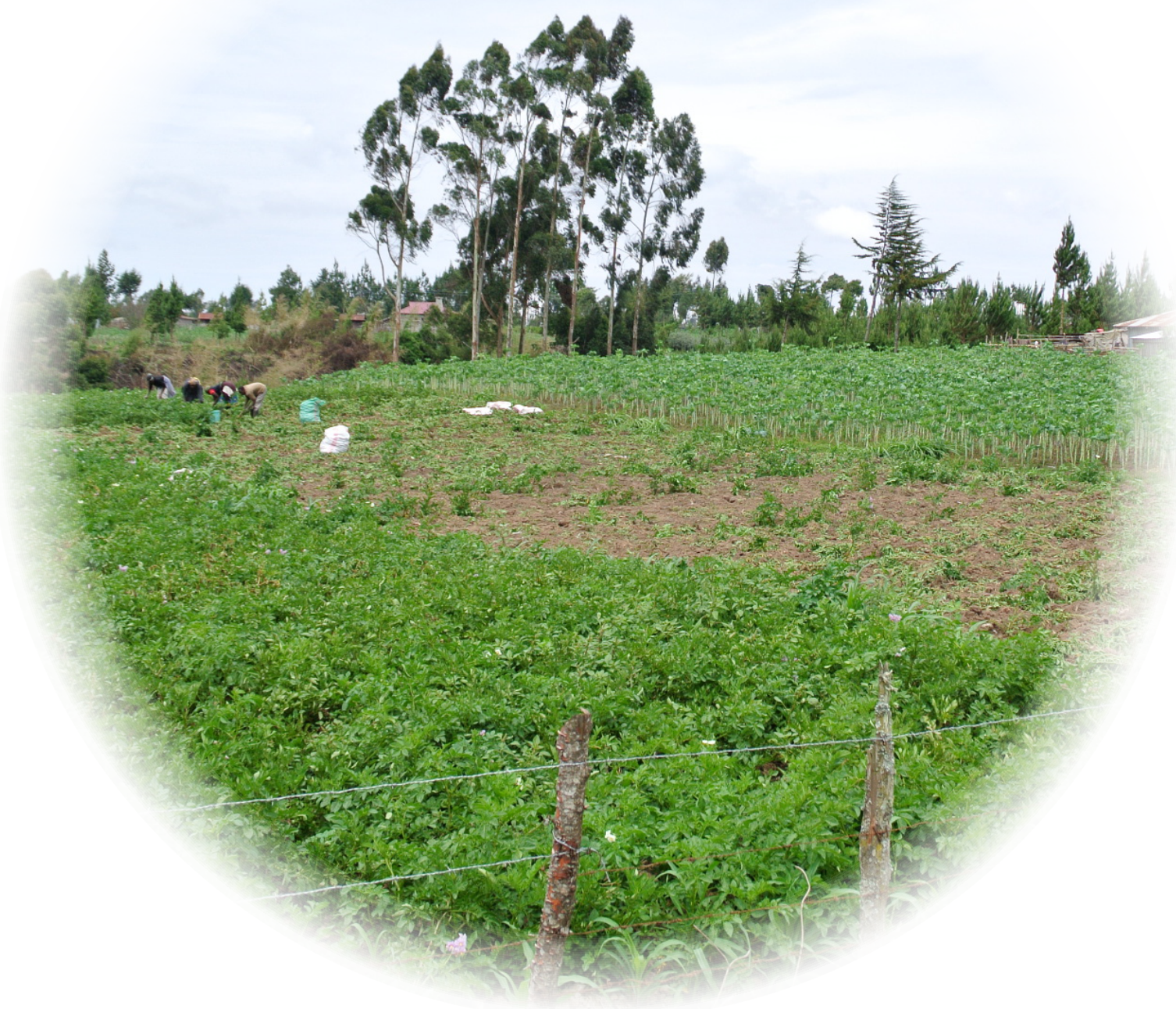

